\title{
Essays on Economic Returns to Fertilizer, Market Structure of Milk Industry, and Air Pollution and Food Security in China
}

\author{
Dissertation \\ to obtain the $\mathrm{Ph}$. $\mathrm{D}$. degree \\ in the International Ph. D. Program for Agricultural Sciences in \\ Goettingen (IPAG) \\ at the Faculty of Agricultural Sciences, \\ Georg-August-University Göttingen, Germany
}

presented by SUN, FEIFEI

born in Nanjing, China

Göttingen, May 2018 



\section{7}

1. Name of supervisor: Prof. Xiaohua Yu, Ph.D.

2. Name of co-supervisor: Prof. Dr. Bernhard Brümmer

Date of dissertation: 17. 05. 2018 



\section{Contents}

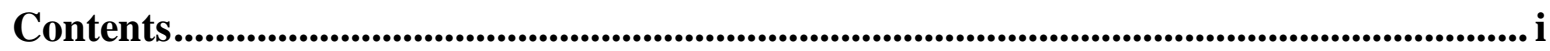

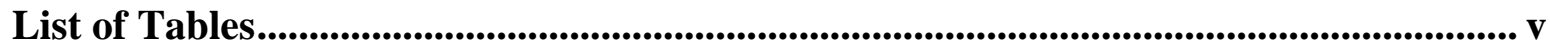

List of Figures ........................................................................................................................................ vii

List of Abbreviations................................................................................................................................... ix

Acknowledgements................................................................................................................ xi

Chapter 1 Executive Introduction …...................................................................................... 1

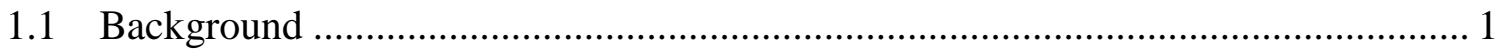

1.1.1 Structural Changes in Chinese Agriculture ............................................... 1

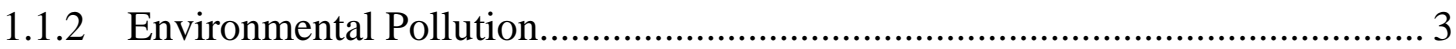

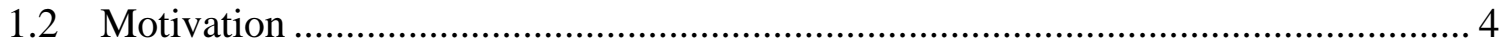

1.2.1 At the Farm Stage — C Crop Structural Change …........................................ 4

1.2.2 In the Market — Market Structural Change _............................................... 5

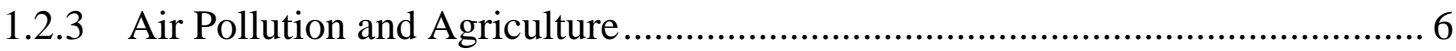

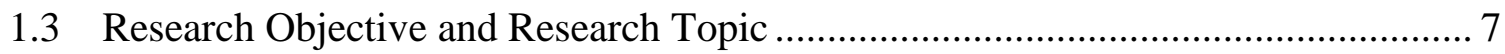

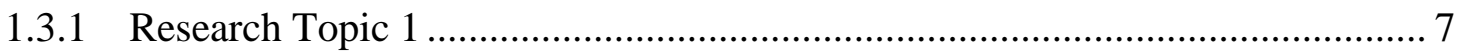

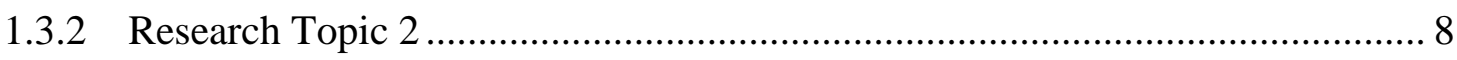

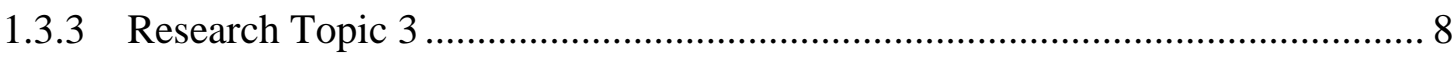

Chapter 2 Crop Allocation and Increasing Returns to Fertilizer Use in China........ 11

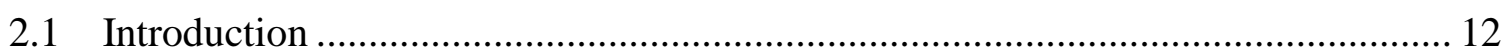

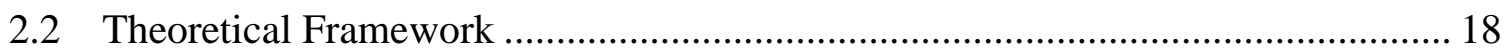

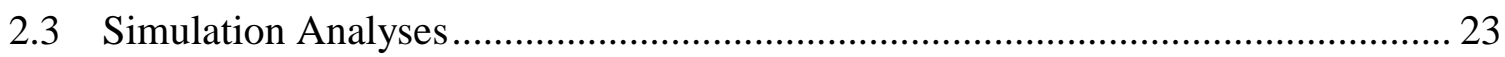

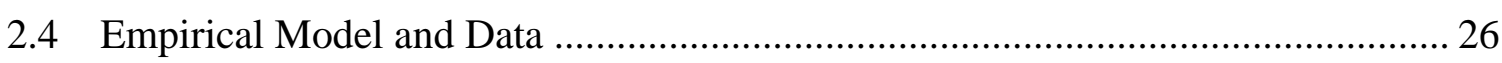

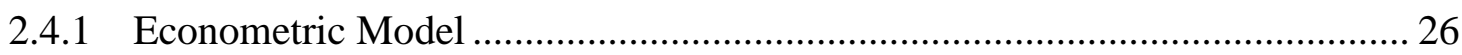

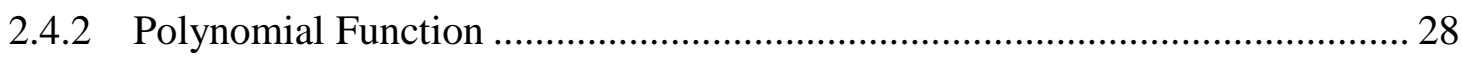

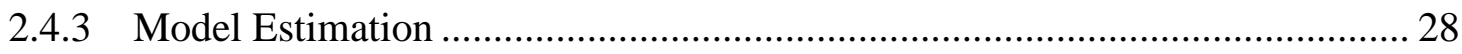

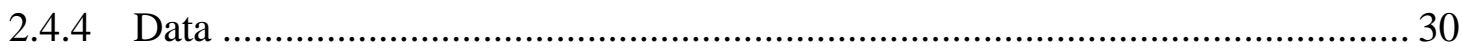

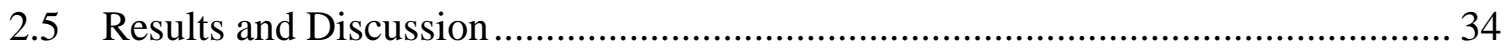

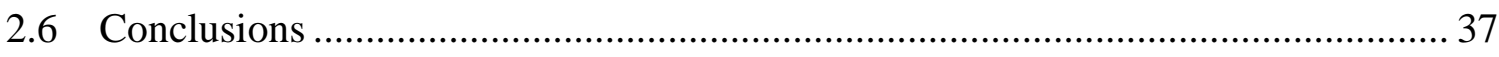

Chapter 3 Market Share and Market Power in Chinese Fluid Milk Industry.......... 39

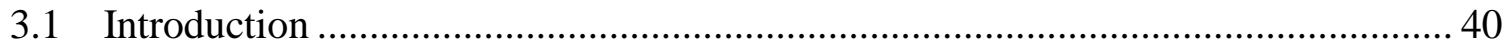




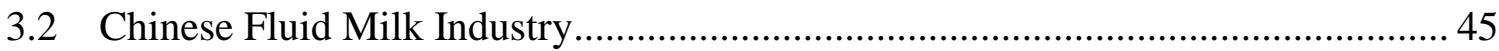

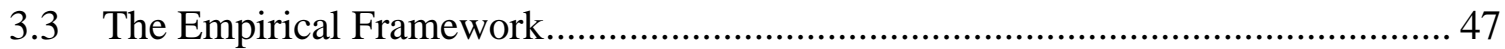

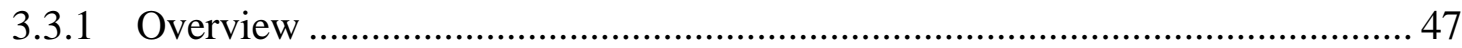

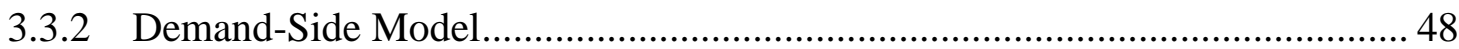

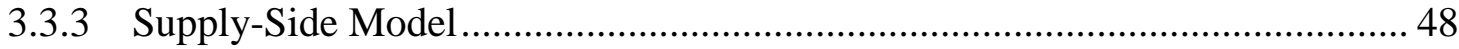

3.3.4 Measuring Market Power .............................................................................. 49

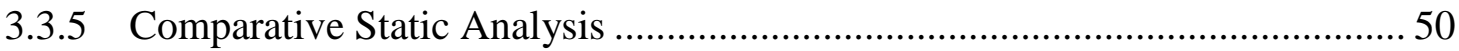

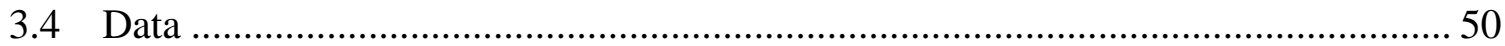

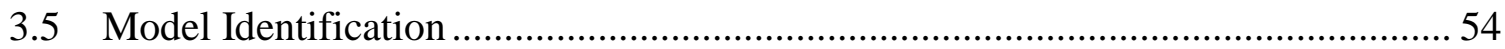

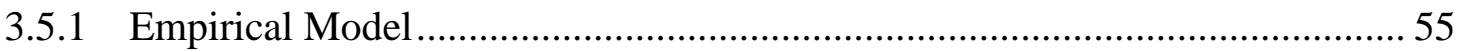

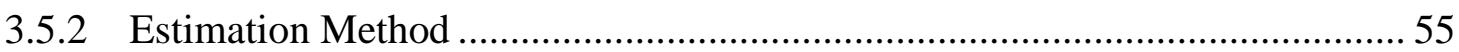

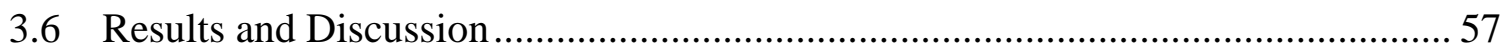

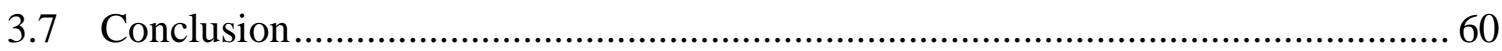

Chapter 4 Air Pollution, Food Production and Food Security: A Review from the Perspective of Food System ..............................................................................6 61

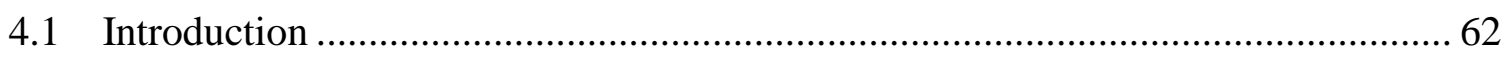

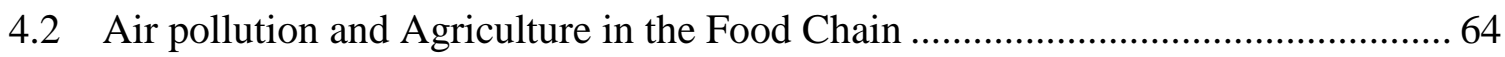

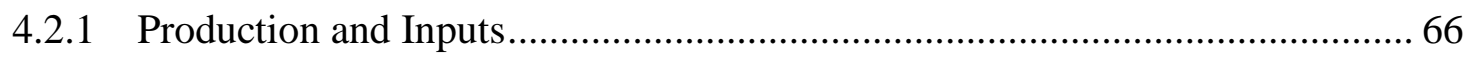

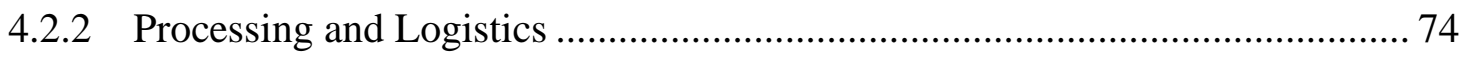

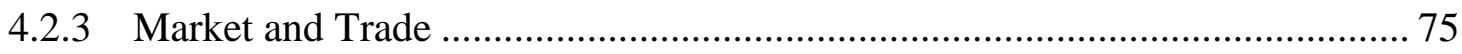

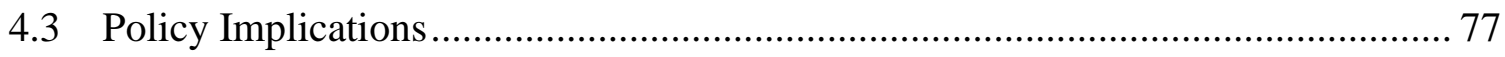

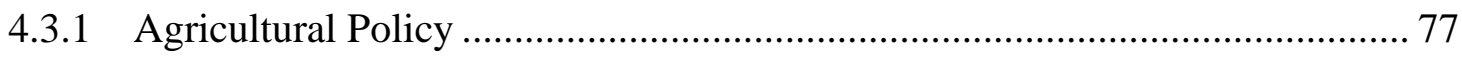

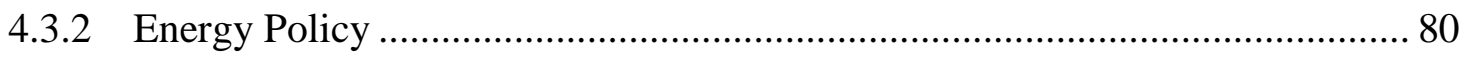

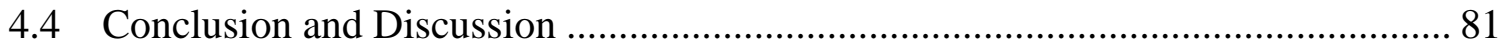

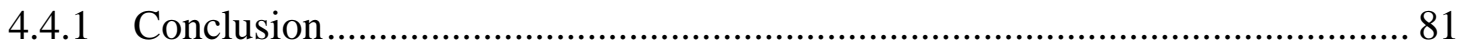

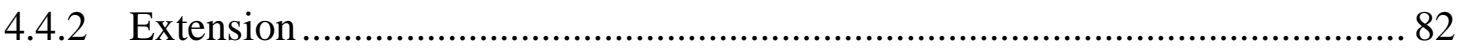

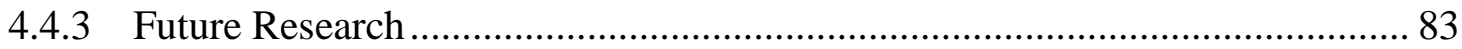

Chapter 5 Air Pollution and Food Prices: Evidence from China .................................. 85

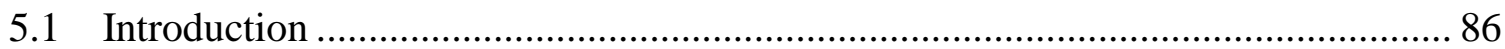

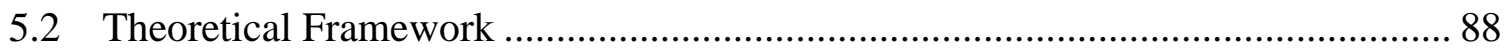

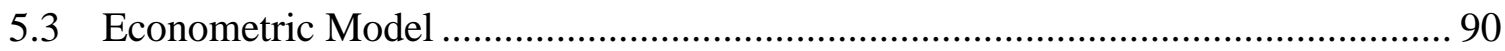

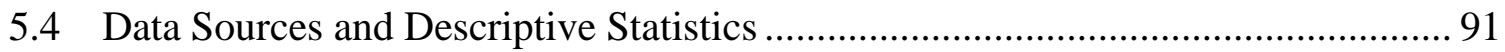

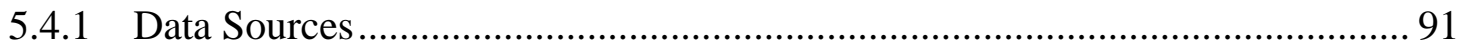




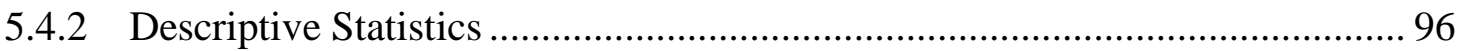

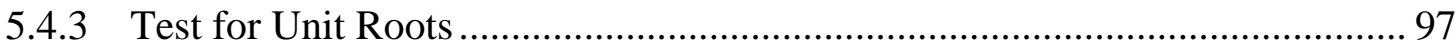

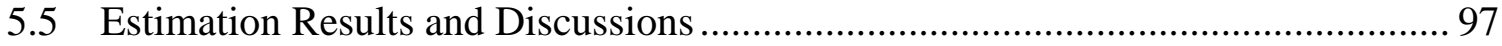

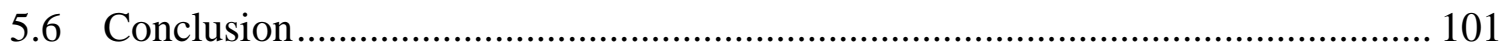

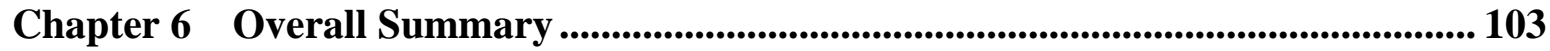

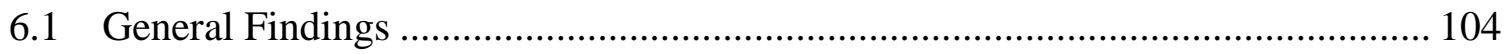

6.2 Policy Implications and Research Significance ................................................. 106

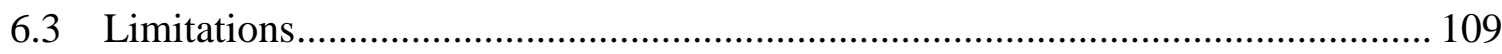

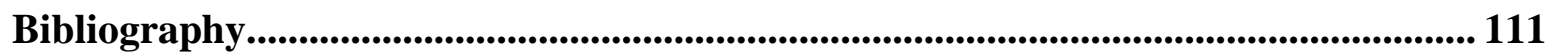

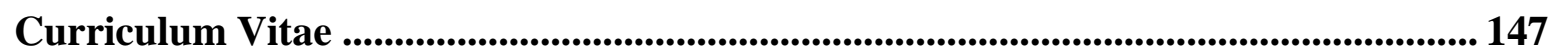





\section{List of Tables}

Table2.1 Total Fertilizer Use in China and World (Million Tons) ................................ 12

Table2.2 Fertilizer Use in China for Major Grains, Vegetables, and Fruits (kg/ha) ........ 16

Table2.3 Output Values for Major Grains, Vegetables, and Fruits (yuan/mu) ................ 17

Table2.4 Comparison of the Differences of the Crop Values and Input Use Levels

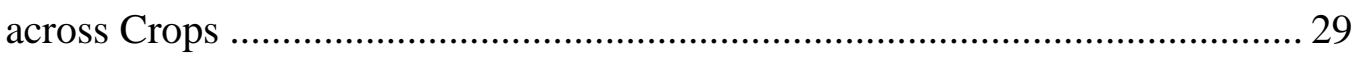

Table2.5 Farm Household Survey Samples ................................................................ 31

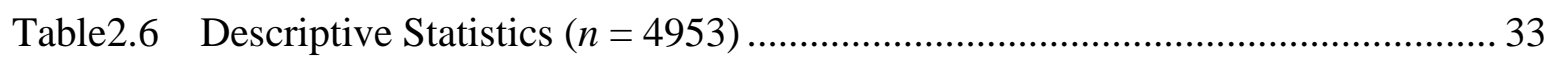

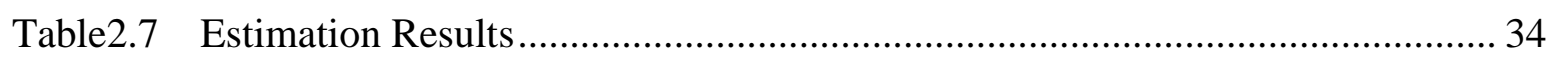

Table3.1 Cow's Milk Production in China and World (Million Tons)........................... 41

Table3.2 Number of Dairy Enterprises above Designated Size ${ }^{\mathrm{a}}$................................... 43

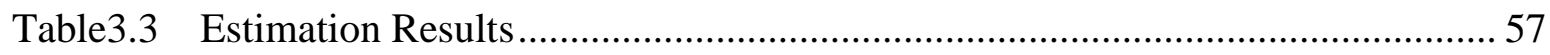

Table3.4 Estimation of Market Power for Major Brands ................................................ 58

Table3.5 Welfare Implication of Market Power for Major Brands (Billion yuan) ........... 60

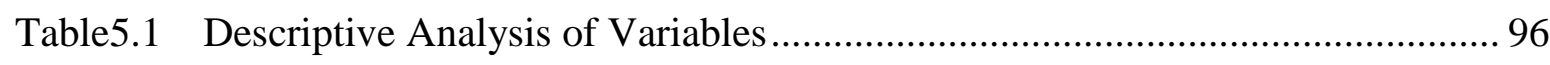

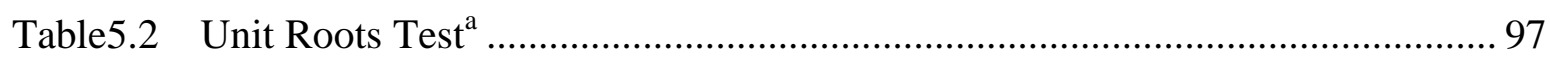

Table5.3 Empirical Results for Chinese Cabbage Price ${ }^{a b c}$............................................ 99

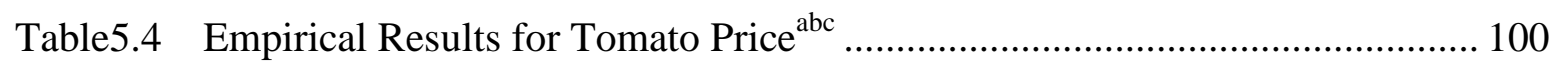

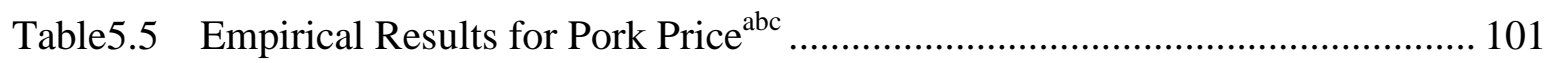





\section{List of Figures}

Figure1.1 Sown Area of Farm Crops (1978-2016) …........................................................ 2

Figure2.1 Harvested Area for Cereals and for Vegetables \& Fruits (million ha) ............. 15

Figure2.2 Crop Choice and the Marginal Value Product (MVP) of Fertilizer................. 19

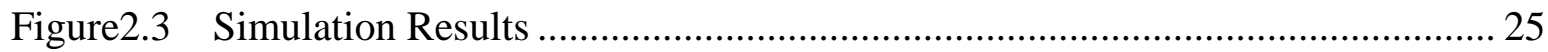

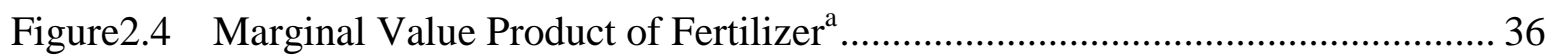

Figure2.5 Scatterplot of Vegetable ${ }^{\mathrm{a}}$ Share of Total Sown Area against Fertilizer Use

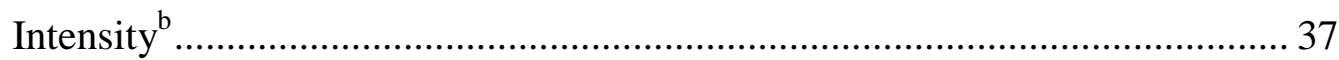

Figure3.1 Retail Market Share of Fluid Milk in China, based on value ......................... 52

Figure3.2 Retail Market Share of Fluid Milk in China, based on volume ....................... 53

Figure3.3 The Unit Retail Price of Fluid Milk for the Major Brands (2008-2015) .......... 54

Figure4.1 Air Pollution and Agriculture in the Food Chain............................................ 65

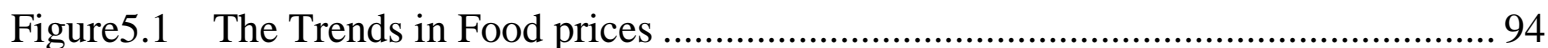





\section{List of Abbreviations}

\begin{tabular}{|c|c|}
\hline $\mathrm{ADF}$ & Augmented Dicky-Fuller \\
\hline AFOLU & Agriculture, Forestry, and Other Land Use \\
\hline AQI & Air quality index \\
\hline AR & Autoregressive \\
\hline ARDL & Autoregressive distributed lag \\
\hline CAP & Common Agricultural Policy \\
\hline CDIA & China Dairy Industry Association \\
\hline CGE & Computable General Equilibrium \\
\hline $\mathrm{CNY}$ & China Yuan \\
\hline CPI & Consumer Price Index \\
\hline CR4 & Four-Firm Concentration Ratio \\
\hline DEA & Data envelopment analysis \\
\hline FAO & Food and Agriculture Organization \\
\hline FMCG & Fast-Moving Consumer Goods \\
\hline GDT & Global Dairy Trade \\
\hline GHG & Greenhouse gas \\
\hline IPCC & Intergovernmental Panel on Climate Change \\
\hline MDGs & Millennium Development Goals \\
\hline MEP & Ministry of Environmental Protection \\
\hline NBSC & National Bureau of Statistics of China \\
\hline NDRC & National Development and Reform Commission \\
\hline OECD & Organization for Economic Co-operation and Development \\
\hline PM & Particulate matter \\
\hline SDGs & Sustainable Development Goals \\
\hline USD & USA dollar \\
\hline WHO & World Health Organization \\
\hline
\end{tabular}





\section{Acknowledgements}

First, I would like to express my sincere gratitude to my supervisor Prof. Xiaohua Yu for his continued support and patient guidance during my Ph.D. study. Without him, I may not devote myself to scholarly activity and also do not have the opportunity to study in Göttingen. I really appreciate all the valuable inputs he contributed to our research. But more importantly, Prof. Yu not only unreservedly imparts his knowledge to me but also teaches me how to deal with others, which benefits me throughout my life.

Moreover, I would like to thank my co-advisor Prof. Bernhard Brümmer. His great suggestions have helped me improve my research article. Of course, my further thanks go to Prof. Stephan v. Cramon-Taubadel, the rest of my thesis committee, for his insightful comments and encouragement, but also for the hard question which incented me to widen my research from various perspectives.

I own lots of thanks to Prof. Dr. Zhou, Yingheng in Nanjing Agricultural University. When I studied under the supervision of him, Prof. Zhou gave me full support for studying abroad and provided me with lots of opportunities to participate in his projects and to take part in international conferences. Additionally, I am grateful to Prof. Dr. David Abler for helping me improve my research and enlightening me with new research idea.

My sincere thanks also go to my colleagues in the chair group for their friendly help and assistance. Special thanks go to Mr. Dieter Kömle, Dr. Xu Tian, and Dr. Wei Huang, who guided me how to write a research paper step by step and shared cutting-edge knowledge and experiences with me. Without their precious support, it would not be possible to conduct this research.

I thank my colleagues and friends in for the sleepless nights we were working together before deadlines, and for all the fun we have had in the last four years. In particular, lots of thanks to our sweet secretary Ms. Jana Nowakowsky, smart Ms. Eva Hasiner, friendly Ms. Farah Wulandari Pangestuty, funny Mr. Tahir Mahmood, genial Ms. Fang Yin, industrious Ms. Elisa Giampietri, and gentle Dr. Ulf Römer. I really appreciate all my friends in Göttingen, who make my time in Göttingen happier. 
I am quite grateful to the Chinese Scholarship Council (CSC). I would like to thank them for providing me financial support for studying in Germany, which allows me to focus on my research.

Last but not least, I would like to thank my parents and grandparents. I appreciate that they endorsed me to pursue a Ph.D. degree in Germany. I never feel alone because I know you are always with me. You are the best parents and grandparents in the world! Ich liebe euch!

Feifei Sun

May 2018, Göttingen, Germany 


\section{Chapter 1 Executive Introduction}

\subsection{Background}

Since 1979, China has remained committed to the reform and opening-up policy, which resulted in remarkable accomplishments in economic development, as well as agricultural growth. With only 7 per cent of the global arable land, China not only successfully feeds the largest population in the world, but also achieves 12 years increase in food crop production in a row. Official figures from the National Bureau of Statistics of China (NBSC) indicate that the gross grain production increased from 305 megatons in 1978 to 616 megatons in 2016, totally overtook the population growth (44\%). Meanwhile, Food and Agriculture Organization (FAO) statistics also indicate that the yields of rice, wheat and maize in China increased by $74 \%, 193 \%$, and $112 \%$, respectively during this period. Nowadays, China has become one of the countries with higher yields in crop production in the world ( $\mathrm{Yu}$ and Zhao 2009).

Notably, the rapid development of Chinese agricultural sector in recent decades has been accompanied by a series of dramatic structural changes (Chen et al. 2009; Cao and Birchenall 2013) and environmental pollution (Ongley, Zhang and Yu 2010), each of which I briefly describe below.

\subsubsection{Structural Changes in Chinese Agriculture}

One of the outstanding phenomena occurring in Chinese agriculture is the spatiotemporal change in the structure of crops produced, with a relative shift away from cereals and toward vegetables and fruits (Xin, Li and Tan 2012). Figure 1.1 shows the primary change in crop production structure in China. Specifically, the sown area of grain crops has decreased more or less continuously since 1978, from about 150 million ha in 1978 to 113 million ha in 2016. By contrast, sown area for oil-bearing crops, sugar crops, and horticultural crops (i.e., vegetables, tea, and fruit) has jumped substantially from 13 million ha to 54 million ha during this period. 


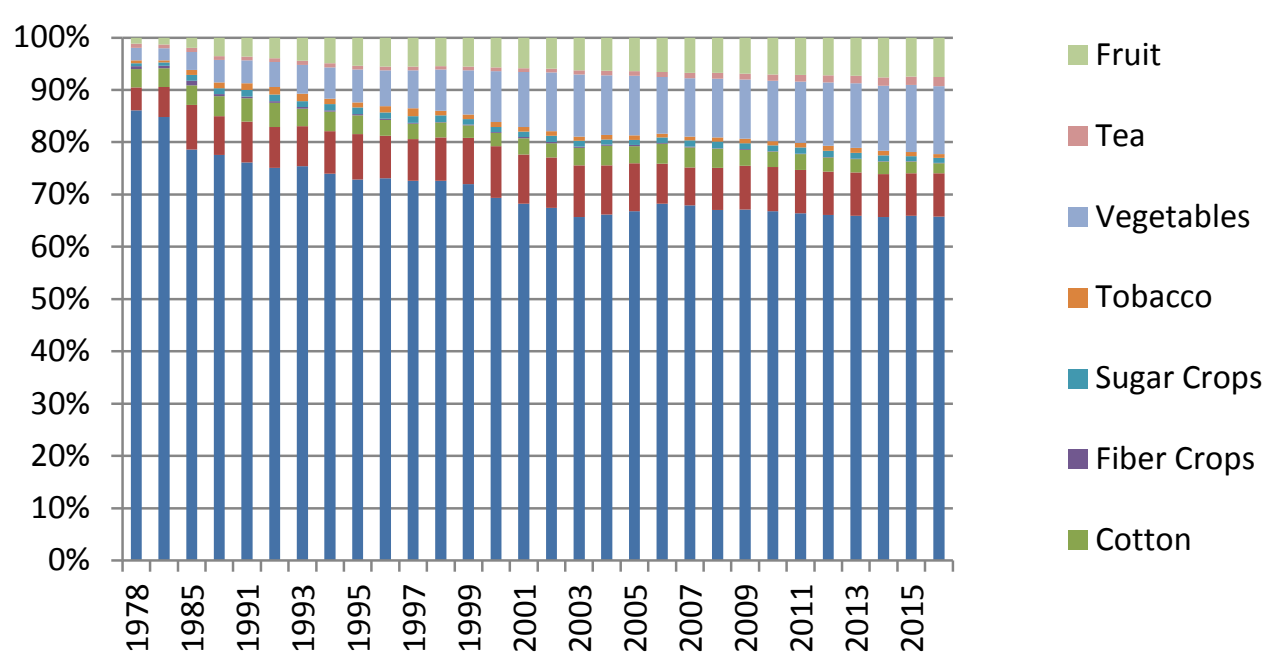

Source: National Bureau of Statistics of China (NBSC)

Figure1.1 Sown Area of Farm Crops (1978-2016)

Additionally, the structural change in Chinese agricultural production is also reflected in the rise of new agricultural operating entities. Land fragmentation (Wan and Cheng 2001; Wu, Liu and Davis 2005), rapid urbanization (Zhang, Yang and Wang 2011; Deininger et al. 2014), feminization and aging of the agricultural labor (De Brauw et al. 2008; Bowlus and Sicular 2003), and environmental degradation (Rozelle, Veeck and Huang 1997; Huang and Rozelle 1995) have constrained the sustainable development of Chinese agriculture for a long time. To address these challenges, the Chinese government has implemented a number of policies to promote land circulation and to encourage the development of so-called four "new type of entities" (i.e., family farm, specialized household, rural cooperative and agricultural enterprise) (Xie and Lu 2017; Wang et al. 2018; Zuo et al. 2015). Till the end of 2014, the farmland circulation area has reached around 27 million ha, accounting for $30.32 \%$ of the total household's contracted land area (Liu, Wang and Shi 2018); about 0.87 million family farms and 3.17 million specialized households cultivated nearly $20 \%$ of total farmland collectively (Zuo et al. 2015). In 2016, the top 20 (D20) dairy enterprises grazed 1.68 million Holstein cows on their self-constructive pastures, accounting for $24 \%$ of the total number of dairy cows in China ${ }^{1}$.

\footnotetext{
${ }^{1}$ Source: Chinese Dairy Quality Report (2017), released by the Chinese Dairy Association. http://www.dac.org.cn/upload/fckupload/file/1500348352177849679367.pdf. (in Chinese)
} 
Practically, in the food processing industry, we observed an enormous structural change as well (Qian et al. 2011; Kong 2012), due to nutrition transition and food safety concerns. As part of nutrition transition, Chinese diet is switching from staple food to high-energy-density and low-fiber foods, such as meat and dairy products ( $\mathrm{Yu}$ and Abler 2009; Yu and Abler 2014; Tian, Sun and Zhou 2015; Yu 2012), which promoted a rapid expansion of food processing industry. However, the constant food safety scandals reduced the trust of Chinese public in domestic food (Pei et al. 2011; Ortega et al. 2011; Chen 2013; Peng et al. 2015) and pushed the government to tighten up regulations on food safety issues (Tam and Yang 2005; Liu 2010; Jia and Jukes 2013; Yan 2012). As a consequence, numerous small agricultural enterprises exited the market and some domestic competitive enterprises, as well as some foreign companies, accomplished a series of merger and acquisition (Jia et al. 2012; Xiu and Klein 2010). Meanwhile, the new national food safety standards increased the barriers to entry into a market, crowded out non-standard companies, and helped some competent incumbents gain more market share (Qian et al. 2011). Consequently, most food or agricultural markets are highly concentrated, and many of which are dominated by a few players (Dai and Wang 2014; Zheng and Wang 2017; Lan and Wang 2018; Chen and Yu 2018; Guo, Wang and Chen 2016).

\subsubsection{Environmental Pollution}

A large number of studies have been conducted up to date to explain the rapid growth in Chinese agriculture from the perspective of input increases (Huang and Rozelle 1995; Huang et al. 2006; Yu and Zhao 2009), technical improvement (Fan 1991; Kalirajan, Obwona and Zhao 1996; Mao and Koo 1997), and institutional changes (Lin 1992; Fan 1991; McMillan, Whalley and Zhu 1989; Brümmer, Glauben and Lu 2006). However, over-dependence on industrial agro-inputs, such as synthetic fertilizers, pesticides, and machinery (Huang and Rozelle 1995; Huang et al. 2006; Yu and Zhao 2009) has caused extensive environmental damages. One of the most notable environmental issues is the air pollution. For instance, the environmental externalities from nitrogen in fertilizer include fine particulate matter air pollution from arising through ammonia $\left(\mathrm{NH}_{3}\right)$ volatilization and emissions of nitrous oxide $\left(\mathrm{N}_{2} \mathrm{O}\right)$, a potent greenhouse gas ( $\mathrm{Gu}$ et al. 2012; Liu et al. 2013; Zou, Lu and Huang 2010; F. Sun, Dai and Yu 2017; Huang et al. 2012). Huang et al. (2012) 
estimate that chemical fertilizers account for about one-third of total $\mathrm{NH}_{3}$ emissions in China; while Chen and Zhang (2010) estimate that cropland accounted for about one-half of anthropogenic $\mathrm{N}_{2} \mathrm{O}$ emissions in China in 2007. However, air pollution can not only affect plant growth and animal health (Wang and Mauzerall 2004; McCormick 1989; Nagajyoti, Lee and Sreekanth 2010) but also influence both the quantity and quality of agro-inputs in the food supply chain and thereby affect food security indirectly (F. Sun, Dai, et al. 2017).

\subsection{Motivation}

\subsubsection{At the Farm Stage — Crop Structural Change}

In general, land, labor, capital, machinery, agrochemicals, improved varieties, and irrigation are considered the major inputs for modern crop cultivation system (F. Sun, Dai, et al. 2017; Yu and Zhao 2009), where the application of chemical fertilizers has played a key role in increasing agricultural production in China (Zhu and Chen 2002; Xu, Han and Taylor 1992; Qiao et al. 2003). FAO statistics indicate that China consumed nearly one-third (31\%) of global fertilizer in terms of nutrients (nitrogen + phosphorus + potassium) in 2015, becoming the single largest user in the world. In addition, the average use of nutrients (nitrogen + phosphorus + potassium) per hectare of cropland in China reached $446 \mathrm{~kg}$ in 2016, more than three times the world average use of $123 \mathrm{~kg} / \mathrm{ha}$.

High rates of fertilizer application have been tied to low fertilizer use efficiency and serious pollution problems (Ma et al. 2014; Wu 2011; Khor and Zeller 2014; Z. Chen, Huffman and Rozelle 2009). Although a substantial number of studies have attempted to explain China's high rates of fertilizer use (Huang et al. 2015; Yang and Fang 2015; Jia et al. 2015; Ebenstein et al. 2011), they ignore the effects of crop structure change on fertilizer application level. In other words, the rapid growth in China's fertilizer use may partly due to the dramatic change in the structure of crops produced in recent decades, as cash crops (vegetables and fruits) are more fertilizer intensive than grain crops (Ju et al. 2006; Kahrl et al. 2010). Moreover, the law of diminishing marginal returns tells us that the marginal product of fertilizer should decline at the intensive margin. However, given the fact that the marginal value product of fertilizer is higher for cash crops at any given level of fertilizer use than for grains (Pingali 1997; Lin 1992), it is possible that intensive margin may be 
outweighed by an increasing marginal product of fertilizer at the extensive margin (due to shifts in the structure of crops produced). If so, then much of the growth in China's fertilizer use may represent a profitable response on the part of farmers to changing economic opportunities, which contradicts to the government policy targets of limiting fertilizer use. From this point of view, it is necessary to explore the economic returns to fertilizer in Chinese agriculture in light of crop allocation.

\subsubsection{In the Market — Market Structural Change}

Market structure is bound up with the market power (Aguirregabiria 2012). The enormous structural change in Chinese agricultural markets will definitely reshuffle the market power for each player. As food is a basic necessity of life and has very little substitutes (Fan, Wailes and Cramer 1995; Wu, Li and Samuel 1995; Halbrendt et al. 1994), the demand for most agricultural goods is price inelastic. Theoretically, the price-cost margin is inversely related to industry price elasticity of demand (Cowling and Waterson 1976; Clarke and Davies 1982). A product with low price elasticity implies that even a little change in market power may still lead to very high welfare transfers (Lijesen 2007). Hence, the structural change occurring in food markets will affect social welfare distribution and food security further. And this is the reason why FAO highlights the central role of competition in food and agricultural markets on food security in its recent report ${ }^{2}$.

China is experiencing the nutrition transition, replacing staple food with meat, fruit and dairy products (Tian and Yu 2015; Pingali 2007; Du et al. 2002; Dong 2006). The growth in household income has played an essential role in the rapid increase in dairy consumption in China, as demand for dairy products is expenditure elastic (Liu and Chern 2003; Dong and Gould 2007; Fuller et al. 2006). In addition, the Chinese government, the healthcare sector, and the dairy plants have been emphasizing the health benefits of regularly consuming dairy products (Fuller et al. 2004). The slogan of "A cup of milk makes a nation strong” has been exerting great influence on Chinese consumers. A growing number of Chinese have changed their mind and have integrated milk into their daily diet rather than regarded it as a nutrition supplement for infants, patients and the elderly (Zhou, Tian and Zhou 2001; Fuller et al.

\footnotetext{
${ }^{2}$ Source: http://www.fao.org/3/a-i5225e.pdf.
} 
2006). The rapid income growth, as well as the change in attitudes towards dairy products, has driven China's tremendous rise in dairy demand. Nowadays, the development of dairy industry has become one of the major concerns of the Chinese government.

However, the food scandal of mixing melamine in milk in 2008 struck a deadly blow to Chinese dairy industry. Statistics released by China Dairy Industry Association (CDIA) show that numerous small enterprises exited the market after the incident with the number of small-scale enterprises dropped from 669 in 2008 to 459 in 2012. Meanwhile, some domestic competitive enterprises, such as Yili and Mengniu, accomplished a series of merger and acquisition. The structural change and fierce competition in the dairy market will definitely have impacts on the market power for each company, which may affect social welfare distribution further. Either from the perspective of academic research or from the policy implication, it is necessary to investigate the market power of Chinese dairy giants under the new regime.

\subsubsection{Air Pollution and Agriculture}

FAO predicts that, by 2050 , the global population will reach 9.1 billion, which requires at least $70 \%$ increase in agricultural production. Specifically, annual cereal production must rise to 3 billion tonnes, and meat production must exceed 200 million tonnes (FAO 2009). Such stress may reinforce the current trends of intensive farming (Matson et al. 1997), even at the cost of environmental deterioration (Godfray et al. 2010; Tilman et al. 2011). Hence, how to mitigate agricultural emissions while ensuring food security is a long-term challenge for both scientists and policymakers.

Although the process of air pollutant formation in routine agricultural operations and consequences of air pollution for plant growth and animal health have been well studied, no systematic review to date on the linkage between air pollution and food security. Therefore, if we can draw a full picture of their relationship from the view of food supply chain, it may help us find potential opportunities for reducing air pollution while ensuring food security.

Notably, air pollution is also one of the top environmental concerns in China. Most existing research related to the impact of air pollution on agriculture only focuses on consequences of air pollution for plant growth (Emberson, Ashmore and Murray 2003) and 
animal health (Holgate et al. 1999). In fact, air pollution may influence both the quantity and quality of agro-inputs in the food supply chain and thereby reduce outputs (F. Sun, Dai, et al. 2017). Meanwhile, consumers tend to reduce outdoor activities to mitigate health risks when air pollution levels are high (Bresnahan, Dickie and Gerking 1997). As a consequence, the aggregate effects of demand and supply in response to air pollution will ultimately embody in food price changes through market equilibrium shift (F. Sun, Koemle and Yu 2017). However, examining the effect of air pollution on food price volatility has largely been neglected in the current literature, which is a worthy topic of research.

\subsection{Research Objective and Research Topic}

Given the fact that there is a dramatic structural change occurring in Chinese agriculture in recent years, will the crop allocation have effects on economic returns to chemical fertilizer? How did the market structure change after the exposure of food safety scandals? And how did the market power of each player change? As agriculture is viewed as the prime culprit of air pollution (Erisman et al. 2007; Bauer, Tsigaridis and Miller 2016), what is the relationship between air pollution and food security? Where are the best opportunities for reducing air pollution in the food system? To answer these questions, this dissertation will revolve around following three topics: the estimation of economic returns to chemical fertilizers, the identification of market power for Chinese food industry, and the exploration of the relationship between air pollution and food security.

\subsubsection{Research Topic 1}

\section{Crop Allocation and Increasing Returns to Fertilizer Use in China}

This research topic is presented in Chapter 2. The objective of this study is to shed light on the effects of crop allocation on economic returns to chemical fertilizer in Chinese agriculture. We show in theory and through simulation analyses that while the marginal product of fertilizer is declining at the intensive margin (for a specific crop), this may be offset by an increasing marginal product of fertilizer at the extensive margin (due to shifts in the structure of crops produced). Thereby, it is possible for the marginal value product of fertilizer (MVP), when aggregated across crops, to exhibit a U-shaped pattern as fertilizer use 
increases. Using farm household-level data from Jiangsu Province for 2004-2013, the empirical results are consistent with this hypothesis. We hence conclude that the horticultural crops are gradually becoming the main forces of fertilizer consumption in China. As the nutritional transition currently occurring in China, we predict that China's fertilizer consumption will not decrease at least in the short run.

\subsubsection{Research Topic 2}

\section{Market Share and Market Power in Chinese Fluid Milk Industry}

Fluid milk industry is dominated by a few large companies in China. Since the 2008 Chinese milk scandal, the enormous structural change and fierce competition have reshuffled the market power for each dairy company, and thereby affected social welfare distribution. In Chapter 3, I propose a simple framework to link market share and the Lerner Index at the firm level, which is used to investigate the market power for Chinese fluid milk industry at the brand level as well. Using aggregated supermarket scanner data, we find that the market power was relatively moderate and has been continuously weak during 2008-2015. The average markup for top five brands was approximately $53 \%$ over the marginal cost, resulting in an annual income transfer of nearly $\$ 2.8$ billion. With aggravation of market competition and government regulation, the market power in the fluid milk industry will be weakened in the future.

\subsubsection{Research Topic 3}

Air pollution negatively impacts food security. There is no doubt that, air pollution has impacts on both food demand and supply, which should ultimately embody in food price changes through market equilibrium shift. However, up to date, there is limited studies focus on this field. Therefore, in Chapter 4, I review the current literature on the relationship between air pollution and food security from the perspective of food system. Subsequently, in Chapter 5, I focus on the impact of air pollution on the short run food prices. 


\section{Air Pollution, Food Production and Food Security: A Review from the Perspective of Food System}

Chapter 4 reviews the current literature on the relationship between air pollution and food security from the perspective of food system. It highlights that agricultural emissions which substantially contribute to air pollution could happen at every stage along the food supply chain. Meanwhile, air pollution can not only affect plant growth and animal health but also shift market equilibrium of both agro-inputs and outputs in the food supply chain and thereby affect food security indirectly. Furthermore, this study evaluates the effects of agricultural policy and energy policy on food security and air pollution, respectively, and provides an overview of potential policy instruments to reduce air pollution while ensuring food security. Finally, we identify the remaining research and policy issues for further studies, mainly focusing on the study of household's bounded rational behaviors and the issue of rural aging population.

\section{Air Pollution and Food Prices: Evidence from China}

Air pollution is one of the top environmental concerns in China. On days with severe air pollution, people (both consumers and producers) often reduce outdoor economic activities in order to avoid possible health damages. This impacts the market trade of fresh food products, at least in a short run. This empirical study sheds light on the impact of air pollution on the short run prices of three major fresh food products (Chinese cabbage, tomatoes and pork) using daily data from the largest outdoor wholesale market in Beijing. With an increase in AQI (Air Quality Index) by 100 units, prices for Chinese cabbage and tomatoes decrease by 1.19 and 0.89 per cent. With an increase in PM2.5 concentration by $100 \mu \mathrm{g} / \mathrm{m}^{3}$, prices for Chinese cabbage and tomatoes decrease by 0.64 and 0.55 per cent. Air pollution affects vegetable prices, but has no significant impact on prices of pork products. This study will be presented in Chapter 5 . 



\section{Chapter 2 Crop Allocation and Increasing Returns to Fertilizer Use in China ${ }^{3}$}

China is one of the largest users of chemical fertilizer in the world on a per hectare basis, and the single largest user in total as well. Although chemical fertilizers have helped China to feed the largest population in the world under limited cropland resources, high rates of fertilizer application have linked to low use efficiency and serious pollution problems. The objective of this study is to shed light on the effects of crop allocation on economic returns to chemical fertilizer in Chinese agriculture. We show in theory and through simulation analyses that while the marginal product of fertilizer is declining at the intensive margin (for a specific crop), this may be offset by an increasing marginal product of fertilizer at the extensive margin (due to shifts in the structure of crops produced). Thereby, it is possible for the marginal value product of fertilizer (MVP), when aggregated across crops, to exhibit a U-shaped pattern as fertilizer use increases. Using farm household-level data from Jiangsu Province for 2004-2013, the empirical results are consistent with this hypothesis. We hence conclude that the horticultural crops are gradually becoming the main forces of fertilizer consumption in China. As the nutritional transition currently occurring in China, we predict that China's fertilizer consumption will not decrease at least in the short run.

\footnotetext{
${ }^{3}$ This chapter is jointly written with Prof. David Abler and Prof. Xiaohua Yu.
} 


\subsection{Introduction}

China is one of the largest users of chemical fertilizer in the world on a per hectare basis, and the single largest user in total. Table 2.1 presents FAO statistics on fertilizer use in China and the world as a whole since 2002. China consumed nearly one-third (31\%) of global fertilizer in terms of nutrients (nitrogen + phosphorus + potassium) in $2015 .{ }^{4}$ FAO statistics also indicate that China's fertilizer consumption in a hectare of arable land reached $316 \mathrm{~kg}$ in 2013, about three times the world average use of $106 \mathrm{~kg} / \mathrm{ha}$. Fertilizer use per hectare of harvested cropland was $215 \mathrm{~kg} / \mathrm{ha}$, almost double of the global average level, $109 \mathrm{~kg} / \mathrm{ha}^{5}$

Table2.1 Total Fertilizer Use in China and World (Million Tons)

\begin{tabular}{lcccccccc}
\hline & \multicolumn{3}{c}{ China } & \multicolumn{5}{c}{ World } \\
\cline { 2 - 10 } & $\begin{array}{c}\text { Nitrogen } \\
\text { Fertilizers } \\
\text { (N total } \\
\text { nutrients) }\end{array}$ & $\begin{array}{c}\text { Phosphate } \\
\text { Fertilizers } \\
\left(\mathrm{P}_{2} \mathrm{O}_{5} \text { total }\right. \\
\text { nutrients })\end{array}$ & $\begin{array}{c}\text { Potash } \\
\text { Fertilizers } \\
\left(\mathrm{K}_{2} \mathrm{O} \text { total }\right. \\
\text { nutrients })\end{array}$ & $\begin{array}{c}\text { Total } \\
\text { Fitrogen } \\
(\mathrm{N} \text { total } \\
\text { nutrients })\end{array}$ & $\begin{array}{c}\text { Phosphate } \\
\text { Fertilizers } \\
\left(\mathrm{P}_{2} \mathrm{O}_{5} \text { total }\right. \\
\text { nutrients })\end{array}$ & $\begin{array}{c}\text { Potash } \\
\text { Fertilizers } \\
\left(\mathrm{K}_{2} \mathrm{O} \text { total }\right. \\
\text { nutrients })\end{array}$ & Total \\
\hline 2002 & 25.22 & 10.71 & 7.77 & 43.70 & 82.59 & 34.55 & 26.66 & 143.80 \\
2003 & 25.35 & 10.96 & 8.16 & 44.47 & 86.58 & 36.99 & 28.41 & 151.98 \\
2004 & 26.39 & 11.48 & 8.77 & 46.65 & 89.02 & 38.59 & 30.83 & 158.45 \\
2005 & 26.78 & 11.88 & 9.31 & 47.97 & 89.45 & 38.82 & 29.60 & 157.87 \\
2006 & 27.39 & 12.43 & 9.79 & 49.60 & 91.96 & 39.78 & 30.45 & 162.19 \\
2007 & 28.12 & 12.84 & 10.41 & 51.37 & 96.08 & 41.68 & 33.45 & 171.21 \\
2008 & 28.51 & 13.24 & 10.87 & 52.62 & 95.57 & 37.62 & 32.21 & 165.40 \\
2009 & 29.07 & 13.71 & 11.36 & 54.14 & 97.65 & 38.36 & 28.38 & 164.39 \\
2010 & 29.64 & 14.12 & 11.92 & 55.69 & 100.79 & 42.95 & 33.21 & 176.95 \\
2011 & 30.23 & 14.58 & 12.42 & 57.23 & 104.35 & 45.41 & 34.88 & 184.65 \\
2012 & 30.74 & 14.98 & 12.86 & 58.58 & 106.28 & 45.47 & 34.35 & 186.10 \\
2013 & 30.90 & 15.23 & 13.19 & 59.31 & 107.08 & 45.69 & 35.50 & 188.27 \\
2014 & 31.07 & 15.56 & 13.52 & 60.16 & 108.94 & 46.70 & 37.65 & 193.29 \\
\hline
\end{tabular}

Source: FAOSTAT, http://faostat3.fao.org/.

\footnotetext{
${ }^{4}$ Source: FAOSTAT, http://faostat3.fao.org/.

5 Arable land can differ from harvested cropland due to arable land that is not planted with crops in a given year, land that is planted but not harvested, and multiple cropping. Arable land counts each hectare once, whereas harvested cropland counts a hectare each time it is harvested during the year.
} 
Although chemical fertilizers have helped China to successfully feed the largest population in the world under limited cropland resources, high rates of fertilizer application have been tied to low fertilizer use efficiency and serious pollution problems. Using 2008 farm-level data, Ma et al. (2014) find that fertilizer use efficiency in rice production in the Taihu Basin is only about 25\%. Similarly, using 2007 farm-level data Wu (2011) finds fertilizer use efficiency is only $33 \%$ for aggregate crop production in five Chinese provinces. Khor and Zeller (2014), using 2004-2008 farm-level panel data, estimated that the marginal product of fertilizer in maize production in Hebei Province, where the average rate of fertilizer application is very high $(535 \mathrm{~kg} / \mathrm{ha})$, is close to zero or perhaps even negative. On the other hand, Chen et al. (2009), using 1995-1999 farm-level panel data, estimate that the marginal product of fertilizer (in yuan of output per yuan spent on fertilizer) ranges from 0.64 in eastern China to 2.11 in southwest China.

Runoff and leaching of nutrients in chemical fertilizers are widely acknowledged as significant environmental problems in China, with consequences including eutrophication of surface waters, contamination of drinking water supplies, and damages to freshwater and coastal water ecosystems (Gu et al. 2013; Ma et al. 2013; Sun et al. 2012). Environmental externalities from nitrogen in fertilizer also include fine particulate matter air pollution from arising through ammonia $\left(\mathrm{NH}_{3}\right)$ volatilization and emissions of nitrous oxide $\left(\mathrm{N}_{2} \mathrm{O}\right)$, a potent greenhouse gas (Gu et al. 2012; Huang et al. 2012; Liu et al. 2013; Zou et al. 2010; Sun, Dai, et al. 2017). Huang et al. (2012) estimate that chemical fertilizers account for about one-third of total $\mathrm{NH}_{3}$ emissions in China; while Chen and Zhang (2010) estimate that cropland accounted for about one-half of anthropogenic $\mathrm{N}_{2} \mathrm{O}$ emissions in China in 2007. High fertilizer application rates over the years and unbalanced nutrient ratios in the fertilizers applied (high levels of nitrogen and phosphorus relative to potassium) have also led to biological and physicochemical damage to agricultural soils in intensively farmed areas of China, causing soil acidification, salinization, and a reduction in microbial activity (Sun et al. 2012; Ju et al. 2009; Yan et al. 2013).

A large number of field experiments and demonstration trials have been conducted in China on alternative fertilization practices (nutrient levels, timing, application methods, etc.). A meta-analysis by Cui et al. (2014) identified 205 published studies for China on nitrogen use efficiency covering 317 study sites. This is by no means all published studies on this topic 
but just those that were the focus of their meta-analysis, namely those that included measures of environmental externalities from nitrogen fertilizer. Almost all the field experiments and demonstration trials proceed from an agronomic objective rather than an economic one: they analyze conventional and alternative fertilization practices and seek to identify those with the highest yields. A common conclusion from the studies in intensively farmed regions of eastern and southern China is that improved fertilizer management strategies could allow nitrogen application rates for grain crops to be reduced by $20-70 \%$ while maintaining or perhaps even increasing crop yields (Ju et al. 2009; Peng et al. 2011; Zhang et al. 2015). Similar conclusions have been reached concerning phosphorus application rates in China's intensive vegetable production systems (Yan et al. 2013).

There is a rich economic literature on why actual fertilizer application rates may differ from agronomically optimal rates, apart from the obvious point that maximizing yield is not synonymous with maximizing profit or utility. In areas where farmers use more fertilizer than agronomically recommended, this literature has examined stochastic impacts of fertilizer on crop yields due to ex ante uncertainty about the weather and soil conditions, which can cause ex ante and ex post optimal application rates to differ; farmer risk preferences and the impact of fertilizer on production risk and profit risk; and seasonal variability in opportunity costs of labor and equipment used in fertilizer application (Rajsic and Weersink 2008; Rajsic, Weersink and Gandorfer 2009; Sheriff 2005; Tumusiime et al. 2011; Paulson and Babcock 2010). In areas where farmers use less fertilizer than agronomically recommended, this literature has examined transportation costs for fertilizer and fertilizer-responsive hybrid seeds; present-biased preferences among farmers that may lead them to procrastinate in purchasing fertilizer; costs of learning how to profitably use fertilizer; and weaknesses in output markets or markets for inputs that are complementary to fertilizer (Suri 2011; Duflo, Kremer and Robinson 2011; Conley and Udry 2010; Matsumoto and Takashi 2011).

Unfortunately, this economic literature has largely bypassed China. Instead, the literature on China's high rates of fertilizer use has focused on other factors, including low levels of nutrient management knowledge by small farmers (Huang et al. 2015); reliance by farmers on recommendations from fertilizer dealers (Yang and Fang 2015); a lack of capacity and accountability on the part of the agricultural extension system to provide information to farmers about more environmentally-friendly production practices (Jia et al. 
2015); and fertilizer acting a substitute in production for the labor lost to agriculture during the last four decades, as hundreds of millions of workers migrated to cities (Ebenstein et al. 2011).

While the China-specific explanations for high rates of fertilizer use may have some validity, and the explanations in the economic literature on high fertilizer use in other countries may have some applicability to China, we believe that both lines of literature miss an important phenomenon in Chinese agriculture: a change in the structure of crops produced in recent decades, with a relative shift away from cereals and toward vegetables and fruits. Figure 2.1 documents this structural change, showing that the harvested area for vegetables and fruits has increased more or less continuously since 1978, from about 6 million ha in 1978 to 38 million ha in 2014. By contrast, harvested area for cereals fluctuated between 77 and 97 million ha during this period.

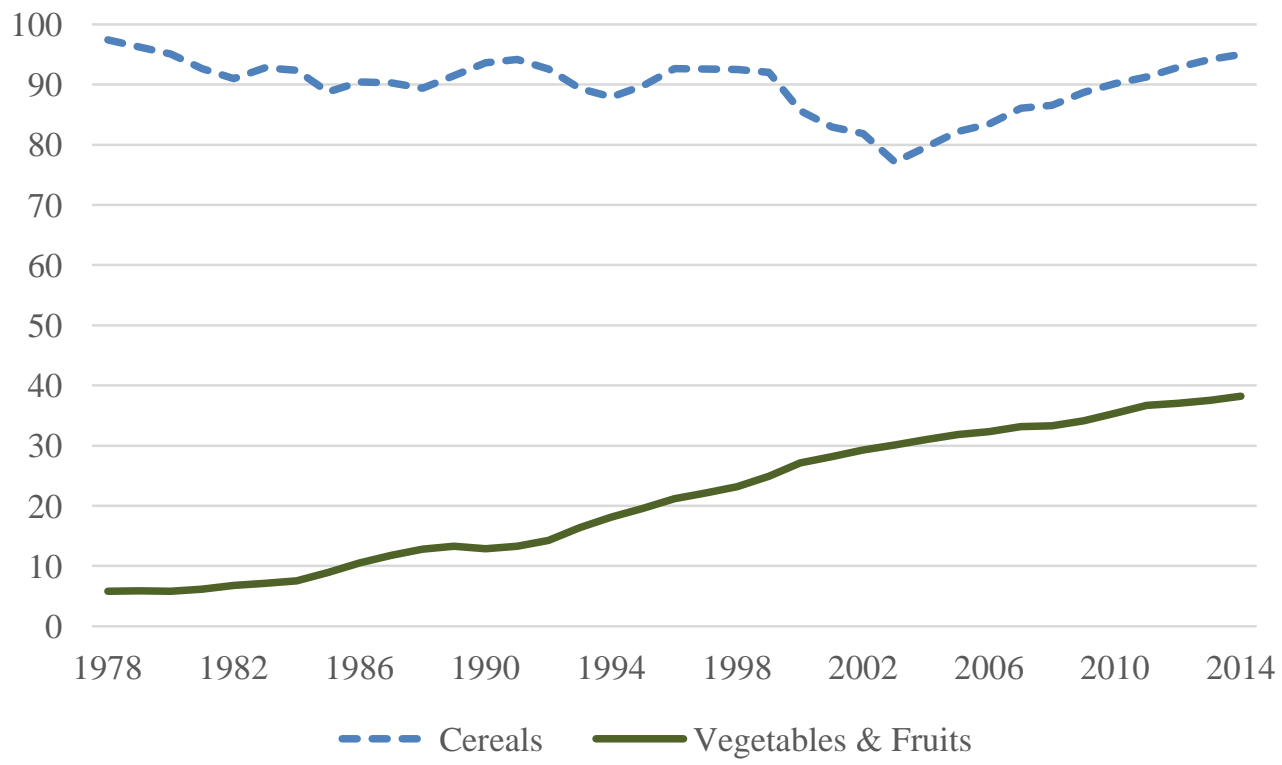

Source: FAOSTAT, http://faostat3.fao.org/.

\section{Figure2.1 Harvested Area for Cereals and for Vegetables \& Fruits (million ha)}

Naturally, the crop structure change may also lead to the changes in input levels, such as the chemical fertilizers. Table 2.2 presents statistics on fertilizer use per hectare by crop in China. On average, during the 2005-2014 period, fertilizer use per hectare was $86 \%$ greater for vegetables, and at least $149 \%$ greater for fruits $(167 \%$ for apple, $157 \%$ for mandarin orange, and $124 \%$ for tangerine), than for cereals (rice, wheat, and maize). 
Statistics in Xin et al. (2012) indicate that about one-half (48\%) of the total growth in fertilizer use in China during 1998-2008 was due to vegetables, about one-fourth (24\%) to tea and fruits, $16 \%$ to grains, and $12 \%$ to economic crops (principally cotton, tobacco, oil palm, sugarcane, and sugar beet).

Table2.2 Fertilizer Use in China for Major Grains, Vegetables, and Fruits (kg/ha)

\begin{tabular}{ccccc|cccc}
\hline Year & Rice & Wheat & Maize & $\begin{array}{c}\text { Average for } \\
\text { three major } \\
\text { grain crops }\end{array}$ & Vegetables & Apple & $\begin{array}{c}\text { Mandarin } \\
\text { orange }\end{array}$ & Tangerine \\
\hline 2005 & 313 & 324 & 276 & 304 & 546 & 750 & 865 & 1061 \\
2006 & 309 & 333 & 301 & 314 & 628 & 767 & 604 & 574 \\
2007 & 323 & 341 & 312 & 325 & 651 & 815 & 699 & 899 \\
2008 & 309 & 344 & 305 & 319 & 574 & 869 & 761 & 737 \\
2009 & 309 & 348 & 321 & 326 & 641 & 864 & 659 & 654 \\
2010 & 323 & 377 & 338 & 345 & 701 & 977 & 1047 & 662 \\
2011 & 321 & 377 & 338 & 345 & 614 & 992 & 1053 & 718 \\
2012 & 320 & 381 & 344 & 348 & 596 & 903 & 997 & 665 \\
2013 & 324 & 381 & 350 & 352 & 649 & 958 & 937 & 683 \\
2014 & 329 & 405 & 365 & 361 & 604 & 1010 & 969 & 818 \\
\hline $2005-2014$ & 318 & 361 & 325 & 334 & 620 & 891 & 859 & 747 \\
Average & & & & & & & & \\
\hline
\end{tabular}

Source: Yearbook of Agricultural Production Costs and Profits in China (various years), National Development and Reform Commission.

In general, the yield maximizing rates for vegetables and fruits are significantly higher than that for field crops. Table 2.3 shows the comparison of output values among major grains, vegetables, and fruits. Between 2005 and 2014, the yield maximizing rate for vegetables was $484 \%$ greater than for cereals (388\% for rice, $593 \%$ for wheat, and $507 \%$ for maize) on average. In particular, the potato is usually regarded as the lowest value product in the vegetable group, but its yield maximizing rate is still higher than the cereals'. Additionally, during this period, compared to cereals, the yield maximizing rate was $648 \%$ greater for apple, and $312 \%$ greater for tangerine. Therefore, we can infer that the marginal value product of fertilizer is higher for vegetables and fruits at any given level of fertilizer use than for grains. 
Table2.3 Output Values for Major Grains, Vegetables, and Fruits (yuan/mu)

\begin{tabular}{|c|c|c|c|c|c|c|c|c|c|}
\hline \multirow{2}{*}{ Year } & \multicolumn{3}{|c|}{ Grains } & \multicolumn{4}{|c|}{ Vegetables $^{\mathrm{a}}$} & \multicolumn{2}{|c|}{ Fruits $^{b}$} \\
\hline & Rice & Wheat & Maize & Tomato $^{c}$ & $\begin{array}{c}\text { Napa } \\
\text { Cabbage }\end{array}$ & Potato & Average $^{\mathrm{d}}$ & Apple & Tangerine \\
\hline 2005 & 686 & 469 & 488 & 5297 & 2238 & 1260 & 3351 & 2818 & 3223 \\
\hline 2006 & 721 & 522 & 557 & 5787 & 2222 & 1343 & 3484 & 3244 & 3933 \\
\hline 2007 & 784 & 564 & 651 & 6894 & 2718 & 1822 & 4329 & 4837 & 3487 \\
\hline 2008 & 901 & 663 & 683 & 6678 & 2485 & 1798 & 4098 & 4203 & 1877 \\
\hline 2009 & 934 & 718 & 726 & 7586 & 2368 & 1542 & 4398 & 6462 & 2739 \\
\hline 2010 & 1076 & 751 & 872 & 8518 & 4235 & 1581 & 5475 & 8881 & 4023 \\
\hline 2011 & 1268 & 830 & 1027 & 11330 & 3734 & 1347 & 6228 & 8773 & 3940 \\
\hline 2012 & 1341 & 852 & 1122 & 11055 & 3052 & 1785 & 6383 & 8772 & 3179 \\
\hline 2013 & 1306 & 902 & 1090 & 10624 & 3593 & 2247 & 6669 & 8141 & 4444 \\
\hline 2014 & 1381 & 1053 & 1146 & 10517 & 3297 & 1743 & 6345 & 8912 & 4941 \\
\hline 2005-2014 average & 1040 & 732 & 836 & 8429 & 2994 & 1647 & 5076 & 6504 & 3579 \\
\hline
\end{tabular}

Source: Yearbook of Agricultural Production Costs and Profits in China (various years), National Development and Reform Commission.

${ }^{a}$ Vegetables include tomato, cucumber, eggplant, cabbage, bell pepper, Napa cabbage, potato, cauliflower, radish, and long bean, which are the most common vegetables Chinese eat. Due to the fact that tomato, Napa cabbage, and potato are the most popular vegetables in China (F. Sun, Koemle, et al. 2017), we only present the statistics on these three items in the table. In particular, the output value of potatoes is usually the lowest in the vegetable group, which provides us a good benchmark for further comparison among grains, vegetables, and fruits.

${ }^{\mathrm{b}}$ Fruits include apple, mandarin orange, and tangerine. In order to save space, we only present the statistics on apple and tangerine. Moreover, the output values of apple and tangerine are the highest and lowest respectively in the fruit group, which provide us good benchmarks for further comparison among grains, vegetables, and fruits.

${ }^{c}$ Tomato includes tomato planted outdoors and the one planted in the greenhouse.

${ }^{\mathrm{d}}$ Average is the average output value of all kinds of vegetables.

The law of diminishing marginal returns tells us that the marginal product of fertilizer should decline at the intensive margin. However, given the fact that cash crops (vegetables and fruits) are more fertilizer intensive than grain crops, and the marginal value product of fertilizer is higher for cash crops at any given level of fertilizer use than for grains, it is possible that intensive margin may be outweighed by an increasing marginal product of fertilizer at the extensive margin (due to shifts in the structure of crops produced). If so, then much of the growth in China's fertilizer use shown in Table 2.1 may represent a profitable response on the part of farmers to changing economic opportunities, which contradicts to the government policy targets of limiting fertilizer use. 
Therefore, the objective of this study is to examine the economic returns to chemical fertilizer in light of the dramatic change in the structure of crop production currently occurring in China. We develop the hypothesis that marginal returns to fertilizer in aggregate crop production may not decline monotonically as fertilizer use increases. To test this hypothesis, we first introduce a constrained optimization model and make a theoretical analysis. Subsequently, we conduct a simulation analysis and then use farm-level data from Jiangsu Province in China to estimate the marginal returns to chemical fertilizer. If our hypothesis is correct, it means that horticultural crops (vegetables and fruits) are gradually becoming the main forces of fertilizer consumption in China. Given the fact that the Asia diets have been shifting away from staples towards vegetables and fruits (Pingali 2007; Pingali 2015; Mergenthaler, Weinberger and Qaim 2009; Gandhi and Zhou 2014), the growing demand for vegetables and fruits would stimulate farmers' interests in growing more vegetables and fruits (Dinham 2003; Reardon et al. 2009).

As horticultural crops (vegetables and fruits) are more fertilizer intensive than grain crops, and the marginal value product of fertilizer is higher for horticultural crops at any given level of fertilizer use than for grains, we hence predict that China's fertilizer consumption will not decrease at least in the short run. Of course, this study also reminds both the researchers and policy makers that the degree of overuse of fertilizer in China might be overvalued if we regard the absolute quantity of total input level as the judging criteria.

\subsection{Theoretical Framework}

To gain some insight into how shifts in production across products may affect the returns to fertilizer, consider a farm with one unit of land that can produce either grains (subscript $g$ ) or vegetables $(v){ }^{6}$ This could also be viewed as a single plot of land on a farm with multiple plots, provided that production decisions are made independently for each plot. Land is an allocable fixed input and there is one variable input, fertilizer $(x)$. The farm's objective is to maximize profits, input and output markets are perfectly competitive, and

\footnotetext{
6 The framework is described as a choice among two crops, but it is equally applicable to a choice between two seasons, two fields, or two different production techniques.
} 
there is no uncertainty. Profits from crop $i(i=g, v)$ are $\pi_{i}=p_{i} f_{i}\left(x_{i}\right)-w x_{i}$, where $p_{i}$ is the output price, $f_{i}\left(x_{i}\right)$ is the production function, and $w$ is the price of fertilizer. Let $x_{i}^{*}$ be the profit-maximizing level of fertilizer use conditional on the choice of producing crop $i$, let $\pi_{i}^{*}$ be the resulting profits, and assume that $x_{i}^{*}>0$ and $\pi_{i}^{*}>0$. The farm will then produce grains if $\pi_{g}^{*}>\pi_{v}^{*}$, it will produce vegetables if $\pi_{v}^{*}>\pi_{g}^{*}$, and it is indifferent if profits from grains and vegetables are equal.

The case where the farm is indifferent between producing grains and vegetables is illustrated in Figure 2.2, which shows the marginal value product (MVP) curves for fertilizer for grains and vegetables, and profit-maximizing fertilizer choices conditional on crop choice. The point where the two MVP curves cross is labeled as $\underline{x}$. Profits from grains are areas A plus $\mathrm{C}$, and profits from vegetables are areas B plus C. Areas A and B are equal, so the farm is indifferent. The curves in Figure 2.2 are drawn in such a way that $x_{v}^{*}>x_{g}^{*}$, which is consistent with the situation in China where fertilizer application rates are generally much higher for vegetables than grains. An outward shift in the MVP curve for vegetables or an inward shift in the MVP curve for grains will make vegetables the most profitable choice, and an inward shift in the MVP curve for vegetables or an outward shift in the MVP curve for grains will make grains the most profitable choice.

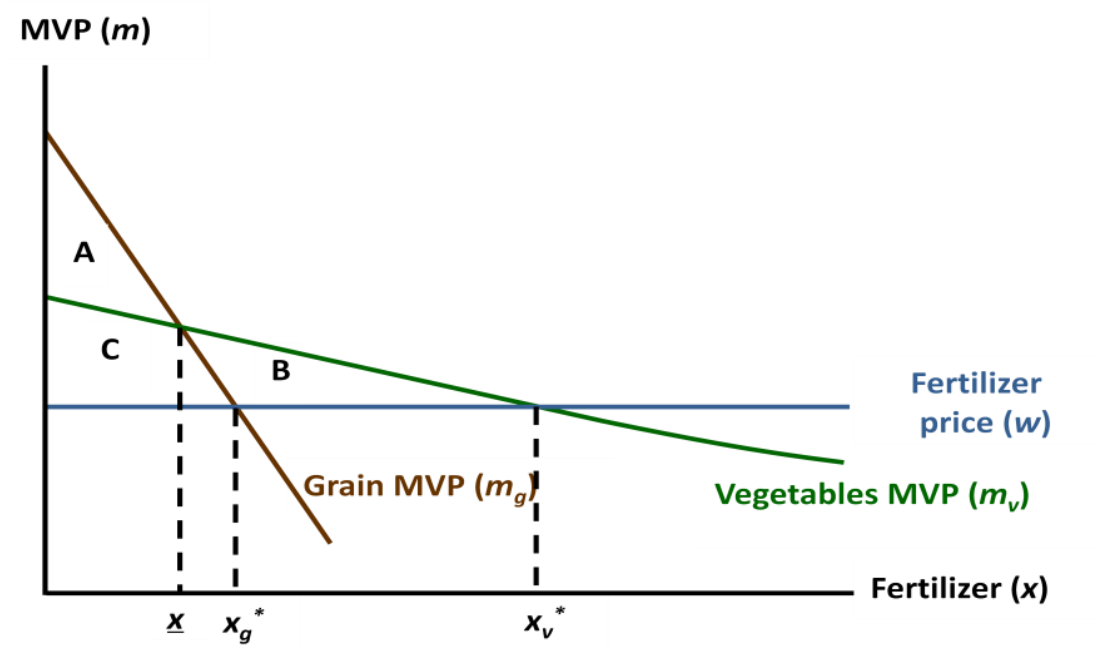

Figure2.2 Crop Choice and the Marginal Value Product (MVP) of Fertilizer 
Moving from the farm level to a more aggregate level, we need to recognize that farms can differ in their crop and fertilizer choices. Or if the model above is applied to a single plot of land on a farm, the aggregation here could be across multiple plots of land on that farm and possibly other farms as well. One simple way to account for differences in production choices is by modifying the vegetables production function so that it is $f_{v}\left(x_{v}, \alpha\right)$, while leaving the grain production function unchanged. $\alpha>0$ is a parameter representing the farm's relative productivity in producing vegetables compared to grain, with different farms having different values of $\alpha$. For given values of $p_{g} / w$ and $p_{v} / w$, there is a critical value of the relative productivity parameter, $\tilde{\alpha}$, at which profits from grains and vegetables are equal. Because there may be adjustment and learning costs if the farm's crop choice is different from its previous choices, we represent these by a switching costs variable $c$ that also influences $\tilde{\alpha}$ :

$$
\tilde{\alpha}=\tilde{\alpha}\left(p_{g} / w, p_{v} / w, c\right)
$$

A farm chooses vegetables if $\alpha>\tilde{\alpha}$ and grain if $\alpha<\tilde{\alpha}$.

Assume for simplicity that farms are continuously and uniformly distributed according to their value of $\alpha$, with a lower bound for $\alpha$ of 0 and an upper bound of 1 , so that the probability density function for $\alpha$ is just 1 . All farms continue to have one unit of land. The proportion of farms producing vegetables, and the proportion of vegetables in total acreage, is

$\theta(\tilde{\alpha})=\int_{\widetilde{\alpha}}^{1} d \alpha=1-\tilde{\alpha}$

The proportion of farms producing grain and the proportion of grain in total acreage is $1-\theta=\tilde{\alpha}$.

Assuming that the production functions are continuous and twice-differentiable, with $\partial f_{i} / \partial x_{i}>0$ and $\partial^{2} f_{i} / \partial x_{i}^{2}<0$, profit-maximizing solutions for fertilizer use conditional 
on crop choice can be written as $x_{g}^{*}=h_{g}\left(p_{g} / w\right)$ and $x_{v}^{*}=h_{v}\left(p_{v} / w, \alpha\right)$, with $\partial x_{i}^{*} / \partial\left(p_{i} / w\right)>0$ because a higher relative price for one specific crop encourages more fertilizer use. As we found in Table 2.2 that vegetables are more fertilizer intensive than grain, we assume that $\partial x_{v}^{*} / \partial \alpha>0$, so that an increase in vegetable productivity augments fertilizer use for vegetables. Across all farms, the mean fertilizer use per unit of land will be

$$
\begin{aligned}
\bar{x}=\bar{x}\left(\tilde{\alpha}, p_{g} / w, p_{v} / w\right) & =\int_{0}^{\widetilde{\alpha}} h_{g}\left(p_{g} / w\right) d \alpha+\int_{\widetilde{\alpha}}^{1} h_{v}\left(p_{v} / w, \alpha\right) d \alpha \\
& =\tilde{\alpha} h_{g}\left(p_{g} / w\right)+\int_{\widetilde{\alpha}}^{1} h_{v}\left(p_{v} / w, \alpha\right) d \alpha
\end{aligned}
$$

Taking the first derivative with respect to the proportion of grain in total acreage $\tilde{\alpha}$, we get $\partial \bar{x} / \partial \tilde{\alpha}=h_{g}\left(p_{g} / w\right)-h_{v}\left(p_{v} / w, \tilde{\alpha}\right)$. Because vegetables are generally more fertilizer intensive than grain (see Table 2.2), the increase in the proportion of grain may drag down the average level of fertilizer application, that is, $\partial \bar{x} / \partial \tilde{\alpha}<0$. Similarly, we take the first derivative with respect to the relative price for one specific crop, $\partial \bar{x} / \partial\left(p_{i} / w\right)$. When the distribution of total acreage between grain and vegetables is constant, a higher relative price for either crop will definitely encourage more fertilizer use, which will lead to a further increase in the average level. So the partial derivative $\partial \bar{x} / \partial\left(p_{i} / w\right)$ is assumed to be positive.

The mean MVP of fertilizer, $m(x)$, as a function of fertilizer use, is a weighted average of the MVPs for across all farms, evaluated at some level of use $x$ :

$\bar{m}=\bar{m}(x, \tilde{\alpha})=\int_{0}^{\widetilde{\alpha}} m_{g}(x) d \alpha+\int_{\widetilde{\alpha}}^{1} m_{v}(x, \alpha) d \alpha=\tilde{\alpha} m_{g}(x)+\int_{\widetilde{\alpha}}^{1} m_{v}(x, \alpha) d \alpha$

where $m_{g}(x)=p_{g} \cdot \partial f_{g} / \partial x_{g}$ and $m_{v}(x, \alpha)=p_{v} \cdot \partial f_{v} / \partial x_{v}$. While the MVP curves for both grain $\left(m_{g}(x)\right)$ and vegetables $\left(m_{v}(x, \alpha)\right)$ are downward-sloping thanks to the assumption that $\partial^{2} f_{i} / \partial x_{i}^{2}<0$, the slope of the mean MVP curve $(\bar{m})$ is not so clear 
because it depends partly on how the allocation of land between grains and vegetables changes as $x$ changes.

Consider a change in the critical value $\tilde{\alpha}$ due to a change in crop switching costs $(c)$, holding relative prices constant. The observed relationship between $\bar{x}$ and $\bar{m}$ as a result of this change will be

$\frac{d \bar{m}}{d \bar{x}}=\left(\left.\frac{\partial \bar{m}}{\partial x}\right|_{x=\bar{x}}\right)+\left(\left.\frac{\partial \bar{m}}{\partial \tilde{\alpha}}\right|_{x=\bar{x}}\right) /\left(\frac{\partial \bar{x}}{\partial \tilde{\alpha}}\right)$

The first term on the right-hand side of equation (2-5), $\partial \bar{m} / \partial x$, represents the intensive margin. This term is negative because the MVP curves for both grain and vegetables are downward-sloping (according to the law of diminishing marginal returns). The second term on the right-hand side of equation (2-5) represents the extensive margin. As noted above, the denominator $(\partial \bar{x} / \partial \tilde{\alpha})$ in this term is negative, so that the sign of the second term is minus one times the sign of the numerator, $\partial \bar{m} /\left.\partial \tilde{\alpha}\right|_{x=\bar{x}}=m_{g}(\bar{x})-m_{v}(\bar{x}, \tilde{\alpha})$. By comparing the yield maximizing rates for grain and vegetables in Table 2.3, we find that the marginal value product of fertilizer is higher for vegetables at any given level of fertilizer use than for grains. In addition, for a profit maximizer, given MVP curves of the general shape shown in Figure 2.2, if some farms are producing vegetables it must be the case that $m_{v}(\bar{x}, \tilde{\alpha})>m_{g}(\bar{x})$. Otherwise we would be in a region of fertilizer use where it is more profitable for every farm to produce grain. Consequently $\partial \bar{m} /\left.\partial \tilde{\alpha}\right|_{x=\bar{x}}<0$ and the second term on the right-hand side of equation (2-5) should be positive.

If the second term on the right-hand side of equation (2-5) were sufficiently large relative to the first term, it would be possible for the mean MVP curve to be upward sloping, $d \bar{m} / d \bar{x}>0$. Given MVP curves as depicted in Figure 2.2, the difference $m_{v}(x, \tilde{\alpha})-$ $m_{g}(x)$ increases as $x$ increases, so that $d \bar{m} / d \bar{x}>0$ may be more likely at a high level of fertilizer use than a low level of use. If so, it is possible that $\bar{m}$ may be U-shaped in $\bar{x}$, with the first term on the right-hand side of (2-5) dominating at low levels of fertilizer use and the second term dominating at high levels of use. 
So far, we have decomposed the marginal product of fertilizer into the intensive margin and extensive margin. Meanwhile, we have proved the point in theory that the marginal value product of fertilizer (MVP), when aggregated across crops, may exhibit a U-shaped pattern as fertilizer use increases. Notably, this hypothesis is derived from the assumption of profit maximization. We don't know whether they are true or not in reality. We hence conduct a simulation analysis and then use farm-level data from Jiangsu Province in China to estimate the marginal returns to chemical fertilizer in the following sections.

\subsection{Simulation Analyses}

This section reports the results of simulation analyses on the circumstances under which marginal returns to fertilizer in aggregate crop production may exhibit a U-shaped pattern as fertilizer use increases. The production functions in the simulations here are quadratic in fertilizer use: $f_{g}(x)=\gamma_{g} x-\left(\beta_{g} / 2\right) x^{2}$ and $f_{v}(x, \alpha)=\gamma_{v} x-1 / 2\left(\beta_{v} / \alpha\right) x^{2}$, where $\gamma_{i}>0$ and $\beta_{i}>0(i=g, v)$ are parameters. The fertilizer MVP curves are $m_{g}(x)=p_{g}\left(\gamma_{g}-\beta_{g} x\right)$ and $m_{v}(x, \alpha)=p_{v}\left[\gamma_{v}-\left(\beta_{v} / \alpha\right) x\right]$. Fertilizer use conditional on crop choice is $x_{g}^{*}=h_{g}\left(p_{g} / w\right)=\left[\gamma_{g}-\left(w / p_{g}\right)\right] / \beta_{g}$ for grain and $x_{v}^{*}=h_{v}\left(p_{v} / w, \alpha\right)=$ $\alpha\left[\gamma_{v}-\left(w / p_{v}\right)\right] / \beta_{v}$ for vegetables.

The mean level of fertilizer use per unit of land across all farms from equation (2-3) can be written as

$\bar{x}=\tilde{\alpha} h_{g}\left(p_{g} / w\right)+(1-\tilde{\alpha}) \overline{h_{v}}\left(p_{v} / w, \tilde{\alpha}\right)$

where $\overline{h_{v}}\left(p_{v} / w, \widetilde{a}\right)=1 / 2(1+\widetilde{a})\left[\gamma_{v}-\left(w / p_{v}\right)\right] / \beta_{v}$ is the mean level of fertilizer use per unit of land across all vegetable farms. The mean MVP of fertilizer across all farms from equation (2-4) can be written as

$\bar{m}=\tilde{\alpha} m_{g}(x)+(1-\tilde{\alpha}) \overline{m_{v}}(x, \tilde{\alpha})$ 
where $\overline{m_{v}}(x, \tilde{\alpha})=p_{v}\left[\gamma_{v}+\beta_{v} x \ln \tilde{\alpha} /(1-\tilde{\alpha})\right]$ is the mean MVP of fertilizer across all vegetable farms.

For the simulations reported here we normalized prices so that $p_{g}=p_{v}=w=1$, and calibrated the grain production function parameters so that the MVP of fertilizer for grain equals 1 at $200 \mathrm{~kg} / \mathrm{ha}$ of fertilizer use and 0 at $500 \mathrm{~kg} / \mathrm{ha}$. These figures are broadly consistent with the literature on returns to fertilizer use in Chinese grain production (Khor and Zeller 2014; Zhang et al. 2015; Chen, Huang and Tang 2011; Yu and Zhao 2009). They yield $\beta_{g}=1 / 300 \approx 0.00333$ and $\gamma_{g}=5 / 3 \approx 1.667$. We tried a variety of other levels of fertilizer use for calibration than 200 and 500, and the results were very similar to those shown here. We calibrated the vegetable production function parameters such that $\overline{x_{v}^{*}}=\overline{h_{v}}\left(p_{v} / w, \tilde{\alpha}\right)=600$ when $\tilde{\alpha}=0.7$ (i.e. $\theta=0.3$ ), which corresponds roughly to the statistics for recent years in Figure 2.1 and Tables 2.1 and 2.2. We also calibrated the vegetable production function parameters so that the MVP curve for vegetables has the same general slope and position relative to the MVP curve for grain shown in Figure 2.2, with the two MVP curves crossing at $100 \mathrm{~kg} / \mathrm{ha}$ (the point labeled $\underline{x}$ in Figure 2.2). This yields $\beta_{v} \approx 0.000550$ and $\gamma_{v} \approx 1.388$. We tried a variety of other calibration points consistent with the statistics and literature, and the results were similar to those reported here.

Figure 2.3 plots the simulated relationship between the mean level of fertilizer use per hectare across all farms $(\bar{x})$, on the x-axis, and the mean MVPs of fertilizer for grain, vegetables, and all crops, on the left-hand side y-axis. The mean MVPs are evaluated at different values of $\tilde{\alpha}$ and the value of $\bar{x}$ associated with each value of $\tilde{\alpha}$. The share of vegetables in total acreage $(\theta=1-\tilde{\alpha})$ is plotted on the right-hand side $y$-axis. The values for $\bar{x}$ shown in Figure 2.3 range from 200 to 380. Given the model parameters, a level of fertilizer use below 200 is never observed, because it would be profitable to increase fertilizer use in grain production up to a level of 200. And if $\bar{x}=200$, no vegetable production must be occurring $(\theta=0)$ because the profit-maximizing level of fertilizer use in vegetables is greater than 200. Larger values of $\bar{x}$ are associated with larger values for $\theta$, which is expected because vegetables are more fertilizer intensive than grain. 


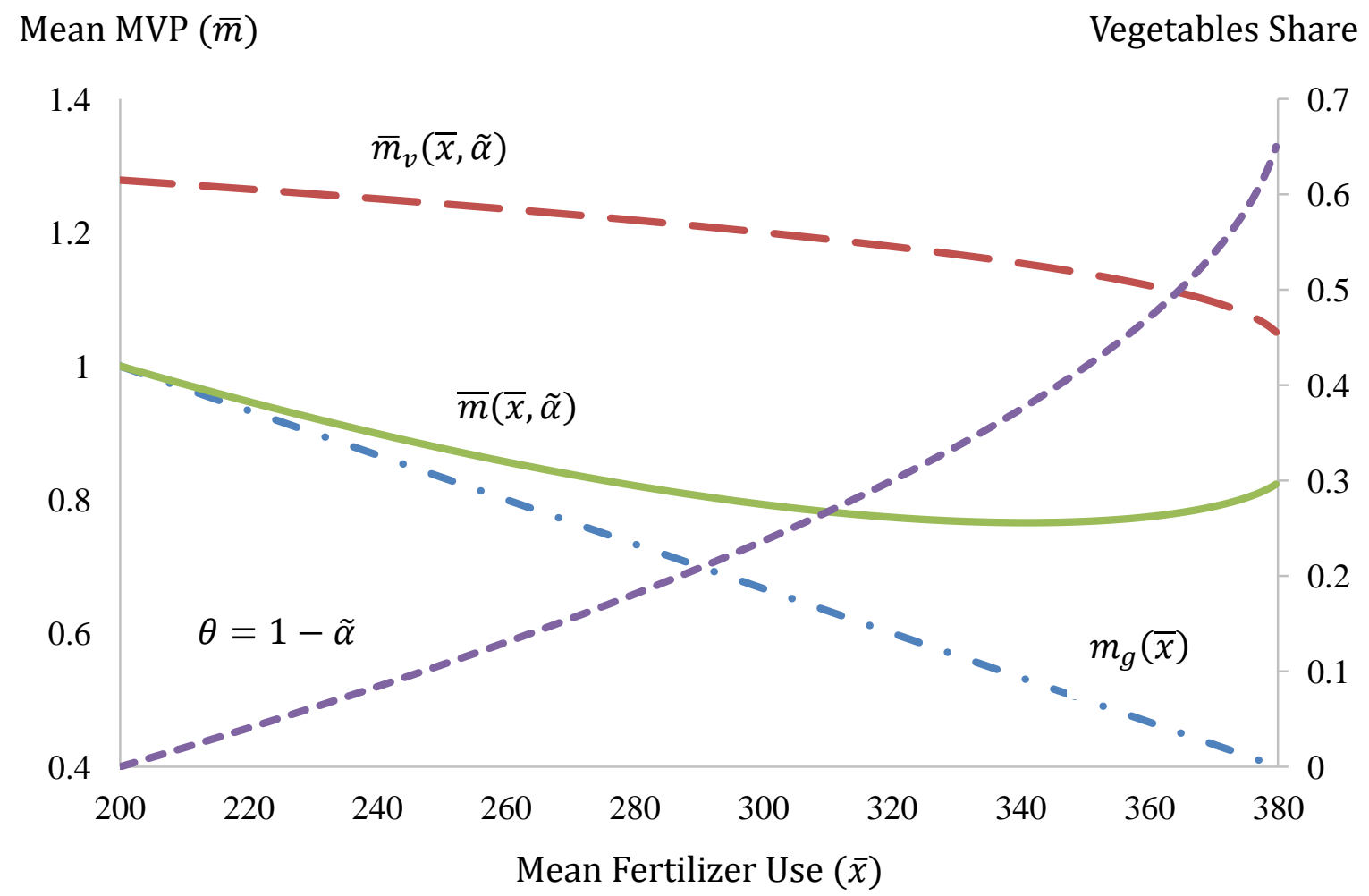

Figure2.3 Simulation Results

The mean MVP for all crops $(\bar{m})$ exhibits a U-shaped pattern, declining from a value of 1 at $\bar{x}=200$ and $\theta=0$ to a minimum of about 0.77 at $\bar{x} \approx 329$ and $\theta \approx 0.38$. From there it rises to about 0.83 at $\bar{x} \approx 380$ and $\theta=0.66$. The mean MVP for grain declines from a value of 1 at $\bar{x}=200$ to about 0.4 at $\bar{x}=380$. The mean MVP for vegetables is flatter, declining from a value of about 1.28 at $\bar{x}=200$ to about 1.05 at $\bar{x}=380$. We now turn to the question of whether the theoretical possibility of a U-shaped mean MVP curve may be occurring in reality. 


\subsection{Empirical Model and Data}

\subsubsection{Econometric Model}

Testing the hypothesis that marginal returns to fertilizer in aggregate crop production do not decline monotonically as fertilizer use increases requires a functional form for the production function in which the slope of the MVP curve for fertilizer can change signs. The Cobb-Douglas form, while popular in the estimation of agricultural production functions, does not work because the MVP for each input is always positive and diminishing in the quantity of that input. Flexible functional forms such as the normalized quadratic that are second-order approximations to the unknown true function are popular in estimating cost and profit functions. However, they are less popular for direct estimation of production function parameters because multicollinearity among the first- and second-order interaction terms involving the inputs can lead to imprecise parameter estimates (Mundlak 2001).

To balance the desire to minimize multicollinearity problems against the need for a functional form that can permit the slope of the MVP curve for fertilizer to change sings over the range of the data, we estimate aggregate crop production functions that are Cobb-Douglas in the non-fertilizer inputs and more flexible with respect to fertilizer. The basic functional form is

$$
\ln y_{i t}=\boldsymbol{\alpha}_{\boldsymbol{i}}+\boldsymbol{\beta}^{\prime} \ln _{i t}+f\left(\ln x_{i t}\right)+\boldsymbol{\delta}^{\prime} \mathbf{Y e a r}_{i t}+\boldsymbol{\gamma}^{\prime} \boldsymbol{R e g i o n}_{i t}+e_{i t}
$$

The subscript $i$ denotes household and the subscript $t$ denotes year. $y_{i t}$ is the value of all crop outputs produced by the household; $\alpha_{i}$ is a household-level fixed effect; $\boldsymbol{l n} \boldsymbol{n}_{\boldsymbol{i t}}$ is a vector of the logarithms of the non-fertilizer inputs (such as land, capital, labor, seed, and pesticides); $x_{i t}$ is chemical fertilizer use; $f(\cdot)$ is some function of the log of fertilizer use; $\boldsymbol{Y e a r}_{\boldsymbol{i t}}$ is a vector of year dummy variables, capturing the potential productivity growth due to technical progress and other time-varying factors; $\boldsymbol{R e g i o n}_{\boldsymbol{i t}}$ is a vector of regional dummy variables, capturing the potential determinants that are not proxied for by 
other explanatory variables ${ }^{7}$; and $e_{i t}$ is a random error.

An alternative to an aggregate crop production function is a multiproduct production function combined with a system of equations describing the allocation of land among various crops, from which empirical counterparts to equations (2-3)-(2-5) could be calculated. However, crop-specific data on the use of fertilizer and other non-land inputs are not available in our dataset. ${ }^{8}$ Although a considerable number of approaches have been explored in estimating multiproduct production relationships in the absence of crop-specific input data (Lence and Miller 1998; Heckelei and Wolff 2003; Paris and Howitt 1998; Just, Zilberman and Hochman 1983), some of them impose strong assumptions. For instance, duality approaches typically assume profit maximization (Zhang and Fan 2001; Guyomard, Baudry and Carpentier 1996), and our theoretical and simulation analyses show that profit maximization at the micro farmer level is consistent with a U-shaped relationship between fertilizer use and marginal returns to fertilizer in aggregate crop production. However, because much of the literature on current levels of fertilizer use in China questions whether farmers are profit maximizers (e.g. Sun et al. 2012), it seems best to avoid making this assumption a linchpin of our empirical work.

Most importantly, the purpose of our study is to prove that the high level of fertilizer use in China is partially due to the rapid increase of the share of horticultural crops in recent years. If we estimated an aggregate production function and observed a U-shaped curve as we expected, it means that our hypothesis is correct. There is no need to apply complicated methods to deal with such simple issue. Last but not least, governments usually make policies based on the aggregated statistics, especially in China. In this case, the fertilizer MVP of the crop at the aggregate level is of interest, as it is related to the policy implications.

\footnotetext{
${ }^{7}$ In the subsequent empirical analysis, we find that prices for each agricultural product are uniform throughout the counties/districts. Given the potential influences of price across regions, we hence include regional dummy variables in our regression.

8 A lack of crop-specific input use data is a common problem in many countries in analyzing multiproduct farms (Carpentier and Letort 2011).
} 


\subsubsection{Polynomial Function}

A straightforward option for $f(\cdot)$ is a polynomial function in $\ln x_{i t}$. Preliminary analyses revealed that the highest-degree polynomial in which all of the estimated coefficients of $f(\cdot)$ are statistically significant is a cubic, so that is what we report here:

$f\left(\ln x_{i t}\right)=\eta_{1} \ln x_{i t}+\eta_{2}\left(\ln x_{i t}\right)^{2}+\eta_{3}\left(\ln x_{i t}\right)^{3}$

The partial output elasticity of fertilizer is

$\varepsilon_{i t}=\eta_{1}+2 \eta_{2} \ln x_{i t}+3 \eta_{3}\left(\ln x_{i t}\right)^{2}$

and the marginal value product (MVP) of fertilizer is $m_{i t}=\left(y_{i t} / x_{i t}\right) \varepsilon_{i t}$. The slope of the MVP function is

$\partial m_{i t} / \partial x_{i t}=\left(y_{i t} / x_{i t}^{2}\right)\left[-\varepsilon_{i t}\left(1-\varepsilon_{i t}\right)+\left(2 \eta_{2}+6 \eta_{3} \ln x_{i t}\right)\right]$

On the basis of the existing literature (Yu and Zhao 2009), we would typically expect that $0<\varepsilon_{i t}<1$, so that the term $-\varepsilon_{i t}\left(1-\varepsilon_{i t}\right)$ on the right-hand side of equation (2-11) is negative. The term $\left(2 \eta_{2}+6 \eta_{3} \ln x_{i t}\right)$ could be positive or negative depending on the parameter values and level of fertilizer use.

\subsubsection{Model Estimation}

Notably, variable input uses are often considered as endogenous in production function models, especially for aggregate-level data (Guan et al. 2006; Mundlak, Butzer and Larson 2012; Sonoda and Mishra 2015). We compare the differences of the values of output and the input levels across crops and present in Table 2.4. We find that the crop acreage share can significantly affect both the crop values and almost all input use levels. Since the critical factor, crop acreage share, is unobserved to the researcher but observable to farmers, variable input uses are classified as endogenous. Therefore, using the ordinary 
least squares (OLS) regression technique to estimate the equation (2-8) may produce biased results due to the potential endogeneity problem.

\section{Table2.4 Comparison of the Differences of the Crop Values and Input Use Levels across Crops}

\begin{tabular}{lccccccc}
\hline & Rice & Wheat & Maize & Rapeseed & Cotton & Vegetable & $\begin{array}{c}\text { Silkworm } \\
\text { Cocoon }\end{array}$ \\
\hline Value of output $^{\mathrm{a}}$ & 1305.90 & 901.93 & 1089.56 & 745.86 & 1962.52 & 3834.52 & 4278.59 \\
Labour $^{\mathbf{b}}$ & 6.87 & 5.03 & 6.60 & 7.86 & 19.44 & 32.80 & 45.68 \\
Capital $^{\mathbf{c}}$ & 7.30 & 3.66 & 2.89 & 4.88 & 11.07 & 175.96 & 111.98 \\
Seed $^{\mathbf{d}}$ & 51.57 & 59.51 & 55.04 & 18.42 & 56.57 & 137.89 & 138.01 \\
Chemical fertilizer $^{\mathbf{e}}$ & 21.58 & 25.39 & 23.35 & 15.08 & 32.36 & 43.28 & 54.02 \\
Pesticides $^{\mathbf{f}}$ & 49.41 & 17.13 & 14.38 & 12.71 & 70.94 & 110.69 & 123.68 \\
Machinery services $^{\mathrm{g}}$ & 159.83 & 119.62 & 95.31 & 44.85 & 90.97 & 75.01 & 1.79 \\
Irrigation services $^{\mathbf{h}}$ & 23.85 & 32.27 & 14.20 & 3.59 & 54.55 & 56.19 & 8.68 \\
\hline
\end{tabular}

Source: Yearbook of Agricultural Production Costs and Profits in China (various years), National Development and Reform Commission.

${ }^{\text {a }}$ Value of output is the total value of output harvested in 2013 per mu of sown area.

${ }^{\mathrm{b}}$ Labor is the number of days engaged in farming per mu of sown area in 2013.

${ }^{\mathrm{c}}$ Capital is the depreciation of fixed assets per mu of sown area in 2013.

${ }^{\mathrm{d}}$ Seed is the seed costs per mu of sown area in 2013.

${ }^{\mathrm{e}}$ Chemical fertilizer is the consumption of pure chemical fertilizers (nitrogenous, phosphate, potash, and synthetic fertilizers) in $\mathrm{kg}$ per mu of sown area in 2013.

${ }^{\mathrm{f}}$ Pesticides refers to the cost of pesticides used per mu of sown area in 2013.

${ }^{\mathrm{g}}$ Machinery services refer to expenditures on farm machinery rental per mu of sown area in 2013.

${ }^{\mathrm{h}}$ Irrigation services refer to expenditures on irrigation and drainage per mu of sown area in 2013.

Without controlling for the effects of crop acreage share, the results are likely to be overestimated or underestimated (Woolridge 2008, pp.196-198). To deal with this problem, possible solution calls for instrumental variable (IV) estimation (Greene 2002, pp.74). For instance, Thijssen (1992) uses a series of instruments and adopts the SUR and 3SLS method to estimate the agricultural production function. Huang et al. (2002) develop an instrument for pesticide application to avoid the potential endogeneity problem. However, almost all of the independent variables are endogenous in our regression. It is very difficult to find valid instruments with high reliability for all of them. 
Apart from the instrumental variables method, there are another three popular techniques dealing with panel data: fixed effects (FE) estimation (Mundlak 1961), a semi-parametric approach proposed by Olley and Pakes (1996) and Levinsohn and Petrin (2003) using proxy variables to control for unobservable, and generalized method of moments (GMM) using lags or differences of both inputs and outputs as instrumental variables (Arellano and Bond 1991; Arellano and Bover 1995; Blundell and Bond 1998). Given the fact that FE estimation assumes unobserved shock should be constant over time, this assumption, no doubt, is so strong that cannot be satisfied in reality. Hence, FE estimation generally fails to solve the endogeneity problems (Ackerberg, Caves and Frazer 2006; Mundlak et al. 2012). Similarly, Olley-Pakes and Levinsohn-Petrin methods require the proxies to be positive, and strictly increasing with productivity, and should not include measurement errors (Sonoda and Mishra 2015), which is also difficult to be satisfied. As for the difference and system GMM estimators, they are essencely the extension of IV estimator. Compared to other IV estimators, such as 3SLS, the difference/system GMM estimator does not impose strong assumptions about the distribution of error term and has the ability to account for heteroscedasticity and autocorrelation (Hall 2005). In general, system GMM uses more instruments than the difference GMM, so the system GMM is more efficient. As system GMM approach is widely used in recent panel data production function estimators (Blundell and Bond 2000; Guan et al. 2006; Druska and Horrace 2004; Carpentier and Weaver 1997), we hence adopt the System-GMM to estimate the production function with fixed effects.

\subsubsection{Data}

This study uses Chinese rural household survey data collected by the Price Department of the National Development and Reform Commission (NDRC) in Jiangsu Province between 2004 and 2013. The NDRC obtains price information with the help of provincial Price Bureau, which conducts an annual rural household survey on agricultural costs and returns. Depending on the year, 50 to 65 counties/districts out of a total of 106 are selected for the survey, and more than 600 households participate in the survey (see Table 2.5). The chosen households sign a contract with the Price Bureau to fully obey the rules of the survey to ensure the accuracy and integrity of the data. These households are required to 
keep a year-long detailed record of all agricultural production activities. The provincial Price Bureau subsequently summarizes each household's agricultural outputs and inputs, and reports the aggregate results to NDRC.

Table2.5 Farm Household Survey Samples

\begin{tabular}{lccc}
\hline Year & Number of counties/districts & $\begin{array}{c}\text { Number of households } \\
\text { surveyed }\end{array}$ & $\begin{array}{c}\text { Number of households } \\
\text { in our analysis }\end{array}$ \\
\hline 2004 & 52 & 611 & 315 \\
2005 & 52 & 643 & 438 \\
2006 & 52 & 658 & 491 \\
2007 & 53 & 673 & 495 \\
2008 & 53 & 674 & 498 \\
2009 & 51 & 661 & 534 \\
2010 & 50 & 638 & 512 \\
2011 & 64 & 794 & 561 \\
2012 & 65 & 884 & 587 \\
2013 & 65 & 883 & 522 \\
\hline Total & - & 7119 & 4953 \\
\hline
\end{tabular}

Although the Jiangsu Province data have a total of 7119 households, only the data for 4953 households are used here, after deleting households with missing information and households that observed once only. Overall, our dataset is unbalanced, where 144 households have 10 years observations ${ }^{9}$. As for the output group, there are 17 crops: medium indica rice, japonica rice, wheat, maize, rapeseed, cotton, silkworm (Bombyx mori) cocoon, tomato (outdoor), tomato (greenhouse), cucumber (greenhouse), eggplant (greenhouse), cabbage (outdoor), bell pepper (greenhouse), Napa cabbage (outdoor), cauliflower (outdoor), radish (outdoor), and long bean (outdoor). In general, field crop growers plant 2-3 crops a year, while greenhouse vegetable growers plant 2-4 crops a year.

\footnotetext{
${ }^{9}$ Specifically, there are 144 households with 10 years observations, 79 households with 9 years observations, 78 households with 8 years observations, 58 households with 7 years observations, 55 households with 6 years observations, 76 households with 5 years observations, 95 households with 4 years observations, 120 households with 3 years observations, and 161 households with 2 years observations, respectively.
} 
In the survey data, households report the values and physical quantities of their various agricultural outputs and inputs for each product. Inputs are divided into eight categories: land, labor, capital, seed, chemical fertilizer, pesticides, farm machinery services, and irrigation services. Output and all inputs except land are divided by the quantity of land. Land refers to actual sown area, which is the sum across crops of cultivated area during the year and is measured in mu. ${ }^{10}$ Land that is cultivated multiple times during a year is counted each time it is sown. Output is defined as the total value of all crops harvested in a year per mu of sown area ${ }^{11}$. Labor refers to the number of days engaged in farming per mu of sown area. Capital refers to depreciation of fixed assets per mu of sown area. Seed refers to seed costs in yuan per mu of sown area. Chemical fertilizer refers to the consumption of pure chemical fertilizers $^{12}$ (nitrogenous, phosphate, potash, and synthetic fertilizers) in $\mathrm{kg}$ per mu of harvest area. Pesticides refer to the cost in yuan of pesticides used per mu of sown area. Farm machinery services refer to expenditures on farm machinery rental per mu of sown area. Irrigation services refer to expenditures on irrigation and drainage per mu of sown area. We use the Consumer Price Index (CPI) for Rural Areas and the Price Index for Investment in Fixed Assets to deflate the total value of output and capital expenditures, respectively, to year 2004 prices. The costs of seed, pesticides, farm machinery, and irrigation services are deflated to 2004 prices using the Means of Agricultural Production General Price Index. These price indices were obtained from the Jiangsu Statistical Yearbook (various editions), which is published by the Statistical Bureau of Jiangsu Province.

Table 2.6 presents descriptive statistics for the variables in this study. The average value of crop production output is about 1027 yuan/mu. The sample mean values of land, labor, capital, seed, chemical fertilizer, pesticides, farm machinery services, and irrigation services are $13.70 \mathrm{mu}$ (less than 1 hectare), 9.35 days/mu, 11.79 yuan/mu, 29.81 yuan/mu, 27.76 $\mathrm{kg} / \mathrm{mu}, 41.20$ yuan/mu, $65.30 \mathrm{yuan} / \mathrm{mu}$, and 17.51 yuan/mu, respectively. The descriptive statistics indicate significant variability in values for output and inputs. For example, fertilizer use ranges from 17.33 to $46.73 \mathrm{~kg} / \mathrm{mu}$. This wide range of fertilizer use helps

\footnotetext{
10 A mu is a unit of land measurement, with $15 \mathrm{mu}$ equal to 1 hectare.

11 Because there are 17 different kinds of crops in our output group, to ensure comparability we measure the total output by the money value of all outputs produced in a given period of time.

12 Different types of fertilizers have different concentrations of effective constituents. For example, the proportion of effective nitrogen in urea is $46 \%$, so $100 \mathrm{~kg}$ of urea is regarded as $46 \mathrm{~kg}$ of pure fertilizer in this study.
} 
motivate our research question of how the MVP of fertilizer changes as the level of use changes.

Table2.6 Descriptive Statistics $(n=4953)$

\begin{tabular}{llllll}
\hline Variable & Mean & $\begin{array}{l}\text { Standard } \\
\text { Deviation }\end{array}$ & Minimum & Maximum & Units \\
\hline Value of output $^{\mathrm{a}}$ & 1026.57 & 1141.46 & 69.23 & 18204.60 & yuan/mu \\
Land $^{\mathrm{b}}$ & 13.70 & 61.84 & 0.20 & 2750.00 & $\mathrm{mu}$ \\
Labor $^{\mathrm{c}}$ & 9.35 & 10.47 & 0.43 & 147.00 & days/mu \\
Capital $^{\mathrm{d}}$ & 11.79 & 47.36 & 0.49 & 809.54 & $\mathrm{yuan} / \mathrm{mu}$ \\
Seed $^{\mathrm{e}}$ & 29.81 & 30.80 & 3.30 & 784.70 & $\mathrm{yuan} / \mathrm{mu}$ \\
Chemical fertilizer $^{\mathrm{f}}$ & 27.76 & 5.78 & 17.33 & 46.73 & $\mathrm{~kg} / \mathrm{mu}$ \\
Pesticides $^{\mathrm{g}}$ & 41.20 & 26.95 & 2.17 & 482.54 & $\mathrm{yuan} / \mathrm{mu}$ \\
Machinery services $^{\mathrm{h}}$ & 65.30 & 31.26 & 3.00 & 261.92 & $\mathrm{yuan} / \mathrm{mu}$ \\
Irrigation services $^{\mathrm{i}}$ & 17.51 & 13.15 & 0.59 & 91.86 & $\mathrm{yuan} / \mathrm{mu}$ \\
\hline
\end{tabular}

${ }^{a}$ Value of output is the total value of all products harvested in one year per mu of sown area, deflated to 2004 prices using the Consumer Price Index of Rural Households.

${ }^{\mathrm{b}}$ Land is the actual sown area, which is the sum of all area cultivated with crops during the year and is measured in mu.

${ }^{\mathrm{c}}$ Labor is the number of days engaged in farming per mu of sown area.

${ }^{\mathrm{d}}$ Capital is the depreciation of fixed assets per mu of sown area, deflated to 2004 prices using the Price Index for Investment in Fixed Assets.

${ }^{\mathrm{e}}$ Seed is the seed costs per mu of sown area, deflated to 2004 prices using the Means of Agricultural Production General Price Index.

${ }^{\mathrm{f}}$ Chemical fertilizer is the consumption of pure chemical fertilizers (nitrogenous, phosphate, potash, and synthetic fertilizers) in kg per mu of sown area.

${ }^{\mathrm{g}}$ Pesticides refers to the cost of pesticides used per mu of sown area, deflated to 2004 prices using the Means of Agricultural Production General Price Index.

${ }^{\mathrm{h}}$ Machinery services refer to expenditures on farm machinery rental per mu of sown area, deflated to 2004 prices using the Means of Agricultural Production General Price Index.

${ }^{1}$ Irrigation services refer to expenditures on irrigation and drainage per mu of sown area, deflated to 2004 prices using the Means of Agricultural Production General Price Index. 


\subsection{Results and Discussion}

Table 2.7 provides an overview of the exogeneity tests performed. For the Hausman test, the system GMM estimate is compared with the OLS estimate. It indicates that the regressors are endogenous as we suspected. The instruments used for the system GMM estimation throughout this paper are all exogenous variables as well as lags and differences of inputs and outputs. Both the Sargan-Hansen tests and Arellano-Bond tests for autocorrelation indicate that the instruments are valid. That is to say, the system GMM estimate is consistent.

Table2.7 Estimation Results

\begin{tabular}{|c|c|c|c|c|}
\hline \multirow[b]{2}{*}{ Variable } & \multicolumn{2}{|c|}{ OLS } & \multicolumn{2}{|c|}{ System GMM } \\
\hline & $\begin{array}{l}\text { Estimated } \\
\text { Coefficient }^{\mathrm{a}}\end{array}$ & $\begin{array}{l}\text { Standard Error } \\
\text { (Robust) }^{\mathrm{b}}\end{array}$ & $\begin{array}{l}\text { Estimated } \\
\text { Coefficient }^{\mathrm{a}}\end{array}$ & $\begin{array}{l}\text { Standard Error } \\
\text { (Robust) }^{\mathrm{c}}\end{array}$ \\
\hline $\ln ($ Land $)$ & $-0.0352^{* * *}$ & 0.0062 & $-0.0287^{* * *}$ & 0.0107 \\
\hline $\ln ($ Labor $)$ & $0.1971^{* * *}$ & 0.0109 & $0.2012^{* * *}$ & 0.0206 \\
\hline $\ln$ (Capital) & $0.0349^{* * *}$ & 0.0057 & $0.0294^{* * *}$ & 0.0098 \\
\hline $\ln ($ Seed $)$ & $0.0247^{* *}$ & 0.0099 & 0.0211 & 0.0172 \\
\hline $\ln ($ Pesticide $)$ & $0.1125^{* * *}$ & 0.0081 & $0.0977^{* * *}$ & 0.0147 \\
\hline $\ln$ (Machinery) & $0.0653^{* * *}$ & 0.0101 & $0.0779^{* * *}$ & 0.0199 \\
\hline $\ln$ (Irrigation) & $0.0669^{* * *}$ & 0.0056 & $0.0609^{* * *}$ & 0.0097 \\
\hline $\ln$ (Fertilizer) & 8.5225 & 6.1907 & $21.5114^{* *}$ & 9.0922 \\
\hline $\ln (\text { Fertilizer })^{2}$ & -2.7204 & 1.8656 & $-6.6270^{* *}$ & 2.7441 \\
\hline $\ln (\text { Fertilizer })^{3}$ & 0.2916 & 0.1869 & $0.6836^{* *}$ & 0.2754 \\
\hline \multicolumn{5}{|c|}{ DIAGNOSTICS \& TESTS } \\
\hline \multicolumn{3}{|c|}{ Hausman test of endogeneity ( $p$-value) } & \multicolumn{2}{|l|}{0.047} \\
\hline \multicolumn{3}{|l|}{ 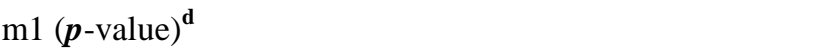 } & \multicolumn{2}{|l|}{0.000} \\
\hline \multicolumn{3}{|l|}{$\mathrm{m} 2(p \text {-value })^{\mathrm{e}}$} & \multicolumn{2}{|l|}{0.275} \\
\hline \multicolumn{3}{|c|}{ Hansen test of overid ${ }^{\mathbf{f}}(p$-value) } & \multicolumn{2}{|l|}{0.318} \\
\hline
\end{tabular}

a $* * *, * *$, and $*$ denote significance at the $1 \%, 5 \%$, and $10 \%$ levels, respectively.

${ }^{\mathrm{b}}$ Robust standard errors were calculated using the Huber/White/sandwich form for the covariance matrix of the parameter estimators (White 1980).

${ }^{\mathrm{c}}$ Robust standard errors were calculated using finite sample correction for the two-step covariance matrix of the parameter estimators (Windmeijer 2005).

${ }^{\mathrm{d}}$ Tests the null hypothesis that the differenced residuals in periods $\mathrm{t}$ and $\mathrm{t}-1$ are uncorrelated.

${ }^{\mathrm{e}}$ Tests the null hypothesis that the differenced residuals in periods $\mathrm{t}$ and $\mathrm{t}-2$ are uncorrelated.

${ }^{\mathrm{f}}$ In robust estimation, Hansen's J statistic is reported instead of the Sargan test. 
The nonlinear regression results are also presented in Table 2.7, excluding the fixed effects (both individual and time) and regional effects which are not reported to save space. As a contrast, we also present the results for an OLS regression controlled for fix effects in the table. Notably, the results of system GMM are two-step estimates, where the standard errors have been corrected by the finite sample for the covariance matrix of the parameter estimators (Windmeijer 2005). Obviously, most of the variables in Table 2.7 are statistically significant. One notable result is the negative estimated coefficient of -0.03 on the log of land, which is lower than expected based on prior research ( $\mathrm{Yu}$ and Zhao 2009) and suggests mild diseconomies of scale at the household level. This may be attributable to farmland fragmentation. Fragmentation encourages farmers to practice crop diversification (Tan, Heerink and Qu 2006) in order to reduce seasonal labor bottlenecks (Bentley 1987; Blarel et al. 1992) and enhance food security, but it also distorts the allocation of other inputs (e.g. farmers taking greater care of plots close to their farmsteads or more fertile plots) and subsequently reduces land use efficiency (Van Dijk 2003).

What we concern in this model are the coefficients of $\ln$ (Fertilizer), $\ln (\text { Fertilizer })^{2}$, and $\ln (\text { Fertilizer })^{3}$. Look at the column 2 of Table 2.7, the coefficients on $\ln$ (Fertilizer) and $\ln (\text { Fertilizer })^{3}$ are significantly positive, while the

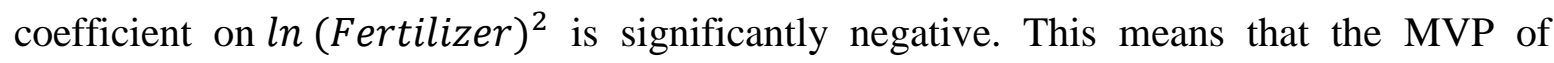
fertilizer exhibits a U-shaped pattern. The bottom of the $U$ occurs at about $25 \mathrm{~kg} / \mathrm{mu}$, which is a region where the estimated partial output elasticity of fertilizer from equation (2-10) is actually positive. At the sample mean of about $28 \mathrm{~kg} / \mathrm{mu}$, the estimated partial output elasticity of fertilizer is approximately 0.11. Figure 2.4 displays the MVP curve for chemical fertilizer. The points in the figure are the MVP predictions of chemical fertilizers. The dotted line is a local polynomial smoothing of the MVP of fertilizer. Shaded areas represent $95 \%$ confidence intervals around the local polynomial smoothing line. 


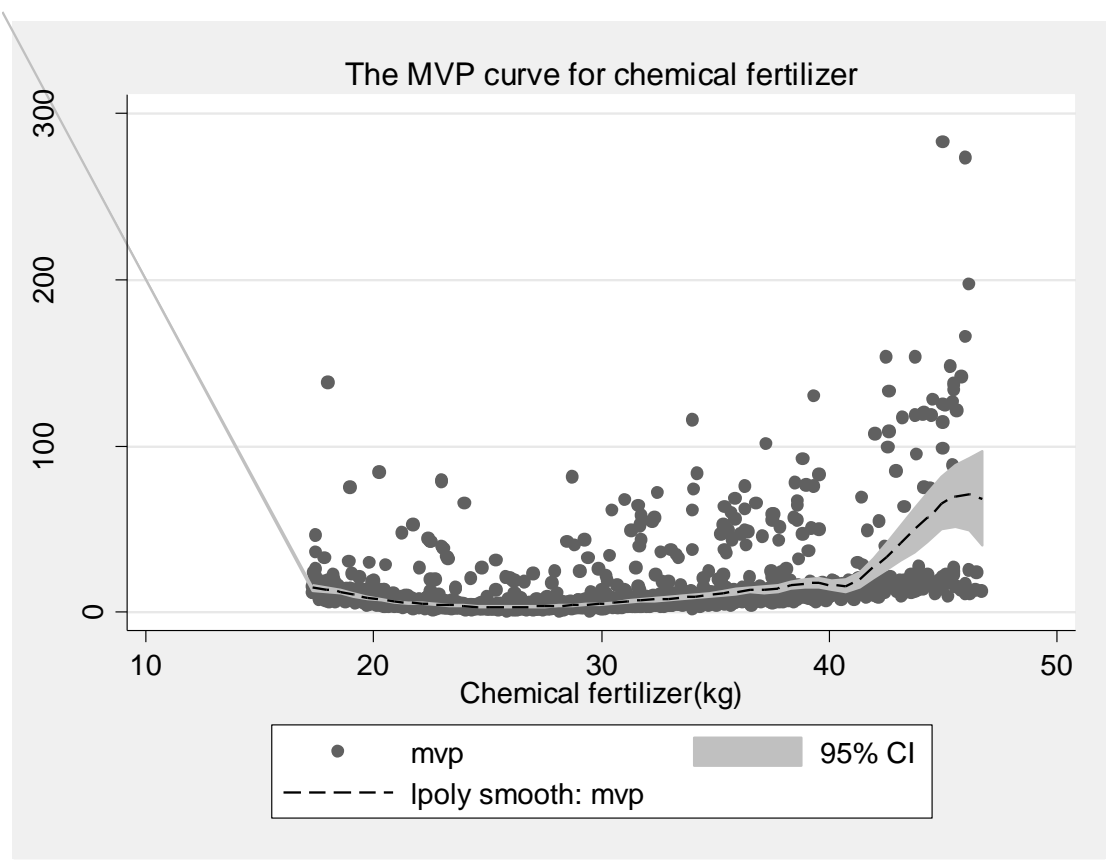

Figure2.4 Marginal Value Product of Fertilizera

${ }^{a}$ The points in the figure are the MVP predictions of chemical fertilizers. The dotted line is a local polynomial smoothing of the MVP of fertilizer. Shaded areas represent $95 \%$ confidence intervals around the local polynomial smoothing line.

In order to figure out whether the increase in the average fertilizer rate is at least partly caused by the change in the crop mix, Figure 2.5 presents a scatterplot of the share of total sown area accounted for by vegetables and sericulture ${ }^{13}$ against fertilizer use intensity. There is a clear positive relationship between these two variables, which is confirmed by the fitted regression line with a slope of 6.34. The correlation coefficient between them is 0.20 and is statistically significant at the $1 \%$ level. Notably, when the vegetable share of total sown area equals 1 , average chemical fertilizer use intensity is $33.75 \mathrm{~kg} / \mathrm{mu}$, which is about four-fifths greater than the average intensity $(27.53 \mathrm{~kg} / \mathrm{mu})$ when the vegetable/sericulture share is 0 . We find that an increase in the proportion of vegetable and sericulture farming is significantly associated with higher fertilizer use intensity. This provides additional direct evidence that crop allocation may lead to increasing returns to fertilizer use.

\footnotetext{
13 Sericulture is an important cottage industry in Jiangsu province, and the silkworm mulberry is a heavy consumer of fertilizers.
} 


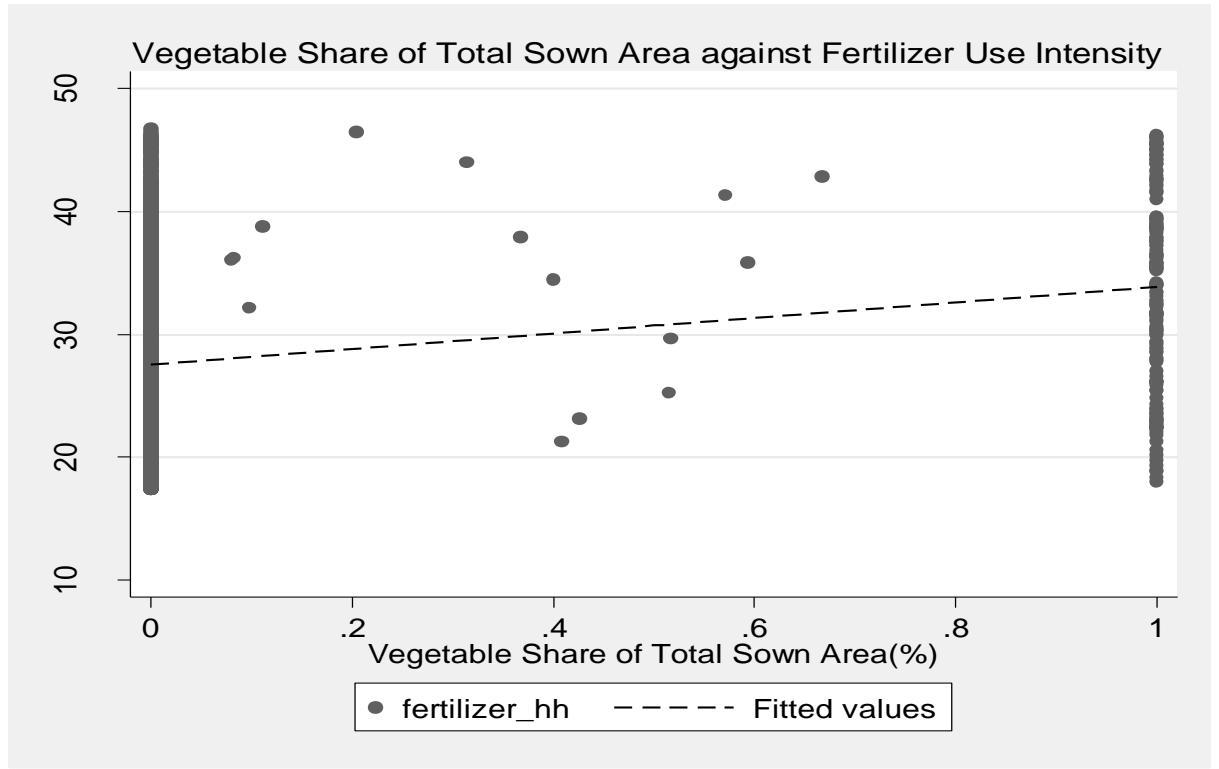

Figure2.5 Scatterplot of Vegetablea Share of Total Sown
Area against Fertilizer Use Intensity

\begin{abstract}
${ }^{a}$ The "Vegetables" here include not only the usual vegetables (i.e. tomato (outdoor \& greenhouse), cucumber (greenhouse), eggplant (greenhouse), cabbage (outdoor), bell pepper (greenhouse), Napa cabbage (outdoor), cauliflower (outdoor), radish (outdoor), and long bean (outdoor)), but also silkworm mulberry.

${ }^{\mathrm{b}}$ The dotted line is the fitted regression line with a slope of 6.34. The correlation coefficient between the two variables is 0.20 and is statistically significant at the $1 \%$ level.
\end{abstract}

\title{
2.6 Conclusions
}

China is one of the most intensive users of chemical fertilizer in the world, which has been linked to low fertilizer use efficiency and serious environmental externalities from water pollution, air pollution, and greenhouse gas emissions. In spite of many attempts, coming up with a satisfactory economic explanation for China's high and increasing use of fertilizer has been a challenge. Different from the existing literature, this study focuses on changes in the structure of crops produced in recent decades, especially a relative shift away from cereals and toward vegetables and fruits. While the marginal product of fertilizer is declining at the intensive margin (for a specific crop), this may be offset by an increasing marginal product of fertilizer at the extensive margin (due to shifts in the structure of crops produced).

This study shows in theory and through simulation analyses that it is possible for the marginal value product of fertilizer (MVP), when aggregated across crops, to exhibit a 
U-shaped pattern as fertilizer use increases. Using farm-level data from Jiangsu Province for 2004-2013, this study finds that the marginal value product (MVP) of fertilizer for agriculture output does exhibit a U-shaped pattern, with the bottom of the U occurring at around $25 \mathrm{~kg} / \mathrm{mu}$, which is slightly less than the sample mean of $28 \mathrm{~kg} / \mathrm{mu}$. These results show that horticultural crops (vegetables and fruits) are gradually becoming the main forces of fertilizer consumption in China. Given the fact that Chinese diets have been shifting away from staples towards vegetables and fruits, the growing demand for vegetables and fruits would definitely boost the expansion of horticultural crops. We hence predict that China's fertilizer consumption will not decrease at least in the short run. The results have important policy implications as most of the policies are made based on the aggregate data.

One caveat on our results is that we do not address potential inefficiencies in fertilizer use on one specific crop production. For grain/horticultural crop farms using significantly more fertilizer than agronomic recommendations, other hypotheses about what is causing high levels of use need to be put forward and tested for China. A second caveat is that we do not examine environmental externalities from fertilizer use. Additional research is needed on socially optimal levels of fertilizer use in China accounting for environmental externalities, levels which may be much different from those that maximize on-farm economic efficiency. Finally, our results are for chemical fertilizer as a whole; we do not disaggregate fertilizer by active ingredients or by the timing of fertilizer applications. 


\section{Chapter 3 Market Share and Market Power in Chinese Fluid Milk Industry ${ }^{14}$}

Fluid milk industry is dominated by a few large companies in China. Since the 2008 Chinese milk scandal, the enormous structural change and fierce competition have reshuffled the market power for each dairy company, and thereby affected social welfare distribution. This paper proposes a simple framework to link market share and the Lerner Index at the firm level, which is used to investigate the market power for Chinese fluid milk industry at the brand level as well. Using aggregated supermarket scanner data, we find that the market power was relatively moderate and has been continuously weak during 2008-2015. The average markup for top five brands was approximately 53\% over the marginal cost, resulting in an annual income transfer of nearly $\$ 2.8$ billion. With aggravation of market competition and government regulation, the market power in the fluid milk industry will be weakened in the future.

\footnotetext{
14 This chapter is jointly written with Prof. Xiaohua Yu.
} 


\subsection{Introduction}

Rapid economic growth and urbanization have been accompanied by a drastic transition of food consumption structure in China, replacing staple food with meat, fruit and dairy products (Tian and Yu 2015; Pingali 2007; Du et al. 2002; Dong 2006). The growth in household income has played an essential role in the rapid increase in dairy consumption in China, as demand for dairy products is expenditure elastic (Liu and Chern 2003; Dong and Gould 2007; Fuller et al. 2006). In addition, the Chinese government, the healthcare sector, and the dairy plants have been emphasizing the health benefits of regularly consuming dairy products (Fuller et al. 2004). The slogan of "A cup of milk makes a nation strong” has been exerting great influence on Chinese consumers. A growing number of Chinese have changed their mind and have integrated milk into their daily diet rather than regarded it as a nutrition supplement for infants, patients and the elderly (Zhou et al. 2001; Fuller et al. 2006). The rapid income growth, as well as the change in attitudes towards dairy products, has driven China's tremendous rise in dairy demand.

FAO statistics indicate that per capita milk consumption in China reached $32.7 \mathrm{~kg}$ in 2013, almost quadruple of the level in $2000(8.5 \mathrm{~kg})$. Boosted by the growing demand, Chinese dairy industry has experienced a rapid expansion in the past two decades as well. Table 3.1 presents FAO statistics on world cow's milk production since 2000. China's milk production has increased dramatically, especially from 2000 to 2005, with an average annual growth rate of $27 \%$. Since then, China steadily maintained the global share of milk production at around 6\%, and is the third largest producer in the world, after the United States and India. Nowadays, the development of dairy industry has become one of the major concerns of the Chinese government.

\footnotetext{
${ }^{15}$ Source: FAOSTAT, http://faostat3.fao.org/.
} 
Table3.1 Cow's Milk Production in China and World (Million Tons)

\begin{tabular}{lcccc}
\hline Year & China & Growth Rate (\%) & World & Global Share \\
\hline $\mathbf{2 0 0 0}$ & 8.27 & -- & 489.98 & 1.69 \\
$\mathbf{2 0 0 1}$ & 10.26 & 24.06 & 496.54 & 2.07 \\
$\mathbf{2 0 0 2}$ & 13.00 & 26.71 & 509.25 & 2.55 \\
$\mathbf{2 0 0 3}$ & 17.46 & 34.31 & 517.22 & 3.38 \\
$\mathbf{2 0 0 4}$ & 22.61 & 29.50 & 526.78 & 4.29 \\
$\mathbf{2 0 0 5}$ & 27.53 & 21.76 & 543.44 & 5.07 \\
$\mathbf{2 0 0 6}$ & 31.93 & 15.98 & 560.34 & 5.70 \\
$\mathbf{2 0 0 7}$ & 35.25 & 10.40 & 572.26 & 6.16 \\
$\mathbf{2 0 0 8}$ & 35.56 & 0.88 & 584.18 & 6.09 \\
$\mathbf{2 0 0 9}$ & 35.19 & -1.04 & 588.65 & 5.98 \\
$\mathbf{2 0 1 0}$ & 35.76 & 1.62 & 598.99 & 5.97 \\
$\mathbf{2 0 1 1}$ & 36.58 & 2.29 & 612.63 & 5.97 \\
$\mathbf{2 0 1 2}$ & 37.44 & 2.35 & 627.21 & 5.97 \\
$\mathbf{2 0 1 3}$ & 35.31 & -5.69 & 635.32 & 5.56 \\
$\mathbf{2 0 1 4}$ & 37.25 & 5.49 & 655.96 & 5.68 \\
\hline
\end{tabular}

Source: FAOSTAT, http://faostat3.fao.org/.

Theoretically, the price-cost margin is inversely related to industry price elasticity of demand (Cowling and Waterson 1976; Clarke and Davies 1982). A product with low price elasticity implies that even a little change in market power may still lead to very high welfare transfers (Lijesen 2007). In China, milk is price inelastic (Dong 2006; Bai, Wahl and McCluskey 2008), and fluid milk industry is dominated by a few large companies, most notably the Yili, Mengniu, and Bright Dairy (Wang, Mao and Gale 2008; Xiu and Klein 2010; Fuller et al. 2006; Ortega et al. 2011). That is to say, if an oligopoly firm increases its price, consumers may face a huge welfare loss. Therefore, it is very important to identify the structure of fluid milk industry and investigate the market power of oligopoly firm in China.

Table 3.2 shows a statistics the number of dairy enterprises in China. The total number of domestic dairy enterprises increased from over 1600 in 1999 to more than 2000 in $2007^{16}$, and the number of enterprises above the designated size with at least 5 million yuan revenue

\footnotetext{
16 Source: China Rural Research Report (2011), Ministry of Agriculture. Rural Economic Center. (Chinese Edition).
} 
almost doubled over that period. Overall, before 2008, Chinese fluid milk production systems were fragmented and unregulated, which sowed the seeds of serious food safety problems (Ortega et al. 2011). Subsequently, the food scandal of mixing melamine in milk in 2008 struck a deadly blow to Chinese dairy industry. On the one hand, numerous small enterprises exited the market, and the number of small-scale enterprises dropped from 669 in 2008 to 459 in 2012. On the other hand, some domestic competitive enterprises, as well as some foreign companies, accomplished a series of merger and acquisition. Additionally, facing the aggravating public pressure, Chinese government tightened up regulations on food safety, particularly targeting on dairy products (Wang et al. 2008; Xiu and Klein 2010). For instance, in October 2008, China State Council issued the Regulations on Supervision and Administration of Dairy Product Quality and Safety (Dairy Product Regulations). In response, the Ministry of Health promulgated a series of new national standards for safe dairy supply which comprised 66 different documents in 2010 (including 15 product standards, 2 production standards, and 49 inspection method standards). These regulations increased the barriers to entry into a market, crowded out non-standard companies, and helped some competent incumbents gain more market share. The enormous structural change and fierce competition will definitely reshuffle the market power for each dairy company, which may affect social welfare distribution. 
Table3.2 Number of Dairy Enterprises above Designated Size ${ }^{a}$

\begin{tabular}{lcccc}
\hline Year & Total & Large-scale & Medium-scale & Small-scale \\
\hline $\mathbf{2 0 0 0}$ & 377 & 33 & 39 & 305 \\
$\mathbf{2 0 0 1}$ & 434 & 33 & 46 & 355 \\
$\mathbf{2 0 0 2}$ & 499 & 36 & 46 & 417 \\
$\mathbf{2 0 0 3}$ & 584 & 9 & 88 & 487 \\
$\mathbf{2 0 0 4}$ & 636 & 8 & 85 & 543 \\
$\mathbf{2 0 0 5}$ & 698 & 10 & 109 & 579 \\
$\mathbf{2 0 0 6}$ & 717 & 9 & 107 & 601 \\
$\mathbf{2 0 0 7}$ & 736 & 12 & 126 & 598 \\
$\mathbf{2 0 0 8}$ & 815 & 9 & 137 & 669 \\
$\mathbf{2 0 0 9}$ & 803 & 13 & 144 & 646 \\
$\mathbf{2 0 1 0}$ & 784 & 13 & 154 & 617 \\
$\mathbf{2 0 1 1}$ & 644 & 15 & 145 & 484 \\
$\mathbf{2 0 1 2}$ & 649 & 37 & 153 & 459 \\
\hline
\end{tabular}

Source: China Dairy Yearbook (various years), China Dairy Industry Association.

${ }^{a}$ By official classification, industrial enterprises above designated size are all state-owned enterprises and non-state owned enterprises with annual revenue from principal business over 5 million yuan from 1998 to 2006, and are industrial enterprise with annual revenue from principal business over 5 million yuan from 2007 to 2010, and are industrial enterprise with annual revenue from principal business over 20 million yuan since 2011.

Historically, the Year 2008 can be regarded as a watershed moment in Chinese dairy industry. The increase of Chinese consumers' awareness about food safety, as well as the push from government and industry regulations, has gradually put the Chinese dairy industry on the right track since then (Ortega et al. 2011; Pei et al. 2011). Either from the perspective of academic research or from the policy implication, it is necessary to investigate the market power of Chinese dairy giants under the new regime. In this study, we try to answer two questions. How did the market power of each Chinese dairy giant change after 2008? What were the welfare implications of market power in Chinese dairy market?

A large number of studies have been conducted to qualify the market power. One strategy widely used in the literature is the new empirical industry organization (NEIO) analysis (Nevo 2001; Appelbaum 1982; Lopez 1984; Bhuyan and Lopez 1997; Bresnahan 
1982; Azzam and Pagoulatos 1990; Bresnahan 1989), estimating the conduct parameter in an econometric structural model; the other is the Solow residual-based (SRB) market power tests which are nonparametric (Raper, Love and Shumway 2007; Hall 1988; Ashenfelter and Sullivan 1987; Norrbin 1993; Roeger 1995), and can measure both oligopsony and oligopoly power simultaneously. A number of studies have investigated oligopoly power in the dairy industry in different countries ( e.g. the U.S., China, and some European countries), and generally find more or less oligopoly power (De Mello and Brandao 1999; Hockmann and Vöneki 2007; Hatirli et al. 2006; Chidmi, Lopez and Cotterill 2005). For instance, Gohin and Guyomard (2000) find that the unit margin for dairy products was $25.03 \%$ higher than that in a competitive market in the French food retail industry during 1977-1993. Chidmi et al. (2005) estimate that the average markup for Boston retail milk was around 25\% from 1996 to 2000.

A few studies also shed light on the market power in Chinese food industries, e.g., wine industry (Zheng and Wang 2017), and dairy industry (Dai and Wang 2014; Guo et al. 2016). Using 1987-2007 industrial level data, Dai and Wang (2014) find that the enterprises usually set their milk price four times higher than the marginal cost, reflecting a very strong oligopoly power in Chinese dairy industry; whereas Guo et al. (2016), using 2005-2008 firm-level panel data, find that Chinese dairy industry as a whole was competitive, while the large firms had considerable market power, with a markup of 1.48 on average, different from small firms. Although the reform and development of China's dairy sector have attracted wide international attention since the melamine scandal in 2008 (Yu 2012; Pei et al. 2011; Xiu and Klein 2010; Jia et al. 2012; Zhou and Wang 2011), there is no research available focusing on the change of market power in Chinese dairy industry after the crisis. Notably, Chinese authorities have been tightening official controls over food safety and try to make domestic production system geared to international standards (Pei et al. 2011). Therefore, using the latest data to estimate the market power of Chinese dairy industry would fill the gap in the current literature and lay the foundation for future research.

In China, the brand name is believed to be an extremely important indicator of milk quality (Wang et al. 2008; Zhang et al. 2010). After the 2008 Chinese milk scandal, consumers usually prefer to buy national brand products, such as Yili and Mengniu. Therefore, this study attempts to measure the market power of major milk brands after the 
2008 Chinese milk scandal. We first develop a simple framework under Bertrand's price competition assumption to figure out the market power. By linking the industry level data (market share) to firm level data, this model bypasses the problem that marginal costs are difficult to obtain. Most importantly, our model provides an approach to estimate the market power with limited data information. Finally, using supermarket scanner data, we empirically evaluate the degree of market power for each Chinese dairy giant and its economic implications.

This paper is organized as follows. We first give a brief background on Chinese fluid milk industry in Section 2. Then, Section 3 introduces a theoretical model and presents how to measure the market power. Section 4 describes the data, and highlights the advantages of using scanner data. Section 5 offers a detailed description on model identification. The empirical results are presented in Section 6. Finally, we conclude the main findings.

\subsection{Chinese Fluid Milk Industry}

Historically, geographic location plays a critical role in China's dairy industry. The major milk source bases are concentrated in northern and western China due to favorable natural conditions and fairly abundant labor resources (Gale and $\mathrm{Hu} 2009$ ). To promote local dairy industrial development, local governments enacted a series of preferential policies and provided large financial support for dairy processing enterprises. Therefore, many small- and medium-scale processing enterprises developed very fast in these regions, where the successful processing enterprises include Yili and Mengniu in the Inner Mongolia Autonomous Region, the Wandashan Dairy in Heilongjiang province and Sanlu Dairy Group in Hebei province (Hu 2009).

Because southern enterprises, such as the Bright Dairy, are far from the major milk source bases, they generally buy raw milk from suburban dairy farms or nearby regions. Consequently, compared with the northern dairy processing enterprises, southern enterprises usually cannot buy high-quality raw milk at a low price. However, the introduction of ultra-high temperature (UHT) processing technology, as well as the application of reconstituted milk powder provides an opportunity for southern enterprises to produce low-cost milk products (Gale and $\mathrm{Hu} 2009$; $\mathrm{Hu} 2009$ ). Most importantly, the realization of 
long-distance milk trade has made every dairy enterprise could compete in the national market.

Nowadays, the dairy processing industry in China is dominated by a few firms in the national market and over 700 small- and medium-scale companies cater to regional markets (Wang et al. 2008; Xiu and Klein 2010; Fuller et al. 2006). Notably, although these small companies have very small or even negligible national market share, some of them still have very strong market power in their home city or province. Overall, the top five dairy brands in the domestic market are Yili, Mengniu, Bright Dairy, Sanyuan, and Want Want, respectively. Particularly, Yili and Mengniu are the two largest dairy enterprises in China, and their total market share is more than $50 \%$. Bright Dairy, the early leader in China's dairy industry, is a well-established dairy company in Shanghai, dominating the east China market, especially Shanghai. Sanyuan is a renowned local brand in Beijing. Want Want is a Taiwanese brand, focusing on dairy beverages.

To seize the market, more and more dairy enterprises issued stock to scale up production (Gale and Hu 2009). In 1996, Yili listed on Shanghai Stock Exchange, becoming the first A-share listed dairy company in China. Subsequently, Bright Dairy listed on Shanghai Stock Exchange in 2000 and Mengniu listed on Hong Kong Stock Exchange in 2004. Additionally, after the 2008 Chinese milk scandal, many enterprises started to upgrade and construct their own milk resource bases (Mo et al. 2012; Qian et al. 2011), and cooperated aggressively with international dairy companies (e.g., constructing integrated dairy base in New Zealand and Europe, creating global resource-R \& D-marketing systems). In marketing, except for price competition, promotion and high-decibel advertising are the common competitive strategies used in China's dairy industry (Hu 2009). For instance, in 2016, Yili spent up to $\$ 1.2$ billion on advertising, accounting for 13 per cent of its sales revenue (Yili 2016 Annual Report); Mengniu spent around $\$ 0.8$ billion, accounting for 10 per cent of its revenue (Mengniu 2016 Annual Report); Bright Dairy spent around \$ 0.2 billion, accounting for 5 per cent of its revenue (Bright Dairy 2016 Annual Report). Competition by advertising seems to be the most prominent feature of this industry. 


\subsection{The Empirical Framework}

\subsubsection{Overview}

Market power and market structure, are crucial concepts in industrial organization (IO). The former refers to the ability of a firm to achieve superior profitability, usually measured by the Lerner Index ${ }^{17}$, while the latter is a synthetic description, including the number of firms in the market and their respective market shares, usually measured by the market concentration, such as Concentration Ratio and the Herfindahl-Hirschman Index (Aguirregabiria 2012). Obviously, market power is an indicator based on firm level, while market share is often based on the industry level. The purpose of our study is to identify the market power for Chinese dairy companies by linking the Lerner Index to their market share. However, in typical firm-level datasets, marginal costs are usually unavailable or difficult to measure. We hence propose a simple model that links market share and market power to find an alternative way to estimate the Lerner Index.

In this section, we present a structural model of consumer and producer behavior. On the demand side, we employ a random utility model of consumer choice among different products (Nevo 2001; Allender and Richards 2010; Aguirregabiria 2012). On the supply side, we assume Nash-Bertrand competition among producers (Yonezawa and Richards 2016; Nevo 2001; Allender and Richards 2010; Draganska and Klapper 2007). There is no doubt that retailer may also have considerable market power (Chidmi et al. 2005; Hovhannisyan and Gould 2012; Allender and Richards 2010). However, due to lack of data on wholesale price at the brand level, we regard the retailer and dairy processing enterprises as a whole to analyze. That is to say, the markup we estimated is an upper bound estimate. Subsequently, we derivate the market power by linking market share and market power. Finally, we perform a comparative static analysis.

\footnotetext{
${ }^{17}$ The Lerner Index is defined as price-cost margin divided by price, i.e., Lerner Index $=(P-M C) / P$.
} 


\subsubsection{Demand-Side Model}

Formally, we assume that consumers choose among $I$ different products. In general, the indirect utility from purchasing product $i \in I$ at time $t$ can be represented by:

$u_{i t}=v_{i}-\alpha p_{i t}+\varepsilon_{i t}$

where, $v_{i}$ is the unobserved utility, allowing for heterogeneity (including quality and taste et al.) among firms. $\alpha$ is a positive parameter, representing the marginal utility of income. $\varepsilon_{i t}$ is a consumer-specific i.i.d. random variable with extreme value type 1 distribution.

Very often we express the market share of product $i$ in logit form (Nevo 2001),

$s_{i t}=\frac{d_{i t} \exp \left\{v_{i}-\alpha p_{i t}\right\}}{1+\sum_{j=1}^{N} d_{j t} \exp \left\{v_{j}-\alpha p_{j t}\right\}}$

where, $d_{i t}$ is a binary indicator of the event "firm $i$ is active at the end of period $t$ ".

\subsubsection{Supply-Side Model}

It is in full agreement that dairy industry is characterized by high concentration, high price-cost margins (Dai and Wang 2014), large advertising-to-sales ratio, and highly homogeneous products ${ }^{18}$. These facts imply that price competition might be an appropriate choice for every firm. Therefore, we employ an econometric model, assuming incumbent firms compete a la Bertrand, to estimate the Lerner Index.

We suppose there are $N$ firms, each of which produces homogeneous products with the same marginal $\operatorname{cost}^{19}, c$, due to technological expansion in the industry. The profit function for firm $i$ at time $t$ is:

$\pi_{i t}=V P_{i t}-F C_{i t}=\left(p_{i t}-c\right) q_{i t}-F C_{i t}$

where $V P_{i t}$ and $F C_{i t}$ respectively denote the variable profit and the fixed cost; $p_{i t}$ and $q_{i t}$ are the price and quantity sold by firm $i$ at time $t$, respectively.

\footnotetext{
${ }^{18}$ Once one company introduces a new product, its rivals can quickly imitate.

${ }^{19}$ If we relax the assumption, and assume marginal costs are heterogeneous, the market equilibrium remains unchanged.
} 
Hence, given the total number of consumers in the market (market size) $H_{t}$, we can get the sale volume for firm $i$ :

$q_{i t}=H_{t} s_{i t}=H_{t} \frac{d_{i t} \exp \left\{v_{i}-\alpha p_{i t}\right\}}{1+\sum_{j=1}^{N} d_{j t} \exp \left\{v_{j}-\alpha p_{j t}\right\}}$

In the Nash-Bertrand equilibrium, the price condition is determined in the standard manner by:

$\frac{d \pi_{i t}}{d p_{i t}}=q_{i t}+\left(p_{i t}-c\right) \frac{d q_{i t}}{d p_{i t}}=q_{i t}+\left(p_{i t}-c\right) \cdot \alpha H_{t} s_{i t}\left(s_{i t}-1\right)=0$

Thus, the unique value of $p_{i t}$ that maximizes the profit function of Equation (3-3) is:

$$
p_{i t}=c+\frac{1}{\alpha\left(1-s_{i t}\right)}
$$

\subsubsection{Measuring Market Power}

Obviously, Equation (3-5) provides us a straightforward way to measure the Lerner Index:

$$
\theta_{i t}=\frac{p_{i t}-c}{p_{i t}}=\frac{1}{\alpha\left(1-s_{i t}\right) p_{i t}}
$$

The above equation links market share and market power and constructs an alternative way to estimate the Lerner Index, bypassing the obstacle of missing variables (i.e., marginal costs). That is to say, once we obtain the parameter $\alpha$, we can easily estimate the Lerner Index for each firm. The parameter $\theta_{i t}$ ranges from 0 to 1 , with higher values implying greater market power. Specifically, for one firm, $\theta=0$, meaning that it has no market power. In the other extreme, $\theta=1$, indicating that this firm is a monopoly. 


\subsubsection{Comparative Static Analysis}

As market power only depends on the price ${ }^{20}$, it is possible to show that,

$$
\frac{\partial \theta_{i}}{\partial p_{i}}=-\frac{1+\alpha p_{i} s_{i}}{\alpha\left(1-s_{i}\right) p_{i}^{2}}<0
$$

And for $i \neq j$ :

$$
\frac{\partial \theta_{i}}{\partial p_{j}}=\frac{s_{i} s_{j}}{p_{i}\left(1-s_{i}\right)^{2}}>0
$$

Therefore, it is intuitive that market power of one firm will increase as rival's price increases or as own price decreases.

In addition, $\frac{\partial \theta_{i t}}{\partial s_{i t}}=\frac{1}{\alpha p_{i t}\left(1-s_{i t}\right)^{2}}>0$. That is, the market power increases in market share.

\subsection{Data}

The supermarket scanner data used in this study were obtained from Beijing Muding Commercial Information Center, which is an affiliated unit of China General Chamber of Commerce. It is a research and consulting institution specializing in data mining and statistical analysis based on sales information of all chain supermarkets. It monitors all sales information across more than 100 categories of fast-moving consumer goods (FMCG) from nearly 300 supermarket chains (across over 160 cities in 30 provinces in China) and aggregates the raw scanner data into brand levels. For the dairy market, it provides information including variety, brand, sales volume, total sales revenue and unit retail price ${ }^{21}$ from 2008 to 2015 .

Scanner data, a more valuable type of data, attracts a large number of researchers in the field of Industrial Organization, as it provides detail information in the firm, brand, and commodity level (Cotterill 1994; Jensen 2002). For instance, using scanner data, Unnevehr

\footnotetext{
${ }^{20}$ It is necessary to highlight that market share is also a function of price.

${ }^{21}$ The unit retail price is derived by dividing total sales by volume. We note that the unit price may include some information of quality (Yu and Abler 2009). However, the quality could be captured by the brand dummy in estimation.
} 
and Gouzou (1998), Bonnet and Simioni (2001), Lin et al. (2008), Smith et al. (2009), and Roheim et al. (2011) calculate the price premiums for a labeled product; Putsis (1997), Hildebrandt and Klapper (2001), and Sudhir (2001) investigate strategic pricing; Steenkamp and Gielens (2003) study the introduction of a new product; Capps et al. (1997) discuss the advertising effects on branded products. However, to the best of our knowledge, no food industry studies have been conducted using scanner data in China, in part because scanner data is costly to obtain. In China, most of the consumers purchase dairy products from supermarkets (Hu, Fuller and Reardon 2004; Fuller and Beghin 2015; Fuller and Hu 2005), implying that the scanner data from supermarkets can accurately describe the market structure of Chinese dairy industry. To some extent, our study fills the gap in the current literature and completes the industrial analysis for Chinese dairy industry at the brand level.

In general, dairy products include fluid milk, yogurt, butter, cream, and cheese. In this study, we only focus on fluid milk, as it is the largest segment for dairy products. The data provided is at a highly aggregated level. We acknowledge some quality difference across brands, and the package size also has a notable influence on market power (Yonezawa and Richards 2016), which however could be captured by the fixed effects in the Equation (3-2).

Market share can be calculated from two dimensions, value and volume. Figure 3.1 displays the value market share of fluid milk in 2008 and 2015, respectively. Obviously, Chinese fluid milk industry is characterized by tight oligopoly, as the Four-Firm Concentration Ratio (CR4) was around $80 \%$. Although, as we expected, the increasing aggravation of market competition and government intervention weakened the power of oligopolies, Yili and Mengniu still accounted for over half of the fluid milk retail market in China in 2015. Notably, Yili, Sanyuan, and other brands gradually took almost $20 \%$ market share from Mengniu over the past seven years. We attribute the success of market share increase of Yili to the high-decibel advertising ${ }^{22}$. As for the other players, we believe that most of the local well-established brands usually have milk source base in their respective regions. Frequent food scandal made consumers care more about milk quality and freshness, so that people might prefer to purchase local brand products (Gale and $\mathrm{Hu} 2009$ ). Moreover,

\footnotetext{
${ }^{22}$ For instance, Yili sponsored a reality television show “Dad! Where are we going?" with its flavored milk, QQ Star, and gained $14 \%$ value growth.
} 
after the milk formula safety crisis in 2008 , some foreign brands took a big leap into Chinese dairy market, which dilutes the market share of domestic firms.

A) In 2008

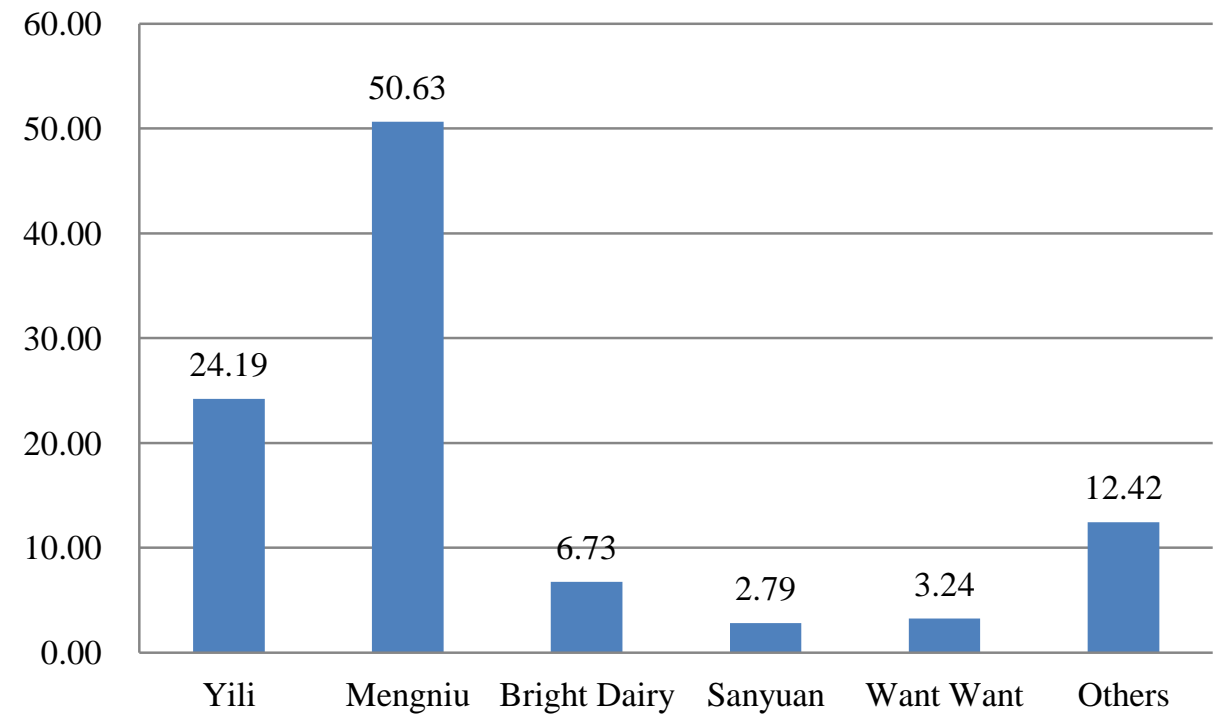

B) In 2015

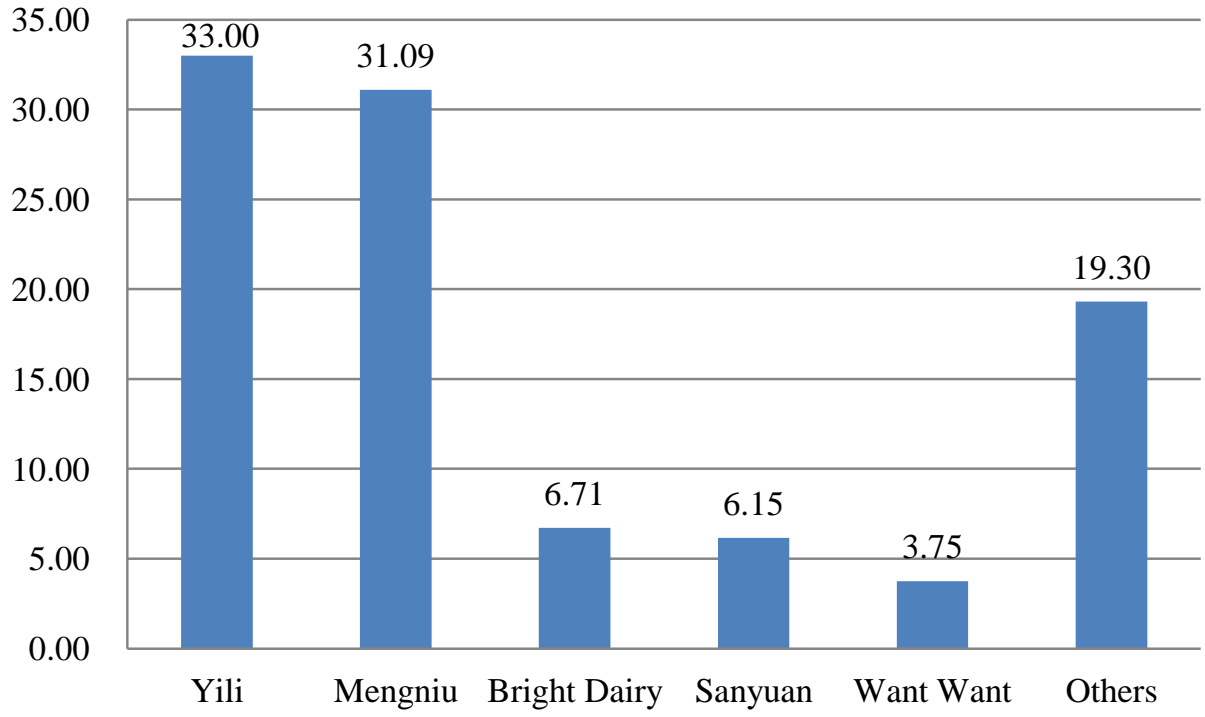

Source: Beijing Muding Commercial Information Center

Figure3.1 Retail Market Share of Fluid Milk in China, based on value 
Figure 3.2 presents the volume market share for major fluid milk brands, which is highly consistent with Figure 3.1. Combined with the Figure 3.1, it indicates that the excessive price set by Bright Dairy offset the loss of losing customers. In addition, the value market share for Mengniu decreased almost 20\%, while its volume market share only decreased $17 \%$, implying that low pricing strategy did not help Mengniu recapture the market share.

A) In 2008

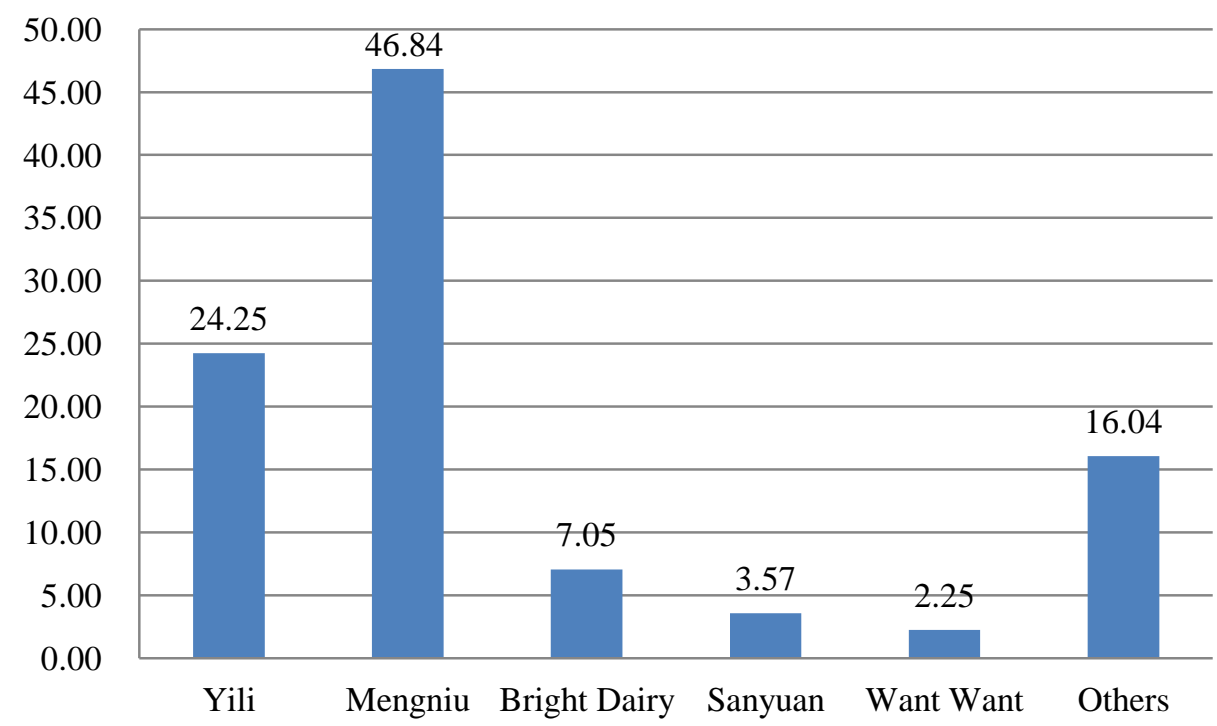

B) In 2015

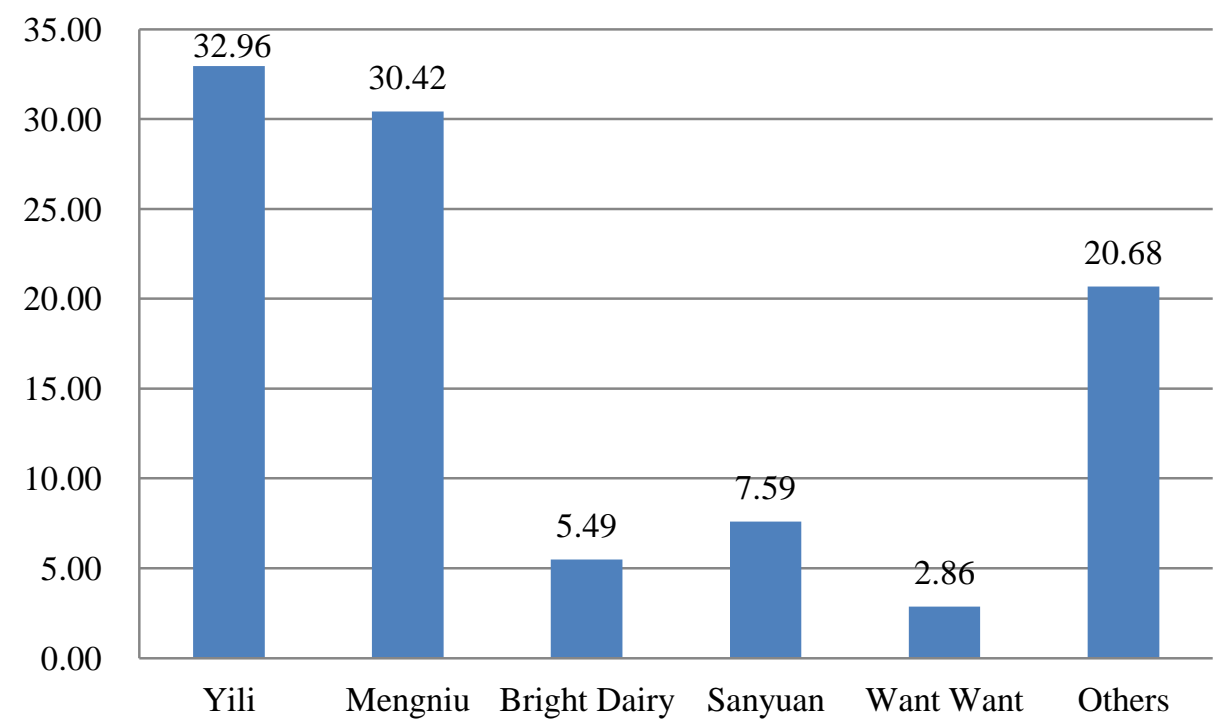

Source: Beijing Muding Commercial Information Center

Figure3.2 Retail Market Share of Fluid Milk in China, based on volume 
Figure 3.3 shows the changes in the unit retail price of fluid milk for the major brands. In general, there was a continuously significant increase in the fluid milk price during 2008-2014, but it decreased slightly in 2015. The average price over all brands was 1.46 yuan/100ml in 2015, more than double of the price in the U.S. (3.42 \$/gal for whole milk ${ }^{23}$ ). Due to similar packing design, homogeneous product, and same target customers, there is no much difference in price among these dairy brands. In 2015, the highest price was 1.46 yuan/100ml (Want Want), while the lowest price was 1.08 yuan/100ml (Sanyuan). Specifically, Want Want always sets a higher price (about 33\% higher than industry average). On the contrary, Sanyuan kept its price lower than the industry average (about 22\%). Meanwhile, we note that both Mengniu and Yili used a low price strategy (about 10\% lower than industry average) after 2011, and Yili always set its price around 4\% lower than Mengniu's. Additionally, Bright Dairy raised its price 9\% higher than the industry average after 2012, next to Want Want's.

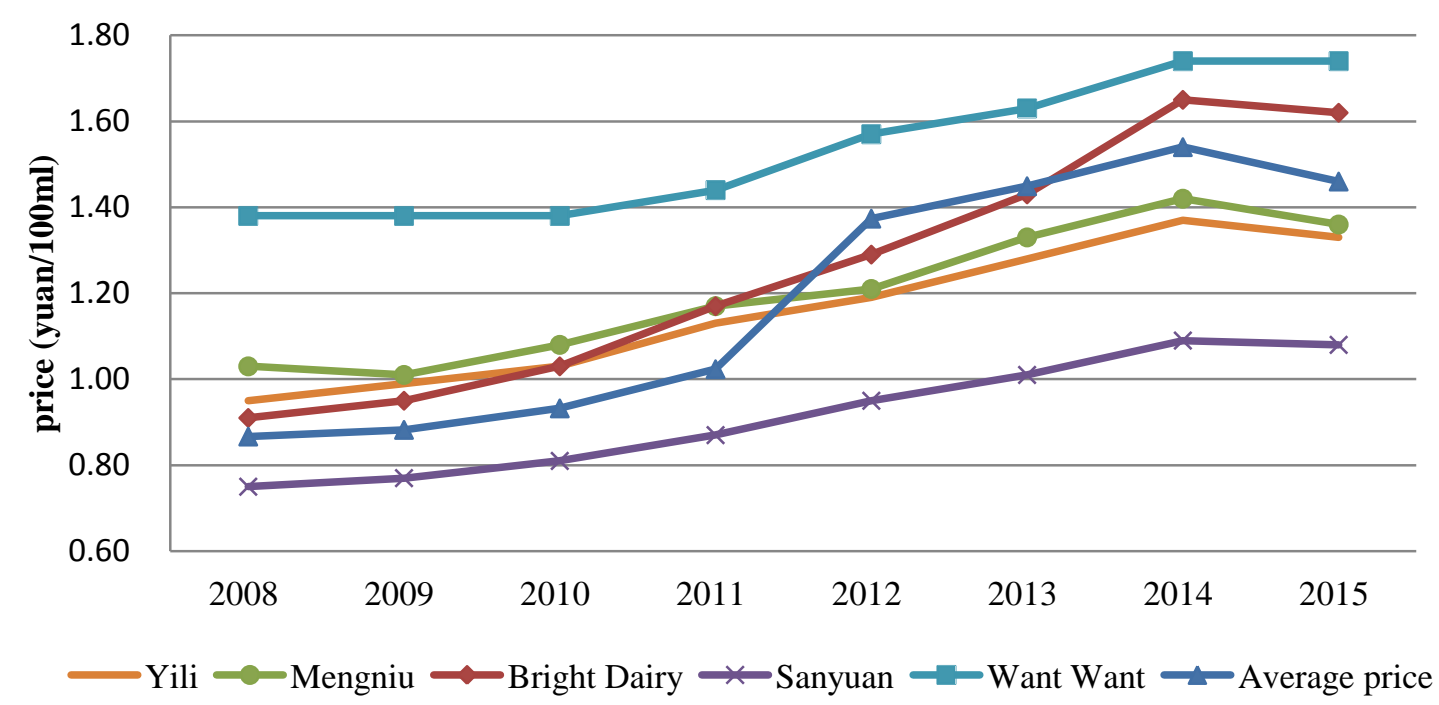

Source: Beijing Muding Commercial Information Center

Figure3.3 The Unit Retail Price of Fluid Milk for the Major Brands (2008-2015)

\subsection{Model Identification}

Our main empirical challenge is to estimate the parameter $\alpha$. Obviously, a feasible approach is to evaluate the market share equation. However, as we have seen, Equation (3-2)

\footnotetext{
${ }^{23}$ Source: United States Department of Agriculture. https://www.ers.usda.gov/.
} 
is nonlinear, implying that there is no closed form solution. In this section, however we propose a linear way to estimate Equation (3-2).

\subsubsection{Empirical Model}

First, we look at the denominator in the right hand of Equation (3-2), $1+\sum_{j=1}^{N} d_{j t} \exp \left\{v_{j}-\alpha p_{j t}\right\}$, which summarizes the utilities of all products in the market. Obviously, it is a constant term at period $t$. Therefore, a straightforward option to linearize the objective function is to rewrite the denominator as a function of time $f(t)$. That is, Equation (3-2) can be rewritten as,

$$
s_{i t}=\frac{d_{i t} \exp \left\{v_{i}-\alpha p_{i t}\right\}}{f(t)}
$$

Taking the logarithm of both sides, we get

$$
\ln s_{i t}=v_{i}-\alpha p_{i t}-\ln (f(t))+\ln d_{i t}
$$

which can be rewritten as an estimable function:

$$
\ln s_{i t}=v_{i}-\alpha p_{i t}+\delta^{\prime} T_{i t}+e_{i t}
$$

where $i$ and $j$ denote brand and year respectively; $s_{i t}$ is the market share; $v_{i}$ is the consumer's utility at the brand level; $p_{i t}$ is price; $T_{i t}$ is a vector of year dummy variables, capturing the information of market size and other time-varying factors; and $e_{i t}$ is the error term.

\subsubsection{Estimation Method}

Specifically, retail price $p_{i t}$ could be an endogenous variable because it may be correlated with the firm's entry/exit decision $d_{i t}$ in the error term. This implies that OLS might be inconsistent. Aguirregabiria (2012) briefly summarizes six different approaches to deal with endogeneity problem. That is, randomized experiment; economic assumptions that imply exogeneity; exclusion restrictions (IV); "natural experiments" as exclusion restrictions; covariance structure in the unobservables, such as Arellano-Bond and Hausman-Nevo 
instruments; and zero covariance between unobservables (Aguirregabiria 2012). In this study, we use the classical instrumental variables method to identify the conduct parameters.

Generally, in the context of our model, the instrumental variables should be highly correlated with retail prices, but not be correlated with the demand shock. Following previous literature (Richards, Acharya and Molina 2011; Richards, Gómez and Lee 2014; Allender and Richards 2010), we use a variety of instruments. First, we include a set of input prices at each brand hierarchy level as the instrumental variables. Apparently, this kind of instrument does not have a direct impact on demand but have an indirect impact through price. There is wide agreement that raw milk costs are the largest single input cost in fluid milk production (Australian Government Productivity Commission 2014). In China, it accounts for $40-50 \%$ of the total input costs. Although each dairy processing enterprise operates many plants nationwide, both the main procurement of raw milk and most of the production activities are done in headquarter. Therefore, it is reasonable to use the raw milk price sold on the regional wholesale market, where each corporate headquarter located, as one of the instruments. Additionally, labor costs account for nearly 5\% of the processing costs in China's fluid milk industry. Hence, the average wage in the manufacturing industry is a valid instrument as well. Second, we include a time-variant dummy variable, indicating whether this company goes public or not. Implicitly, a public company can raise capital by issuing securities and expand production, which would eventually affect cost but not demand. Third, we include year dummy variables, the strictly exogenous explanatory variables in the model to pick up some unobserved time-varying factors.

Want Want is a special case that we need to discuss individually. Want Want, as alluded to above, is a Taiwan-funded enterprise, focusing on dairy beverages. The direct material of their dairy beverages is reconstituted milk ${ }^{24}$, not raw milk. In China, dairy processing enterprises usually mix one ton milk powder with eight tons water to make nine tons reconstituted milk. As for Want Want, it relies heavily on imported milk powder. We hence combine the conversion ratio with the international trade price of whole milk powder from Global Dairy Trade (GDT) to estimate the price of reconstituted milk for Want Want. In addition, Want Want invested its first production plant in Changsha, Hunan in 1992, which is

\footnotetext{
${ }^{24}$ Reconstituted milk is a kind of liquid milk obtained by adding water to milk powder.
} 
its largest production base in mainland China. Therefore, we use the average wage in the manufacturing industry in Hunan province as another instrument for Want Want.

\subsection{Results and Discussion}

In this section, we first present the results from demand-system, and then test for endogeneity of retail prices in our brand-level scanner data using a Hausman (1978) specification test. Finally, we estimate the market power for each brand and calculate the income transfers stemming from their market power.

Using standard IV methods, we first estimate the model in Equation (3-9) and perform a series of endogeneity test to check the validity of our instruments. Notably, as value market share includes pricing information, we use the volume market share in empirical analysis. All the results are presented in Table 3.3. Look at the bottom of the table, as we expected, we fail to reject the overidentification test for all instruments, which means that our instruments are strictly exogenous. Moreover, a high value of the Cragg-Donald Wald F statistic in the weak identification test indicates that our excluded instruments are highly correlated with the endogenous regressor $p_{i t}$. The underidentification test is also rejected, implying that our instruments are relevant. In conclusion, our instruments are strong and valid (strictly exogenous) predictors of the retail price $p_{i t}$.

Table3.3 Estimation Results

\begin{tabular}{|c|c|c|c|c|}
\hline \multirow[b]{2}{*}{ Variable } & \multicolumn{2}{|c|}{ OLS } & \multicolumn{2}{|c|}{ IV } \\
\hline & $\begin{array}{c}\text { Estimated } \\
\text { Coefficient }\end{array}$ & Standard Error & $\begin{array}{c}\text { Estimated } \\
\text { Coefficient }\end{array}$ & Standard Error \\
\hline Price & $-3.0939^{* * * *}$ & 0.4408 & $-2.4340^{* * * *}$ & 0.6660 \\
\hline Year2008 & $-1.5829^{* * *}$ & 0.2376 & $-1.3425^{* * *}$ & 0.3013 \\
\hline Year2009 & $-1.3460^{* * *}$ & 0.2321 & $-1.1179^{* * *}$ & 0.2914 \\
\hline Year2010 & $-1.2618^{* * *}$ & 0.2183 & $-1.0667^{* * *}$ & 0.2659 \\
\hline Year2011 & $-0.9834^{* * * *}$ & 0.1969 & $-0.8486^{\text {*** }}$ & 0.2246 \\
\hline Year2012 & $-0.9856^{* * *}$ & 0.1665 & $-0.9341^{* * *}$ & 0.1741 \\
\hline Year2013 & -0.2640 & 0.1629 & -0.2601 & 0.1663 \\
\hline Year2014 & 0.1612 & 0.1669 & 0.1065 & 0.1752 \\
\hline \multicolumn{5}{|c|}{ Endogeneity test } \\
\hline \multicolumn{3}{|c|}{ Weak identification (Cragg-Donald) } & \multicolumn{2}{|c|}{14.54} \\
\hline \multicolumn{3}{|c|}{ Underidentification test (Anderson) } & \multicolumn{2}{|c|}{$28.29(\mathrm{P}-\mathrm{val}=0.0000)$} \\
\hline \multicolumn{3}{|c|}{ Overidentification (Sargan) } & \multicolumn{2}{|c|}{$0.57(\mathrm{P}-\mathrm{val}=0.7504)$} \\
\hline \multicolumn{3}{|c|}{ Hausman test } & \multicolumn{2}{|c|}{$1.75($ Prob $>$ chi $2=0.9878)$} \\
\hline
\end{tabular}


As a comparison, we also report the OLS estimation results in Table 3.3. Apparently, most of the variables are statistically significant, and the estimated coefficients of two models are consistent with each other. Therefore, we perform the Hausman specification test to determine whether there exists an endogeneity problem or not. Results, however, show that there is no statistically significant difference between OLS and IV. As the OLS estimator is consistent and efficient, we hence use it to estimate the market power for each brand.

The key estimator in this study is the coefficient of price. In the OLS estimators, the estimator of parameter $\alpha$ is 3.09 at the $1 \%$ significance level. We then use this value to calculate the Lerner Index for each brand. Table 3.4 presents the estimation of market power for top five brands. In general, the market power was relatively moderate for fluid milk industry in China during 2008-2015. The value of the Lerner index suggests that the top five brands do take advantage of their oligopoly power to mark up retail prices (approximately 53\% over the marginal cost on average). We find that, in 2008, the average market power of top five brands was 0.43 , implying that the average markup estimate was around 1.75 , which is consistent with prior research (Guo et al. 2016). Additionally, we note that the Lerner Index for every player has been slowly coming down over the past seven years. This means that market conduct tends to be more competitive after 2008. It is reasonable and conforms our priori expectations.

Table3.4 Estimation of Market Power for Major Brands

\begin{tabular}{lllllllll}
\hline Brand & $\mathbf{2 0 0 8}$ & $\mathbf{2 0 0 9}$ & $\mathbf{2 0 1 0}$ & $\mathbf{2 0 1 1}$ & $\mathbf{2 0 1 2}$ & $\mathbf{2 0 1 3}$ & $\mathbf{2 0 1 4}$ & $\mathbf{2 0 1 5}$ \\
\hline Mengniu & 0.59 & 0.55 & 0.52 & 0.48 & 0.42 & 0.37 & 0.34 & 0.34 \\
Yili & 0.45 & 0.43 & 0.43 & 0.39 & 0.38 & 0.36 & 0.34 & 0.36 \\
Bright Dairy & 0.38 & 0.37 & 0.34 & 0.29 & 0.27 & 0.24 & 0.21 & 0.21 \\
Sanyuan & 0.47 & 0.44 & 0.42 & 0.39 & 0.36 & 0.35 & 0.32 & 0.32 \\
Want Want & 0.24 & 0.24 & 0.24 & 0.23 & 0.21 & 0.21 & 0.19 & 0.19 \\
\hline
\end{tabular}

Mengniu was the undisputed champion in Chinese dairy industry in 2008. However, with the loss of market share, its market power dropped dramatically from 0.59 in 2008 to 0.34 in 2015. Its forceful rival, Yili, harvested substantial market share through high-decibel advertising and new product development, but its market power index decreases from 0.45 in 2008 to 0.36 in 2015 mainly due to price competition. In addition, the market powers of 
Bright Dairy, Sanyuan, and Want Want also have decreased substantially. As a market-oriented manufacturer, Bright Dairy only has a monopoly in East China market, especially in Shanghai. It is well known that Shanghai is the richest and most international city in China, and consumers can conveniently purchase various imported dairy products from the market. After the milk formula safety scandal in 2008, foreign brands have easily taken some market share in China. Meanwhile, price hike by Bright Dairy also leads to the decrease in market power to some degree.

The empirical results further show that low pricing strategy can really help the firm to gain more market power, as we discussed before. Sanyuan is a typical example: although it has a domestic market share of less than 8 per cent, its market power can almost catch up with Mengniu and Yili, due to its long-term low price strategy. Meanwhile, the pricing behavior of both Mengniu and Yili also illustrates the importance of lower price in maintaining high market power.

To quantify the welfare implications, we calculate the income transfers from consumers to each dairy enterprise and present the results in Table 3.5. Theoretical, for each dairy giant, the income transfers are equal to the product of their estimated markup and the sales volume. We find that the estimated annual income transfer to top five dairy enterprises was nearly 19 billion yuan (approximately $\$ 2.8$ billion), where Mengniu and Yili contributed up to $86 \%$ of the total welfare implications. It is interesting to note that there was a dramatic change in the welfare distribution between Mengniu and Yili within these eight years. Specifically, the income transfer to Mengniu decreased from 13.25 billion yuan in 2008 to 7.17 billion yuan in 2015, while the income transfer to Yili increased from 4.82 billion yuan in 2008 to 8.08 billion yuan in 2015. Although the intensified market competition weakened the market power for each dairy enterprise, Yili applied a variety of appropriate competitive strategies (e.g., advertising, new product development, and low pricing) and successfully increased its sales volume by $49 \%$, which eventually led to more consumer surplus transferred to Yili. On the contrary, during this period, Mengniu saw a $29 \%$ decrease in its sales volume, which is no surprise that Mengniu cannot retain its throne. 
Table3.5 Welfare Implication of Market Power for Major Brands (Billion yuan)

\begin{tabular}{lllllllll}
\hline Brand & $\mathbf{2 0 0 8}$ & $\mathbf{2 0 0 9}$ & $\mathbf{2 0 1 0}$ & $\mathbf{2 0 1 1}$ & $\mathbf{2 0 1 2}$ & $\mathbf{2 0 1 3}$ & $\mathbf{2 0 1 4}$ & $\mathbf{2 0 1 5}$ \\
\hline Mengniu & 13.25 & 10.21 & 10.87 & 12.04 & 10.20 & 9.37 & 7.94 & 7.17 \\
Yili & 4.82 & 4.66 & 5.40 & 5.97 & 6.82 & 7.29 & 7.65 & 8.08 \\
Bright Dairy & 1.14 & 1.05 & 1.07 & 1.12 & 1.50 & 1.19 & 1.23 & 0.96 \\
Sanyuan & 0.55 & 0.70 & 0.73 & 0.95 & 1.22 & 1.37 & 1.41 & 1.35 \\
Want Want & 0.34 & 0.41 & 0.47 & 0.60 & 0.63 & 0.69 & 0.57 & 0.48 \\
\hline
\end{tabular}

\subsection{Conclusion}

This paper proposes a simple framework to link the concentration ratio and the Lerner Index and investigates the market power and welfare implications for Chinese fluid milk industry at the brand level after the 2008 Chinese milk formula scandal. Using aggregated supermarket scanner data, we find that the market power was relatively moderate for fluid milk industry in China during 2008-2015. The average markup for top five brands (Mengniu, Yili, Bright Dairy, Sanyuan, and Want Want) on Chinese fluid milk was approximately 53\% over the marginal cost, resulting in an annual income transfer of nearly $\$ 2.8$ billion. However, with the increasing aggravation of market competition and government regulation, the power of oligopolies will be weakened in the future. Moreover, the Comparative Static Analysis indicates that low pricing strategy can help firms to gain more market power, which can benefit consumers as well.

In this study, we do not differentiate the segment in the fluid milk market. For simplicity, we assume all the products are homogenous and regard fluid milk as a whole to analyze. Future research could be extended to one specific product. Secondly, due to lack of data on wholesale price at the brand level, we regard the retailer and dairy processing enterprises as a whole to analyze. That is to say, the markup we estimated is an upper bound estimate. In addition, we suppose that incumbent firms compete a la Bertrand. In practice, it is possible that firms may engage in Stackelberg competition, as retail prices of dairy products are usually set by large firms (Guo et al. 2016). Additional research is needed on exploring the degree of market power for Chinese dairy industry under different "nature" of competition. Finally, we do not address the heterogeneity in the marginal utility of income for consumers, i.e., the parameter $\alpha$. Further studies can adopt the random coefficients model to tackle this issue. 


\section{Chapter 4 Air Pollution, Food Production and Food Security: A Review from the Perspective of Food System ${ }^{25}$}

Air pollution negatively impacts food security. This paper reviews the current literature on the relationship between air pollution and food security from the perspective of food system. It highlights that agricultural emissions which substantially contribute to air pollution could happen at every stage along the food supply chain. Meanwhile, air pollution can not only affect plant growth and animal health but also shift market equilibrium of both agro-inputs and outputs in the food supply chain and thereby affect food security indirectly. Furthermore, this study evaluates the effects of agricultural policy and energy policy on food security and air pollution, respectively, and provides an overview of potential policy instruments to reduce air pollution while ensuring food security. Finally, we identify the remaining research and policy issues for further studies, mainly focusing on the study of household's bounded rational behaviors and the issue of rural aging population.

\footnotetext{
${ }^{25}$ This chapter is jointly written with Dr. Yun Dai and Prof. Xiaohua Yu and has been published in Journal of Integrative Agriculture, 2017, Vol. 16(12): 2945-2962.
} 


\subsection{Introduction}

Since the beginning of $20^{\text {th }}$ century, the intensification of agricultural land use and a dramatic rise in yields have gradually taken the place of extensification and become the new engines of agricultural growth (Foley et al. 2005; Matson et al. 1997). FAO statistics ${ }^{26}$ indicate that during 1961-2014, world population increased by $136 \%$, while the production of grain and meat went up by 188 and $345 \%$, respectively. Apparently, the growth rate of agricultural outputs far overtakes population growth worldwide, and hence human well-being has been significantly enhanced. In the same period, yields of wheat, rice, and maize have rapidly increased by 204, 144, and 189\%, respectively. From 1965 to 2004, agricultural intensification avoided an estimate of 18-27 million hectares from being converted to farmland (Stevenson et al. 2013).

Different from traditional agriculture, intensive farming relies heavily on industrial agro-inputs, such as synthetic fertilizers, pesticides, and machinery (Woodhouse 2010; Kimbrell 2002; Pingali 1997). FAO statistics show that in 2012, world synthetic nitrogen fertilizer consumption reached 100 million tons, and total agricultural energy consumption peaked at 8728 petajoules. Although industrial agriculture has successfully fed the world and achieved sustained food surpluses, over-dependence on fossil fuels and intensification have also caused extensive environmental damage. One of the most notable environmental issues is the air pollution. Air pollution in turn could damage agricultural production, and shift equilibrium of food markets.

According to the latest report from Intergovernmental Panel on Climate Change (IPCC), Agriculture, Forestry, and Other Land Use (AFOLU) sector contributes approximately a quarter of global greenhouse gas (GHG) emissions ${ }^{27}$. This share is expected to rise along with increasing demand for meat products in developing and low-income countries (Garnett 2011; Yu 2015; Hasiner and $\mathrm{Yu}$ 2016). Additionally, ammonia $\left(\mathrm{NH}_{3}\right)$ emissions, mainly from fertilized land and animal waste (Hristov 2011; Sheppard, Bittman and Bruulsema 2010), are currently responsible for $75 \%$ of global emissions (FAO 2001). The primary

\footnotetext{
${ }^{26}$ Source: FAOSTAT, http://faostat3.fao.org/.

${ }^{27}$ Source : http://www.ipcc.ch/report/ar5/syr/.
} 
environmental concern with ammonia emissions is formation of particles as a result of atmospheric reactions (Hamaoui-Laguel et al. 2014). Compared with other harmful air pollutants, particulate matters (PM) are more lethal (WHO 2009). Nowadays, both in the United States and the European Union, agriculture is viewed as the prime culprit of air pollution (Erisman et al. 2007; Bauer et al. 2016).

Meanwhile, atmospheric pollution might be adverse to agricultural production in turn. For instance, the toxic air pollutants, such as sulfates, nitrates, dusts, and heavy metals can accumulate in the food chain by diffusion, settling, and precipitation, and consequently harm plants and animals (McCormick 1989; Nagajyoti et al. 2010). Global warming, caused by the GHG emissions, is changing the distribution and behavior of species, which would influence agricultural productivity in the long-term (Chen et al. 2011; Lobell and Gourdji 2012). Besides, the health effects caused by air pollution would reduce worker productivity (Chang et al. 2016; Zivin and Neidell 2012), and thereby threaten food supply indirectly (F. Sun, Koemle, et al. 2017).

FAO predicts that, by 2050 , the global population will reach 9.1 billion, which requires at least $70 \%$ increase in agricultural production. Specifically, annual cereal production must rise to 3 billion tonnes, and meat production must exceed 200 million tones (FAO 2009). Such stress may reinforce the current trends of intensive farming (Matson et al. 1997), even at the cost of environmental deterioration (Godfray et al. 2010; Tilman et al. 2011). Hence, how to mitigate agricultural emissions while ensuring food security is a long-term challenge for both scientists and policymakers.

Agricultural emissions could happen at any point along the food supply chain_production, processing, distribution, and consumption configurations (Aneja, Schlesinger and Erisman 2008). The process of air pollutant formation in routine agricultural operations has been well studied (Mosier et al. 1998; Sommer and Hutchings 2001; Stehfest and Bouwman 2006). However, ancillary emissions, related to the farming operation, such as emissions from transportation and agro-input manufacturing industries, are usually ignored by researchers, which would underestimate agricultural sector's contributions to air pollution. 
Similarly, most existing research related to the impact of air pollution on agriculture only focuses on consequences of air pollution for plant growth (Emberson et al. 2003) and animal health (Holgate et al. 1999). In fact, air pollution could influence both the quantity and quality of agro-inputs in the food supply chain and thereby affects food security indirectly. For instance, it is evident that air pollution can significantly reduce labor productivity (Chang et al. 2016; Zivin and Neidell 2012) and affect outdoor activities (Neidell 2005; Wen, Balluz and Mokdad 2009), and thus influence food supply and demand and shift market equilibrium (F. Sun, Koemle, et al. 2017).

There is, however, no systematic review to date on the linkage between air pollution and food security. This study will draw a full picture of their relationship by reviewing current literature from the view of food supply chain, which could help us find potential opportunities for reducing air pollution while ensuring food security.

\subsection{Air pollution and Agriculture in the Food Chain}

Agricultural sector produces considerable amounts of air pollutants from farm to table (Huxham et al. 2015), mainly GHG, $\mathrm{NH}_{3}$, and PM (Erisman et al. 2008; Fenger 2009). Meanwhile, at each link, air pollution in turn affects both food supply and demand as well. Figure 4.1 illustrates interactions between air pollution and food system. At the farm stage, plants and animals produce massive amounts of air pollutants through the natural process (e.g., excrete), while manufacture and use of agro-inputs make contaminations worse. On the other hand, air pollution can not only directly impact plant growth and animal health, but also indirectly affect effectiveness of agricultural inputs through diffusion, settling, and precipitation and thereby negatively influence farming operation. During food processing and distribution, industrial wastes and vehicle exhaust generate significant amounts of air pollutants, while air pollution might obstruct food supply by reducing worker productivity as well. Finally, because of air pollution, consumers may change their purchase behavior to mitigate health risks. The impacts of air pollution on consumer demand and food supply would shift market equilibrium, and eventually change food price. 


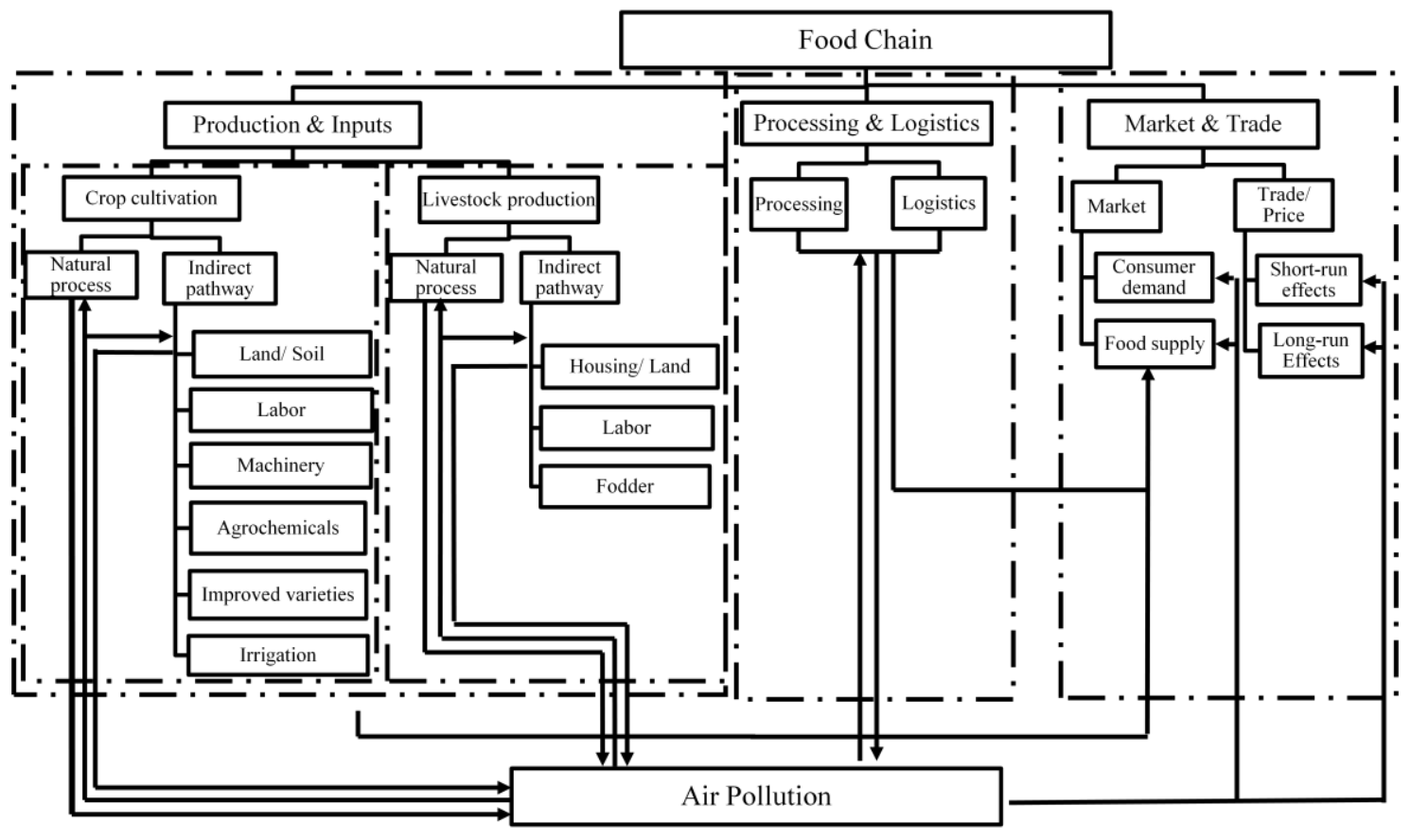

Figure4.1 Air Pollution and Agriculture in the Food Chain

In this section, we will briefly review and summarize the main findings from the current literature from the perspective of the food chain. 


\subsubsection{Production and Inputs}

\section{Crop cultivation system}

In general, GHGs, $\mathrm{NH}_{3}$, and $\mathrm{PM}$ are the primary pollutants emitted from crop cultivation system (Aneja et al. 2008; Cole et al. 1997). Additionally, the chemical reactions of nitrogen oxides and volatile organic compounds can form the secondary pollutant_-ozone $\left(\mathrm{O}_{3}\right)$. Ideally, land occupation and soil microbial activity are the principal pathways of causing air pollution through the natural process (Bellarby, Foereid and Hastings 2008; Conrad 1996; Smith et al. 2003). However, the manufacture and use of industrial inputs, such as synthetic fertilizer and farm machinery, make contamination worse (Aneja, Schlesinger and Erisman 2009; Fenger 2009).

A large number of field experiments have been conducted worldwide to investigate the impact of air pollution on plants. Nitrogen dioxide $\left(\mathrm{NO}_{2}\right)$, sulfur dioxide $\left(\mathrm{SO}_{2}\right)$, ozone $\left(\mathrm{O}_{3}\right)$, and particulate matter (PM) are now considered as major air pollutants that have adverse effects on plant growth by obstructing photosynthesis or changing organizational structure and function (Crittenden and Read 1978; Heagle, Body and Heck 1973; Honour et al. 2009; Rai et al. 2010). In addition, air pollution can also alter effectiveness of agricultural inputs through diffusion, settling, and precipitation (Alloway 2013; Zivin and Neidell 2012) and thereby negatively influence crop yield.

Land, labor, machinery, agrochemicals (e.g., synthetic fertilizers and pesticides), improved varieties, and irrigation are considered the major inputs for modern crop cultivation system (Yu and Zhao 2009). In the following paragraphs, we will discuss their relationship with air pollution one by one.

\section{(1) Land/Soil}

Soil and land use generate substantial GHG emissions through microbial processes (Conrad 1996; Smith et al. 2003). Specifically, the aerobic decomposition of biomass produces significant amounts of carbon dioxide emissions (Janzen 2004), while anaerobic decomposition of organic matter, such as rice cultivation, releases methane that makes up $10 \%$ of total agricultural emissions (Mosier et al. 1998). Moreover, soil microbial activities also 
produce considerable nitrogen oxide by biological nitrification and denitrification, especially when the soil is fertilized by animal waste or synthetic fertilizer (Colliver and Stephenson 2000). Apart from microbial processes, Bellarby et al. (2008) point out that land use change is also an important source of agricultural emissions, accounting for approximately $6-17 \%$ of global GHG emissions. It is, however, gratifying to note that net GHG emissions from this item have been declining steadily (Tubiello et al. 2014).

Additionally, tillage and wind erosion of soils may generate PM in the form of dust (Nordstrom and Hotta 2004; Funk et al. 2008). A large number of field measurements and laboratory simulations indicate that tillage operations alleviate soil compaction so that soils can be easily blown into the air (Funk et al. 2008; Goossens, Gross and Spaan 2001; Nordstrom and Hotta 2004) and form PM. During this process, toxic substances in soils, such as heavy metal and trace elements, may get into the atmosphere with the dust (Lu et al. 2010).

On the other hand, air pollutants may enter into the soil through dispersion, settling, and precipitation, and then influence plant growth. For instance, in the atmosphere, sulfur dioxide reacts with the water molecules and forms sulfuric acid; nitrogen oxides dissolve in water vapor and form nitric acid, they eventually fall as acid rain to the ground. Moreover, soil microbes digest the ammonia in the atmosphere and produce nitrate and acidic hydrogen ions, which make the soil more acidic (Nosengo 2003). Apparently, acidic soils would lower microbial activities or even kill intolerant microorganisms, which would reduce the diversity of soil microbial communities (Fierer and Jackson 2006). Notably, the hydronium ions in the acid rain would leach away essential nutrients and minerals for plant growth, such as calcium and magnesium (Aber et al. 1998; Kochian, Hoekenga and Piñeros 2004), which makes the plant more vulnerable to adverse environmental influences.

So far, a series of studies have been carried out concerning the impact of heavy metal contamination of settling particles on soil quality and plant growth. In general, heavy metals can deposit onto topsoil via sedimentation, impaction, and interception ( $\mathrm{Li}$, Poon and Liu 2001). Massive heavy metals and other trace elements have been detected in farming soils in industrial areas (Loska, Wiechulła and Korus 2004). Roadside soils usually contain many metal compounds, such as cadmium $(\mathrm{Cd})$, chromium $(\mathrm{Cr})$, copper $(\mathrm{Cu})$, lead $(\mathrm{Pb})$, nickel $(\mathrm{Ni})$, 
and zinc (Zn) (Christoforidis and Stamatis 2009; Legret and Pagotto 2006; Pagotto et al. 2001; Werkenthin, Kluge and Wessolek 2014; Wei and Yang 2010). These trace elements, particularly $\mathrm{Cd}$ and $\mathrm{Zn}$, can be absorbed through roots and accumulated in plant tissues (Kloke, Sauerbeck and Vetter 1984; Voutsa, Grimanis and Samara 1996). There is no doubt that excess heavy metals would significantly affect seed germination and plant growth, and thereby reduce crop outputs (Peralta et al. 2001; Pandey and Sharma 2002). Eventually, these heavy metals could enter human body through consumption, and cause health risks to human.

Finally, global warming, caused by the greenhouse effect, is causing a northward expansion of cultivation and a reduction of the life cycle for existing determinate crops (Olesen et al. 2011; Olesen and Bindi 2002). It implies that global crop acreage is expected to increase by land development and multiple cropping due to temperature increase. But, in the meantime, global warming is also causing a rise in sea levels and land loss (Solomon et al. 2009), which might reduce the amount of land available for agricultural operation.

In conclusion, lands release massive GHGs and PM to the atmosphere. In return, air pollution affects agricultural outputs by changing arable land areas and by reducing soil quality.

\section{(2) Labor}

Air pollutants can be derived from natural process and human activity. Ironically, the latter contributes most to air pollution (Ramanathan et al. 2001; Kampa and Castanas 2008). Inappropriate behaviors in agricultural practice, including overuse of fertilizers, wrong timing and method of fertilization, and crop residue burning, have released substantial amounts of GHG, ammonia, particulate matter, and trace contaminants (Huxham et al. 2015; Isermann 1994).

Unfortunately, farmers are at a higher risk of respiratory disease compared with other occupational groups, because this group tends to be exposed to a high concentration of hazardous substances (Lovelock 2012; Bang et al. 2006; Karjalainen et al. 2003). These include exposure to dust, engine exhausts, and particulate matters when operating tractors and combine harvesters (Arslan, Aybek and Ekerbicer 2010; Nilsson, Lindahl and 
Norström 1987); exposure to toxic aerosols when spraying pesticides and fertilizers (Hoppin et al. 2002; Hoppin et al. 2009; Mostafalou and Abdollahi 2013). Furthermore, long-term exposure to organic solvents and chemicals also dramatically increases the risks of other chronic diseases (Mostafalou and Abdollahi 2013), such as dermatoses (Penagos 2002; Spiewak 2001; Spiewak 2003), and neurodegenerative diseases (Baldi et al. 2003; Elbaz et al. 2004; Freire and Koifman 2012; Van Maele-Fabry et al. 2012). As the first study that assesses environmental effect on farm productivity, Zivin and Neidell (2012) find that a 10 -ppb increase in average ozone exposure would lead to a $5.5 \%$ decrease in worker productivity. Therefore, air pollution might reduce farmers' productivity or change their working time and then affect agricultural production.

\section{(3) Machinery}

The application of farm machinery is another significant source of air pollution in the agricultural sector. FAO indicates that, in 2010, GHG emissions from energy use for agricultural production exceeded 785 million tonnes of $\mathrm{CO}_{2}$ eq.. Besides, the combustion of fossil fuels when operating farm machinery (e.g., tractor and combine harvester) also generates high levels of primary aerosols (Arslan et al. 2010). Notably, the toxic metals in petrol and diesel fuel, such as lead and manganese, may enter the atmosphere from exhaust emissions (Kummer et al. 2009; Wang et al. 2003).

In general, fossil-fuel combustion to power the machinery is considered a straightforward pathway to release air pollutants (Huxham et al. 2015). From a life cycle perspective, the ancillary emissions from agricultural machinery manufacturing, mechanical repairs and maintenance, and recycling, are of equal importance, but often overlooked. Dyer and Desjardins (2006) find that the energy demand for farm machine manufacturing is almost as high as that for machine operation, implying that they have an equal amount of GHG emissions. The waste recycling process generates various toxic chemicals, such as incomplete combustion of e-waste and dumping of processed materials (Wong et al. 2007), which is a potential emitter of air pollution.

The primary pollutant that affects farm machinery is acid rain. Acid rain can corrode certain types of metals and accelerate depreciation of machinery (Oki and Anawe 2015). 
Meanwhile, a large number of statistical studies have found that machinery operators are usually exposed to high concentrations of air pollution during agricultural operations (Kimbell-Dunn et al. 2001; Dyer and Desjardins 2006) so that this occupational group is more likely to get respiratory infections (Kogevinas et al. 1999; Blanc and Toren 1999). Therefore, air pollution may affect the performance of machine operators and indirectly reduce the efficiency of farm machines.

In summary, over its lifetime, farm machinery produces a substantial amount of air pollution. In return, air pollution affects agricultural production by accelerating depreciation of machinery and by reducing machine operator efficiency.

\section{(4) Agrochemicals}

The manufacture of synthetic fertilizers is energy and resource intensive, and generates substantial GHG emissions (Wood and Cowie 2004). Kongshaug (1998) indicates that fertilizer production consumes nearly $1.2 \%$ of world energy demand and contributes approximately $1.2 \%$ of global GHG emissions. The capacity expansion for the fertilizer industry is expected to worsen air pollution (Heffer and Prud'homme 2010).

Depending on the source of raw material, exhaust gas released from fertilizer manufacturing industry may contain more or less hazardous materials. For instance, phosphate rock is the raw material for manufacturing phosphorus fertilizers. It includes a broad range of heavy metals and natural radionuclide (Da Conceicao and Bonotto 2006; Mehmood et al. 2009; Jiao et al. 2012). These trace elements may enter into the environment through industrial discharge (Aoun et al. 2010).

As we discussed before, soil microbial activities are the dominant nitrous oxide source. However, the application of nitrogen fertilizers accelerates the microbial reactions, especially enhances nitrification (Bremner and Blackmer 1978; Davidson 2009) and further leads to stratospheric ozone depletion and global warming (Bouwman, Boumans and Batjes 2002). FAO indicated that the use of synthetic fertilizers was responsible for $13 \%$ of agriculture's GHG emissions in $2011^{28}$. Approximately half of global anthropogenic $\mathrm{N}_{2} \mathrm{O}$

\footnotetext{
${ }^{28}$ Source : http://www.fao.org/news/story/en/item/216137/.
} 
emissions result from nitrogen fertilizer (IPCC 2007). Most importantly, nitrogen from fertilizer may volatilize as ammonia or be oxidized into other nitrogen oxides and finally form particulates, nitric acid, and nitrate (Erisman et al. 2007).

Similarly, the production and utilization of other agrochemicals, such as pesticides and herbicides, are also associated with air pollution (Armenta and de la Guardia 2016). For instance, Van den Berg et al. (1999) find that up to $30-50 \%$ of pesticides are lost to the atmosphere during spraying, which is in agreement with the finding of Cross et al. (2001). Apart from the drift of pesticides, the effective pesticides deposited on leaves and soil may enter the air through volatilization, degradation, and wind erosion (Van Pul et al. 1999; Bidleman 1999; Majewski et al. 1998) and cause atmospheric organic contamination (Gil and Sinfort 2005; Gil et al. 2007).

Global warming tends to accelerate the volatilization of nitrogen fertilizers and pesticides (Bedos et al. 2002; Bloomfield et al. 2006; Sommer, Olesen and Christensen 1991), implying that fewer agrochemicals can reach the plant. Moreover, acid rain results in acidification of soil, which dramatically damages the ability of roots to absorb nutrients in fertilizers (Baligar and Bennett 1986; Baligar, Fageria and He 2001). Therefore, air pollution reduces agrochemicals use efficiency and consequently influences agricultural outputs.

\section{(5) Improved varieties}

Using a global economic model, Stevenson et al. (2013) estimate the impact of Green Revolution research on global land cover change during 1965 to 2004 . They find that the widespread adoption of improved varieties avoided an estimated of approximately 18-27 million hectares from being converted to farmland. Crop variety improvement is an effective way to reduce GHG emissions (Burney, Davis and Lobell 2010).

\section{(6) Irrigation}

Out of all water resource on earth, fresh water makes up $2.5 \%$ of it, whereas only a small per centage is easily accessible (Oki and Kanae 2006). Given the shortage of fresh water, waste water especially sewage water is being widely used for field irrigation (Singh, 
Deshbhratar and Ramteke 2012). However, numerous studies, and particularly the practice in developing countries, have shown that the long-term wastewater irrigation has transferred large amounts of heavy metals and persistent organic contaminants to the soil (Bao et al. 2014; Chen, Wang and Wang 2005; Liu et al. 2005; Sridhara, Kamala and Samuel 2008). In dry and windy weather, these compounds might be blown into the atmosphere and form the particulates (Li et al. 2004), as we discussed before.

Similarly to the case of farm machinery, the manufacture, operation, repair and maintenance, and recycling of agricultural irrigation equipment are certainly important sources of air pollution. Meanwhile, air pollution affects agricultural production by accelerating depreciation and by reducing worker productivity. But these should be further scrutinized.

\section{Livestock production system}

Methane resulting from enteric fermentation is now the largest source of GHG emissions in the agricultural sector. Based on the latest report from FAO, enteric fermentation contributed $39 \%$ of agricultural total GHG outputs in $2011^{29}$. What is more, existing ammonia emissions inventories from most of the countries indicate that livestock excreta is responsible for more than half of the total ammonia emissions (Goebes, Strader and Davidson 2003; Huang et al. 2012; Webb et al. 2005). These emissions may further react with sulfuric acid, nitric acid, hydrochloric acid and water to form atmospheric particulate matter (Cambra-López et al. 2010; Hristov 2011).

Land, housing, labor, and fodder are considered the essential inputs to livestock production (Kompas and Che 2006; Tian et al. 2015)(Kompas and Che 2006; Tian et al. 2015). Similar to the case of crop cultivation system, except for the natural process, the production and use of these inputs may introduce more air contaminants as well (Cambra-López et al. 2010; Takai et al. 1998). On the other hand, air pollution can cause detrimental effects not only on animal health and performance (Donham 1991; Homidan 1998) but also on these inputs (Linaker and Smedley 2002; May, Romberger and Poole 2012) and thereby influence livestock production.

\footnotetext{
${ }^{29}$ Source : http://www.fao.org/news/story/en/item/216137/.
} 


\section{(1) Land /Housing}

On average, a factory farm concentrates tens or hundreds of thousands of farm animals in a limited area. The environment of factory farming is, no doubt, crowding and muggy, which makes the indoor air quality worse.

Livestock housing is an important source of ammonia, carbon dioxide, hydrogen sulfide, and particulate matter (Ni et al. 2012). Specifically, animal excreta generate substantial ammonia; animal respiration and manure breakdown generate carbon dioxide; anaerobic fermentation of manure generates hydrogen sulfide. In livestock houses, PM usually contains organic dust (e.g., proteins, poly-carbohydrates), endotoxins, and microorganisms (e.g., bacteria, fungi) (Seedorf 2004; Wathes et al. 1998), which originate from manure, feathers, animal's skin, feed, and bedding (Cambra-López et al. 2011; Donham et al. 1986; Heber et al. 1988). Besides, mechanical forces and ventilation system are also secondary sources of particles within the buildings (Seedorf 2004).

\section{(2) Labor}

To boost farm profits, farmers tend to expand farm size and increase stocking density. However, concentrated animal feeding operations are usually accompanied by terrible air quality, in particular, odor (Donham 2000; Donham 2010). High animal density treatment is also considered as an important source of indoor air pollution (Donham 1991; Sevi et al. 1999).

Compared with other occupations, including crop farmers, livestock farmers are more likely to suffer from a variety of diseases, especially respiratory diseases (Lee et al. 2002; May et al. 2012; Radon et al. 2001). The decline in workers' productivity would affect final outputs.

\section{(3) Fodder}

Livestock is the largest user of global land resources. This sector uses one-third of arable land to plant feed crops and harvests more than $40 \%$ of world cereal production (FAO 2013). The changes in landscape driven by animal production could change GHG emission 
globally. Apart from directly affecting animal health and performance, air pollution can threaten fodder crops supply and subsequently affect livestock production.

Notably, to promote animal growth and enhance feed efficiency, feed-additive antibiotics have been widely used in livestock production system (Cromwell 2002). Similar to the case of agrochemicals, the manufacture and application of antibiotics may also result in air pollution, but unfortunately, the current literature only conducted limited research on this issue.

\subsubsection{Processing and Logistics}

\section{Processing}

Food processing industry is a critical link in the food chain. It involves processing and packaging of raw ingredients, which contributes considerable air pollution. Apart from GHGs and toxic exhaust emissions due to fossil-fuel combustion, indoor organic dust pollution is unique to this sector (Lenters et al. 2010; Liebers, Brüning and Raulf-Heimsoth 2006). A large number of surveys have been conducted to identify the high polluted workplace in food and agricultural processing industries. In general, textile mills (Lenters et al. 2010; Astrakianakis et al. 2007), wood processing plants (Demers, Teschke and Kennedy 1997; Mandryk, Alwis and Hocking 2000), cigarette factories (Reiman and Uitti 2000; Fishwick et al. 2001), potato processing plants (Zock et al. 1998; Zock, Heederik and Hans 1995), breweries (Carvalheiro et al. 1994), and sugar-beet processing plants (Forster et al. 1989) are reported to contain high levels of particles, such as bacteria, endotoxin, and occupational antigens.

World Health Organization (WHO) has stated that prolonged exposure to high levels of indoor air pollution might cause acute respiratory syndrome, which would reduce worker productivity significantly (Mendell 1993; Wyon 2004). Based on the observation from a pear-packing factory, Chang et al. (2016) evaluate the effects of fine particulate matter on the productivity of workers. They find that with an increase in PM2.5 concentration by $10 \mu \mathrm{g} / \mathrm{m}^{3}$, worker productivity significantly decreases by $6 \%$. Evidence from an Indian garment factory, however, shows a relatively minor effect: a $10 \mu \mathrm{g} / \mathrm{m}^{3}$ increase in PM2.5 concentration only reduces worker efficiency by $0.3 \%$ (Adhvaryu, Kala and Nyshadham 2014). In short, air 
pollution may reduce worker productivity in the processing industry and thereby influence food supply.

\section{Logistics}

Logistics plays an important role in the distribution of agricultural products, as it is responsible for transporting agricultural products from the farms to the markets. However, road traffic emissions, resulting from vehicle exhaust, road dust, and brake-wear, have become the dominant sources of air pollution in megacities and developing countries (Abu-Allaban et al. 2003; D’Angiola et al. 2010). Except for the GHGs, the most widely reported pollutants on road are carbon monoxide, nitrogen and sulfur oxides, hydrocarbons, particulate matter, and airborne trace metals (Wei and Yang 2010; Zhang and Batterman 2013). Compared with other engines, diesel engines seem to emit a higher level of pollutants (Yamada et al. 2011). Because most of the vehicles used for transporting agricultural products are diesel-powered trucks, transportation of agricultural products contributes enormously to road traffic air pollution. Notably, rapid urbanization implies an increasing burden on transportation of agricultural commodities, which makes air pollution even worse (D’Angiola et al. 2010).

Visibility impairment is a direct consequence of air pollution typically due to particulate matter suspended in the air (Hyslop 2009). As it can easily cause road traffic accidents (Abdel-Aty et al. 2011), the transport agency sometimes orders to shut down highways temporarily (F. Sun, Koemle, et al. 2017). Additionally, long-term exposure to vehicle exhaust increases the risk of respiratory disease for lorry drivers (Chen et al. 2015; Hansen 1993). Both traffic control and physical discomfort induced by air pollution may lead to a delivery delay, which subsequently affects food supply.

\subsubsection{Market and Trade}

\section{Market}

\section{(1) Consumer demand}

Numerous medical studies have shown that air pollution has been associated with increases in mortality and morbidity (Kampa and Castanas 2008; Kim, Jahan and Kabir 
2013). Therefore, people tend to reduce outdoor activities to mitigate health risks when air pollution levels are high (Bresnahan et al. 1997), especially when they are informed about real-time air quality and receive health alerts (Kelly et al. 2012; Neidell 2009; Wen et al. 2009; Zivin and Neidell 2009). For instance, using a regression discontinuity design, Neidell (2005) explores the public response to smog alerts in Southern California and finds that attendance at outdoor facilities would decline significantly by 3 to $11 \%$ when warnings are issued. Therefore, transitory air pollution may change consumer purchase behavior, such as adjusting shopping time, which would eventually result in a shift in food demand (F. Sun, Koemle, et al. 2017).

In the long-term, consumers may vote with their feet, moving to another place with better air quality (Ridker and Henning 1967; Evans and Jacobs 1981; Tracey and Walsh 2008), or take defensive measures to protect themselves, such as wearing facemasks and investing in air filter products (Shen et al. 2005; Zhang and Mu 2017; C. Sun, Kahn and Zheng 2017). Although air pollution indeed affects people's daily lives (F. Sun, Koemle, et al. 2017), it seems to have a minor impact on food demand in the long-term.

\section{(2) Food supply}

Air pollution, especially haze pollution, contributes to visibility impairment, which increases traffic congestion (Kang et al. 2013). Moreover, it is evident that traffic jams produce more vehicle emissions than normal traffic conditions and make air quality worse (Zhang and Batterman 2013; Zheng, Liu and Hsieh 2013). Apart from the vicious circle between traffic congestion and air pollution, air pollution may cause drivers experience physical discomfort (Rank, Folke and Jespersen 2001; van Wijnen et al. 1995) so that the goods cannot be delivered on time. From the perspective of logistics, air pollution curbs food supplies. However, the influence is negligible in the short run (F. Sun, Koemle, et al. 2017).

A large number of experiments in both lab and field have demonstrated that air pollution may damage agricultural outputs, either by reducing yield or by deteriorating product quality. Avnery et al. (2011) indicate that the total loss of global staple crop (soybean, maize, and wheat) production due to surface ozone exposure was 79-121 million metric tons in 2000, 
worth 11-18 billion USD. A cross-over design carried out by Elenbaas-Thomas et al. (2005) shows that the ozonation treatment at $0.1 \mathrm{ppm}$ mean concentration can significantly reduce pig daily weight gain by $0.13 \mathrm{~kg}$. Therefore, air pollution may reduce food supply in the long run.

\section{Trade}

Air pollution has impacts on both food demand and supply, which should ultimately embody in food price changes through market equilibrium shift. Using daily price data from the outdoor wholesale market in Beijing, Sun et al. (2017) find that air pollution can significantly reduce vegetable prices, but it has no significant impact on pork prices in the short run. Specifically, a 100 units increase in AQI (Air Quality Index) decreases the prices for Chinese cabbage and tomatoes by 1.19 and $0.89 \%$ respectively; an increase of $100 \mu \mathrm{gm}^{-3}$ in PM2.5 concentration decreases the prices for Chinese cabbage and tomatoes by 0.64 and $0.55 \%$, respectively.

Notably, storage is momentous in food consumption, particularly for foods with a long shelf life (Gibson and Kim 2012). Therefore, the short-run aggregate effect of air pollution on food price would be mitigated in the long run.

The preceding analysis demonstrates that in the long-term, air pollution may have a minor impact on food demand, but may cause a considerable reduction in food supply. We hence predict that air pollution may increase food price, but it needs to be further verified.

\subsection{Policy Implications}

\subsubsection{Agricultural Policy}

Since air pollution is highly related to agricultural supply, demand and trade, agricultural policies could also influence air quality while promoting agricultural development through market function (Zilberman, Templeton and Khanna 1999).

In general, agricultural subsidy and output price supports are the most common policy instruments (Bayes, Parton and Piggott 1985; Yu and Zhao 2009). Since the middle of $20^{\text {th }}$ 
century, governments around the world have been vigorously promoting input subsidy programs, and particularly for synthetic fertilizers (Dorward and Chirwa 2011; Fan, Gulati and Thorat 2008; Hertel 1989; Jayne and Rashid 2013; Schmid, Sinabell and Hofreither 2007). For instance, since 2004, the agricultural input subsidies in China have accumulated up to 778.1 billion $\mathrm{CNY}^{30}$. In 2011, 10 African countries allocated about 1.05 billion USD to agricultural input subsidies, amounting to nearly $30 \%$ of their public expenditures on agriculture (Jayne and Rashid 2013). In Nigeria, fertilizer subsidies historically accounted for roughly $30 \%$ of the total federal budget for the agricultural sector (Takeshima and Nkonya 2014).

The intensification and scale management of farming initially driven by agricultural subsidies have significantly improved global agricultural productivity growth, contributing to feeding the world and poverty reduction (Fan, Hazell and Thorat 2000; Griliches 1963; Thirtle, Lin and Piesse 2003). Among all agro-inputs, fertilizer is the largest contributor to agricultural growth. Using provincial level panel data, Fan and Pardey (1997) quantify the sources of agricultural growth in China during 1965-1993 and attribute 21.7\% of agricultural growth to the application of chemical fertilizers. Using data from several long-term field experiments in the U.S., England, and the tropics, Stewart et al. (2005) suggest that at least 30 to $50 \%$ of crop yield in the U.S. is attributable to commercial fertilizer nutrient inputs.

Meanwhile, agricultural intensification has been proven effective for GHG mitigation, even considered emissions from fertilizer production (Burney et al. 2010). However, if we add the emissions from other agricultural inputs manufacturing, such as farm equipment manufacturing, or re-estimate the impact of agricultural intensification on GHG mitigation from the entire global food chain, the conclusion may be pessimistic. More importantly, GHG is only a prominent example of various air pollutants. Taking fully into account the ammonia pollution released from fertilized land and animal waste and the particulate matter emissions, we may get the conclusion that agricultural intensification is not conducive to reduce emissions.

To some extent, input subsidy programs easily lead to the overuse of farm inputs (Duflo

\footnotetext{
${ }^{30}$ Source: Ministry of Agriculture of the People's Republic of China. http://english.agri.gov.cn/.
} 
et al. 2011; Ricker-Gilbert 2014). However, according to the law of diminishing marginal returns, as well as evidence from field experiments, high levels of agrochemicals application have been tied to low use efficiency and severe pollution problems (Duflo, Kremer and Robinson 2008; Marenya and Barrett 2009; Yu and Zhao 2009). For instance, using 2007 farm-level data, Wu (2011) employs a stochastic frontier production function to examine the fertilizer use efficiency (FE) in China and find that the mean score is only 0.33 , implying that there are about two-thirds of the chemical fertilizers overused in China. Similarly, a data envelopment analysis (DEA) framework employed by Thanh Nguyen et al. (2012), using 2003-2007 farm-level panel data, examine the cost and environmental efficiency of rice farms in South Korea. They estimate that the mean technical efficiency score is 0.772 and the mean environmental efficiency score is 0.309, indicating a low-cost efficiency and environmental efficiency, so that they suggest removing input subsidies and improving technical efficiency.

Furthermore, it is evidence that output price supports could distort producer decisions (Fraser 1991; Yi, Sun and Zhou 2015; Yu and Zhao 2009) and thereby have an influence on air quality. For instance, using 1996-2001 farm-level panel data, Foltz (2004) predicts that the New England Dairy Compact's price support has resulted in a $2.4 \%$ increase in dairy cattle numbers. Because cattle are a typical example of ruminant animals, the expansion of dairy herds apparently results in GHG emissions far higher than before. It suggests that price support may lead to a significant increase in favorable products production, the structure changes in agricultural production hence lead to the changes in air pollutants concentrations (Searchinger et al. 2008).

Overall, however, since the end of the 20th century, there has been a marked shift away from price support to direct payments to farmers in OECD countries (Dewbre, Antón and Thompson 2001; Patton et al. 2008; Young and Westcott 2000) and some developing countries, in particular, China, also came after (Heerink, Kuiper and Shi 2006; Yu and Jensen 2010). Theoretically, agricultural income support programmes or similar decoupled agricultural policies are independent of production, implying that such a switch no doubt will boost air quality. Nevertheless, a growing number of studies argue that decoupled direct payments linked to land still have considerable production effects through positively affecting land rent (Goodwin and Mishra 2005; Patton et al. 2008). Hence, it should be 
further scrutinized the influence of such agricultural supporting policy transition on the improvement of air quality.

Notably, in 2015, the United Nations released a report on the Sustainable Development Goals (SDGs), which follow and expand on the Millennium Development Goals (MDGs). The SDGs once again emphasize the importance of promoting sustainable agriculture. In practice, the U.S. launches a series of agri-environmental payment programs, including Cost-share and incentive payments, Long-term contracts, Long-term or permanent easements, and Environmental credit trading (Claassen, Cattaneo and Johansson 2008; Fleming 2017). The Common Agricultural Policy of the EU (CAP) introduces a "green" payment for farmers and encourages organic farming (Donald et al. 2002; Lowe, Buller and Ward 2002; Offermann, Nieberg and Zander 2009). Similarly, in order to reduce GHG emissions, the Chinese government has attempted to advocate straw returning methods by increasing the subsidy for compliance and penalty for violence (Qu et al. 2012; Yu et al. 2017). These sustainable farming practices will enable the farmers to earn a reasonable level of income without damaging the environment.

\subsubsection{Energy Policy}

Ever-increasing energy prices, concerns about petroleum supplies, and negative environmental consequences of fossil fuel combustion have driven the interest in biofuels all over the world (Hill et al. 2006). Moreover, it is evidence that a shift from fossil-fuel energy to biofuel can significantly reduce PM and GHG emissions (Hill et al. 2009; Smith et al. 2008; Wilson et al. 2011). Therefore, many countries actively implement policies to stimulate the production and use of biofuels (Banse et al. 2008). In 2010, global biofuels production amounted to 105 billion liters. The U.S. and Brazil are the two largest producers of bioethanol, which generated 49 billion and 28 billion liters, respectively in $2010^{31}$. The EU is the largest biodiesel producer in the world. In 2007, biodiesel production in Europe reached 5.5 million tons, where Germany contributed to nearly half (Banse et al. 2008).

Theoretically, biofuel policies pursued by the government would enhance demand for feedstock used in biofuel production, which leads to a change in land use (Searchinger et al.

\footnotetext{
${ }^{31}$ Source: http://www.worldwatch.org/biofuels-make-comeback-despite-tough-economy.
} 
2008; Melillo et al. 2009). In general, there are two pathways: without interfering existing agricultural structure, farmers may convert forest and grassland to new cropland for biofuel crops production. Whereas, the increase in land use would no doubt significantly change landscape and exacerbate air pollution and particularly GHG and PM emissions. Secondly, without increasing land use, farmers may adjust planting structure, expanding the planting area for biofuel crops. Land-use competition for production of food and biofuels, however, would trigger higher food prices and force farmers to convert more forest and grassland for producing food crops (Ajanovic 2011; Banse et al. 2008; Rathmann, Szklo and Schaeffer 2010). A global CGE model constructed by Timilsina et al. (2012) examine the long-term impacts of biofuel targets on land use change and food prices. They predict that, in 2020, there will be nearly 18.4 million hectares of global forest losses and the prices of primary biofuel feedstock would increase by 1-9\%. Using the same model, Melillo et al. (2009) indicate that indirect land use related to bioenergy production release substantially more GHGs than direct land use, consistent with the results in Searchinger et al. (2008).

Therefore, some researchers suggest using agricultural residues as feedstock for biofuel production (Sarkar et al. 2012; Searchinger et al. 2008). First, using waste products to replace biofuel crops does not burden land use, implying that it can cost-effectively achieve mitigation. Most importantly, using biomass to produce biofuels can avoid air pollution due to agricultural residues combustion, turning waste into wealth.

In sum, diversion of food crops to biofuels is not available to reduce air pollution, but fortunately, the application of biomass fuel provides an opportunity for us.

\subsection{Conclusion and Discussion}

\subsubsection{Conclusion}

Air pollution is highly correlated with the food system. Along the food supply chain, agricultural production, processing, and distribution generate substantial air pollutants, mainly $\mathrm{GHG}, \mathrm{NH}_{3}$, and PM. On average, at the farm stage, overuse of chemical fertilizers and animal husbandry are the largest sources of agricultural emissions. Beyond the farm gate, industrial waste and vehicle exhaust related to food system contribute significantly to air 
pollution. In return, air pollution not only reduces raw ingredients supply but also obstructs food supply in processing and distribution. Additionally, air pollution may affect consumer behavior in the short run. The impacts of air pollution on consumer demand and food supply would eventually change food price. Finally, this study evaluates the effects of agricultural policy and energy policy on food security and air pollution, respectively.

\subsubsection{Extension}

An enormous body of literature has investigated the opportunity for reducing air pollution through the technical and pecuniary means (Garnett 2011; Ndegwa et al. 2008; Tuomisto et al. 2012). The following paragraphs provide an overview of potential approaches to reduce air pollution while ensuring food security.

\section{Optimizing production technology}

Irrigation management plays a vital role in GHG emission in paddy fields (Nguyen et al. 2015; Yang et al. 2012). Prompt drainage at an appropriate time could significantly reduce global paddy-derived methane and nitrous oxide emissions (Hou et al. 2012; Li et al. 2002; Nishimura et al. 2004).

\section{Enhancing agrochemicals use efficiency}

Because of excessive subsidies and inappropriate fertilization practices (Ricker-Gilbert et al. 2013; Sheriff 2005), farmers tend to apply fertilizer above agronomically recommended rates. Therefore, removing input subsidies and improving fertilizer use efficiency are of primary concern. Given the loss during spraying of pesticides and liquid fertilizers, it is necessary to explore a cost-efficient spraying pattern.

\section{Improving productivity}

Regardless, increasing yields can significantly reduce land use, and thereby mitigate GHG emissions. It includes improving human capital, rationally applying agrochemicals, enhancing pest and disease forecasting and management, developing improved varieties, expanding irrigation land, adopting advanced wastewater treatment technology, optimizing animal feed, and improving livestock housing environment. 


\section{Utilizing agricultural waste}

Using agricultural residues as feedstock to produce biofuel does not burden land use, while it can avoid air pollution due to combustion, which should be promoted by government policies.

\section{Changing dietary}

A growing number of studies suggest that dietary shift might be an effective means of reducing air pollution (Carlsson-Kanyama 1998; Weber and Matthews 2008; Friel et al. 2009; Garnett 2011). Compared with crop cultivation system, livestock production and particularly ruminants husbandry has more influence on air pollution. Therefore, Weber and Matthews (2008) suggest replacing red meat and dairy products by chicken, fish, eggs, and a vegetable-based diet. Theoretically, such a low-meat diet, in particular with very moderate or even no red meat, is healthful, but there is a long way to go (Garnett 2011).

\subsubsection{Future Research}

Overall, although a large number of studies have investigated the relation between air pollution and food security, the current literature only conducted limited research on identifying micro behavior (Shen et al. 2005; Zhang and Mu 2017; C. Sun et al. 2017). There is no doubt that household's bounded rational consumption and production behaviors are highly correlated with air pollution (Duflo et al. 2011; Kamenica, Mullainathan and Thaler 2011; Lindbeck 1997; Thaler 2008; Thaler and Sunstein 2008), which offers a fertile field for further study. How to take into account the results of behavioral economics, such as nudge theory, in agricultural policy making process is an attractive future research field.

Notably, farm population aging is an increasingly common trend in many parts of the world (Clawson 1963; Davis and Bartlett 2008; Zhong 2011; Burholt and Dobbs 2012). It reflects not only the changes in fertility and mortality, but also the social consequence of immigration (Davis and Bartlett 2008; Li and Sicular 2013; Zhong 2011). In this context, the aging of the rural labor force will have a significant influence on agricultural production, characterized by the dramatic substitution of machinery and agro-chemicals for human labor. To some extent, it will eventually lead to the environmental degradation, including air 
pollution. However, as mentioned above, air pollution has both acute and chronic adverse effects on human health, especially on the elderly (Seaton et al. 1995). The decrease in farmer productivity may further increase the demand for machinery and agro-chemicals ( $\mathrm{Li}$ and Sicular 2013). It generally becomes a vicious cycle. Today, both researchers and policymakers are consequently faced with a thorny problem: how to balance food security with the sustainability of agricultural production in an aging world. 


\section{Chapter 5 Air Pollution and Food Prices: Evidence from China ${ }^{32}$}

Air pollution is one of the top environmental concerns in China. On days with severe air pollution, people (both consumers and producers) often reduce outdoor economic activities in order to avoid possible health damages. This impacts the market trade of fresh food products, at least in a short run. This empirical study sheds light on the impact of air pollution on the short run prices of three major fresh food products (Chinese cabbage, tomatoes and pork) using daily data from the largest outdoor wholesale market in Beijing. With an increase in AQI (Air Quality Index) by 100 units, prices for Chinese cabbage and tomatoes decrease by 1.19 and 0.89 per cent. With an increase in PM2.5 concentration by $100 \mu \mathrm{g} / \mathrm{m}^{3}$, prices for Chinese cabbage and tomatoes decrease by 0.64 and 0.55 per cent. Air pollution affects vegetable prices, but has no significant impact on prices of pork products.

\footnotetext{
${ }^{32}$ This chapter is jointly written with Dieter Koemle and Prof. Xiaohua Yu and has been published in Australian Journal of Agricultural and Resource Economics, 2017, Vol. 61(2): 195-210.
} 


\subsection{Introduction}

In developing countries rapid economic growth and drastic urbanization are usually accompanied by increasing environmental pollution, and China is no exception ( $\mathrm{Yu}$ and Abler 2010; Zheng and Kahn 2013). Particularly, air pollution is a top environmental concern in urban China, and the major pollutants include nitrous oxides $\left(\mathrm{NO}_{\mathrm{x}}\right)$, carbon monoxide (CO), and atmospheric particulate matters. Smog outbreaks are frequently observed in China. According to the official data published by the Ministry of Environmental Protection, the proportion of haze-fog ${ }^{33}$ days in 2013 was 35.9 per cent, and the annual average PM2.5 (particles less than 2.5 micrometers in aerodynamic diameter) concentration was $26 \sim 160 \mu \mathrm{g} / \mathrm{m}^{3}$, far above the safety standard set by the World Health Organization (10 $\left.\mu \mathrm{g} / \mathrm{m}^{3}\right)$.

Air pollution can lead to severe health damages. It is linked to increases in mortality rate, incidences of cancers, visits to physicians, low birth weight, and significantly shortens life expectancy (Brunekreef and Holgate 2002; Chen et al. 2013; Hoek et al. 2002; Künzli et al. 2000; Seaton et al. 1995; Yu and Abler 2010). On days with heavy air pollution, people often reduce outdoor activities in order to avoid health damages.

During Chinese public holidays in October 2016, Beijing, one of the most popular tourist destinations in China, suffered from very heavy hazes, which directly led to an 11.2 per cent decrease in the number of tourists compared to the previous year ${ }^{34}$. Poor visibility due to fog, mist, and haze can easily cause road traffic accidents, cancellation of flights and closedown of highways.

In December 2013, we conducted a household survey in Beijing of people's behavior on pollution days. Amongst our 624 respondents, 43.15 per cent stated that their daily life has been "severely affected", 52.39 per cent "somewhat affected", and only 4.46 per cent stated

\footnotetext{
${ }^{33}$ Haze-fog is the result of constant interaction between specific climatic conditions and human activities. When PM2.5 emissions exceed the environmental capacity, the sunlight, high relative humidity, and stagnant air flow, make it is very easy for haze and fog to form.

${ }^{34}$ See http://env.people.com.cn/n1/2016/1003/c1010-28755747.html.
} 
"not affected" in pollution days. In sum, more than 95 per cent of people have their daily life affected by air pollution.

We conjecture that these daily activity changes could alter both supply and demand conditions, which consequently shifts market equilibrium. Thus, air pollution could increase the volatility of commodity prices, which is particularly true for some fresh food products. However, this phenomenon is not well studied in the literature.

An enormous body of literature shows that the social and economic impact of air pollution could be colossal, diverse, and long lasting. For example, part of this literature sheds light on the effect of air pollution on property values with use of the hedonic price techniques (Brasington and Hite 2005; Harrison and Rubinfeld 1978; Ridker and Henning 1967; Smith and Deyak 1975; Smith and Huang 1995). Some other studies have empirically investigated the influence of air pollution on labor efficiency and firm productivity. For instance, Zivin and Neidell (2011) find that a $10 \mathrm{ppb}$ decrease in ozone concentrations increases agricultural worker productivity by 4.2 per cent. Similarly, Chang et al. (2014) reveal a significant negative impact of PM2.5 on the productivity of indoor workers, and find that reductions in PM2.5 in the U.S. during 1999-2008 generated \$19.5 billion in labor cost savings, accounting for nearly one-third of the total estimated welfare benefits. Cui et al. (2016) find an inverse relationship between firm productivity and pollution emission per unit output, and exporting firms have lower emission per unit output.

In the agricultural sector, the literature finds that air pollution can stunt plant growth (Emberson et al. 2003; Heck, Taylor and Tingey 1988), thereby reducing crop yield. A number of studies have evaluated the impact of some common air pollutants (e.g. $\mathrm{SO}_{2}$, $\mathrm{NO}_{\mathrm{x}}$ and $\mathrm{O}_{3}$ ) on agricultural crop growth (e.g. Voutsa et al. 1996; Agrawal et al. 2003).

Food prices are strongly connected with both consumer and producer welfare $(\mathrm{Yu}$ 2014a; Yu 2014b). The current literature mainly attributes domestic food price volatility to the international food market, unpredictable weather shocks, petroleum/energy prices and government policies (Gerrard and Roe 1983; Ramaswami and Balakrishnan 2002; Clapp 2009; Yu and Zhao 2009; Mueller, Anderson and Wallington 2011; Anderson and Nelgen 2012; Gardebroek and Hernandez 2013; Meyer and Yu 2013; Catão and Chang 2015; Yu 
and Abler 2016; Yu 2014a). However, examining the effect of air pollution on food price volatility has largely been neglected in the current literature.

To fill in the research gap, we evaluate the effects of air pollution on food prices in Beijing (city), using the wholesale market prices for three major fresh food products consumed in China: Chinese cabbage, tomatoes, and pork. To do this, we develop a theoretical model based on the market equilibrium and employ the autoregressive distributed lag (ARDL) model. As the capital and second largest city in China, for years Beijing has been well known to have serious air pollution problems. Such a study could also have significant policy impacts.

The study is organized as follows. Section 2 presents a theoretical framework for modeling the effects of air pollution on food prices. Section 3 discusses our empirical strategy, which is followed by a description of the data in Section 4. Section 5 presents the estimation results and the discussion. Finally, we conclude in Section 6.

\subsection{Theoretical Framework}

Air pollution could affect commodity prices through the channels of both supply and demand. On the one hand, the fall in labor productivity (Zivin and Neidell 2012; Chang et al. 2016), or decline in crop yields (Agrawal et al. 2003; Emberson et al. 2003; Heck et al. 1988), or the decrease in outdoor activities of farmers or traders, could lead to a decrease in supply, which could push up food prices. On the other hand, based on the weather forecast, consumers may adjust shopping times and store some shelf-stable food to avoid exposure to harmful air pollution (Wen et al. 2009), which would eventually shift demand and would affect commodity prices. The final effect of air pollution on commodity prices depends on the aggregate effects of demand and supply in response to air pollution. This study formalizes ideas and adopts a similar theoretical framework as proposed by Yu (2014a).

Assume both demand $D_{i t}$ and supply $S_{i t}$ of food $i$ at time $t$ are determined by food price $P_{i t}$ and air quality $A_{t}$,

$D_{i t}=D\left(A_{t}, P_{i t}\right)$ 


$$
S_{i t}=S\left(A_{t}, P_{i t}\right)
$$

Taking a total derivative,

$$
\begin{aligned}
& d D_{i t}=\frac{\partial D_{i t}}{\partial A_{t}} d A_{t}+\frac{\partial D_{i t}}{\partial P_{i t}} d P_{i t} \\
& d S_{i t}=\frac{\partial s_{i t}}{\partial A_{t}} d A_{t}+\frac{\partial s_{i t}}{\partial P_{i t}} d P_{i t}
\end{aligned}
$$

Based on the market equilibrium condition, $d D_{i t}=d S_{i t}$ and,

$$
\frac{d P_{i t}}{d A_{t}}=\frac{\frac{\partial D_{i t}}{\partial A_{t}}-\frac{\partial S_{i t}}{\partial A_{t}}}{\frac{\partial S_{i t}}{\partial P_{i t}}-\frac{\partial D_{i t}}{\partial P_{i t}}}
$$

By first rewriting Equation (5-3), we can then obtain the food price elasticity $\eta_{P_{i}, A}$ with respect to air quality for food $i$.

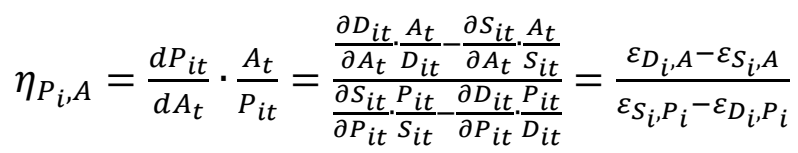

where $\varepsilon_{D_{i}, A}$ and $\varepsilon_{S_{i}, A}$ are, respectively, demand and supply elasticities with respect to air quality for food $i . \varepsilon_{D_{i}, P_{i}}$ and $\varepsilon_{S_{i}, P_{i}}$ are the price elasticities of demand and supply, respectively.

Economic theory indicates that for a normal good, the sign of price elasticity of demand $\varepsilon_{D_{i}, P_{i}}$ is negative, while the price elasticity of supply $\varepsilon_{S_{i}, P_{i}}$ is positive. Therefore, the denominator of Equation (5-4) is always positive. Notably, we presume that the denominator is a positive constant, because the price elasticities of demand and supply are independent of air quality.

However, the sign of the numerator of Equation (5-4) is difficult to infer. As aforementioned, both consumers and suppliers tend to reduce their outdoor activities on heavy pollution days to avoid health damage, which simultaneously pushes down both demand and supply in the short run. Both the signs of $\varepsilon_{D_{i}, A}$ and $\varepsilon_{S_{i}, A}$ are positive, although their magnitudes are different depending on the properties of the food (e.g. storability). 
Finally, the aggregate effect of air quality on food prices depends on the relative scales of demand and supply elasticities with respect to air quality.

1. If the stimulating effect of air quality on demand is larger than that on supply, then $\varepsilon_{D_{i}, A}>\varepsilon_{S_{i}, A}$, we have $\eta_{P_{i}, A}>0$, implying that the food price increases with the improvement of air quality.

2. If the stimulating effect on demand is offset by that on supply, then $\varepsilon_{D_{i}, A}=\varepsilon_{S_{i}, A}$, that is $\eta_{P_{i}, A}=0$, implying that air quality has no significant effect on food price.

3. If the stimulating effect on demand is smaller than that on supply $\left(0<\varepsilon_{D_{i}, A}<\varepsilon_{S_{i}, A}\right)$, or air pollution stimulates demand for some special foods $\left(\varepsilon_{D_{i}, A}<0\right)$, then $\eta_{P_{i}, A}<0$ implying that the food price increases with the deterioration of air quality.

The demand and supply elasticities with respect to air quality and the final aggregate effect on prices may differ for each product. For instance, vegetables may be different from meat products due to a different demand and supply structure. In this study, we shed light on three specific fresh food products: Chinese cabbage, tomatoes and pork products, which are all staple daily foods for Chinese consumers (Yu and Abler 2014; Zhou, Yu and Herzfeld 2015).

\subsection{Econometric Model}

Food price determination is a dynamic process, which could be modeled by many different econometric models. However, finite lag models often impose very strong restrictions on the lagged response of the dependent variable to a change in independent variables. As a general compromise, the Autoregressive Distributed Lag (ARDL) model provides a more flexible platform to model time series (Greene 2007, pp.681). Particularly, the $\operatorname{ARDL}(1,1)$ model has become the most frequently used in modern time series analysis (Greene 2007, pp.689). The model is specified as:

$$
\begin{aligned}
\ln P_{t}= & \alpha_{0}+\sum_{i=1}^{p} \delta_{i} \ln P_{t-i}+\sum_{j=1}^{n} \sum_{i=0}^{q} \omega_{j, i} X_{j, t-i}+\rho \text { Holiday }_{t}+\sum_{k=1}^{6} \gamma_{k} \text { Week }_{t k}+ \\
& \sum_{l=1}^{11} \theta_{l} \text { Month }_{t l}+\sum_{m=1}^{1 o r} \varphi_{m} \text { Year }_{t m}+\varepsilon_{i t}
\end{aligned}
$$


where $P_{t}$ is the food price at time $t, \delta_{i}$ is the coefficient for the lag of food prices. $X_{j, t}$ is a vector of exogenous variables, including air pollution levels, daily temperature and 24-h precipitation. $\omega_{j, i}$ captures their effects on food prices at different times. Severe weather condition, as well as pollution, may have both influences on consume behavior (Agnew and Thornes 1995; Murray et al. 2010) and commodity supply (Olesen and Bindi 2002; Zhang and Carter 1997), so it is reasonable to add these variables into regression. Additionally, food prices tend to increase during traditional festivals, so we add a dummy variable Holiday in the baseline model. We also include dummies for each day in a week (with Sunday as the omitted category) $W e e k_{t k}$, for each month of the year (with December as the omitted category) Month $_{t l}$, and year dummies Year $_{t m}$ to net out potential seasonality effects. $\alpha_{0}$ is a constant, $\varepsilon_{t}$ is the error term, and $p$ and $q$ are maximum lag orders.

The ARDL model provides a general form for us to test the dynamic impact of air pollution on food prices. When $\omega_{i}=0$, the $\operatorname{ARDL}(1,1)$ model degenerates to an $\operatorname{AR}(1)$ model.

Notably, ARDL model requires that the dependent variable does not have a unit root. Hence, a test of unit roots for $\ln P_{i t}$ is a precondition for conducting these econometric exercises. In addition, there may exist serial correlation in the error terms, which may lead to incorrect standard errors. Hence, we use the Newey-West method to correct the standard errors (Newey and West 1987). Greene (2007, pp.643) proposes the lags in Newey-West could be $N^{1 / 4}$ where $N$ is the sample size.

\subsection{Data Sources and Descriptive Statistics}

\subsubsection{Data Sources}

Beijing is the capital and second largest city in China. It has been well known for its severe air pollution for many years, due to its basin geographic location, increasing population, limited resources, and heavy pollution in neighboring regions. In order to carry out the abovementioned research, we collected daily food prices, daily AQI numbers, and daily PM2.5 concentration from various sources. 


\section{(1) Air quality measures}

There are many ways to measure air quality. In general, air pollutants are subdivided into criteria and non-criteria air pollutants. The former group includes particulate matter (PM2.5 and PM10), ozone $\left(\mathrm{O}_{3}\right)$, nitrogen dioxide $\left(\mathrm{NO}_{2}\right)$, sulphur dioxide $\left(\mathrm{SO}_{2}\right)$ and carbon monoxide $(\mathrm{CO})$, and most countries have regulated the maximum amount of each criteria pollutant in ambient air. On the other hand, non-criteria air pollutants are much more numerous, but no general maximum levels exist.

The Ministry of Environmental Protection (MEP) in China is responsible for monitoring the level of air pollution. Based on the content of criteria air pollutants, the MEP then calculates the air quality index (AQI), ranging from 0 to 500, and categorizes air quality into six levels: Grade I (Excellent, AQI $\leq 50$ ), Grade II (Good, $50<\mathrm{AQI} \leq 100)$, Grade III (Light Pollution, $100<$ AQI $\leq 150$ ), Grade IV (Medium Pollution, $150<$ AQI $\leq 200$ ), Grade V (Heavy Pollution, $200<$ AQI $\leq 300$ ), and Grade VI (Extremely Heavy Pollution, $300<$ AQI). If air quality is worse than Grade II, it may be harmful to health. The statistics from the National Bureau of Statistics of China show that more than half of the days in Beijing were in fact polluted in recently years.

As the AQI is the most prevalent index used for measuring air quality in China, we take the daily AQI published by the MEP to measure air quality. As these data have been published since 2014, the time frame is from 1 January 2014 to 31 December 2015.

However, for the general public, the AQI calculation is often not understandable, and the accuracy of AQI is frequently questioned by researchers (Ghanem and Zhang 2014). In addition, the AQI is capped at 500, so that the extreme pollution cases, which could significantly affect human behavior, may not be correctly mirrored by this index.

As a comparison, we also use PM2.5 concentration data published by the U.S. Embassy in Beijing ${ }^{35}$ to measure air quality. PM2.5 is a particularly harmful pollutant particle, as it can penetrate deep into the lungs and blood streams, causing severe health damages. The PM2.5 concentration data of the U.S. Embassy in Beijing are an independent measure of air

\footnotetext{
${ }^{35}$ Source: http://www.stateair.net/web/historical/1/1.html.
} 
quality and are believed to be less manipulated. The U.S. Embassy reports hourly air pollution information, so we use the 24-hour average to obtain daily PM2.5 concentrations. To match the daily prices data, the PM2.5 data we used spans three years, from 1 January 2013 to 31 December 2015. However, we find that the trends between AQI and PM2.5 are basically consistent.

\section{(2) Food prices}

We collect daily food prices from Beijing Xinfadi Agricultural Products Wholesale Market ${ }^{36}$. This market is located in southern Beijing, between the $4^{\text {th }}$ and $5^{\text {th }}$ Ring Roads and much of the fresh food supply comes from Hebei and Shandong Province ${ }^{37}$, which are also highly air polluted areas in northern China. This outdoor food market is able to satisfy over 90 per cent of food demand in the city. It bears 70 per cent of the vegetable supply and 80 per cent of super market fruit supply in Beijing. Therefore, the daily commodity trading prices published by Xinfadi is a good reflection of the city's food prices. As Chinese cabbage and tomatoes are particularly popular vegetables in northern China, we specifically shed light on these two products. For comparison, pork (mainly the carcass meat) is also included in the analysis, as more than 60 per cent of consumed meat products in China are made from pork (Yu and Abler 2014). Although Xinfadi Wholesale Market also sporadically reports the prices of other products, they cannot be used in this study due to many missing observations. The trends of the three food prices are presented in Figure 5.1.

\footnotetext{
${ }^{36}$ Beijing Xinfadi Agricultural Products Wholesale Market was established in 1988, and has become the largest professional agri-products wholesale market in Asia. It can handle up to 16000 tons of vegetables, 16000 tons of fruit, more than 3000 pigs, 3000 sheep, 500 cattle, and 1800 tons of aquatic products every day.

${ }^{37}$ In 2014, 20.5\% vegetables sold in Xinfadi came from Hebei province and $19.0 \%$ vegetables were coming from Shandong province. Source: http://www.xinfadi.com.cn/company/cintros.shtml.
} 
A) Chinese Cabbage

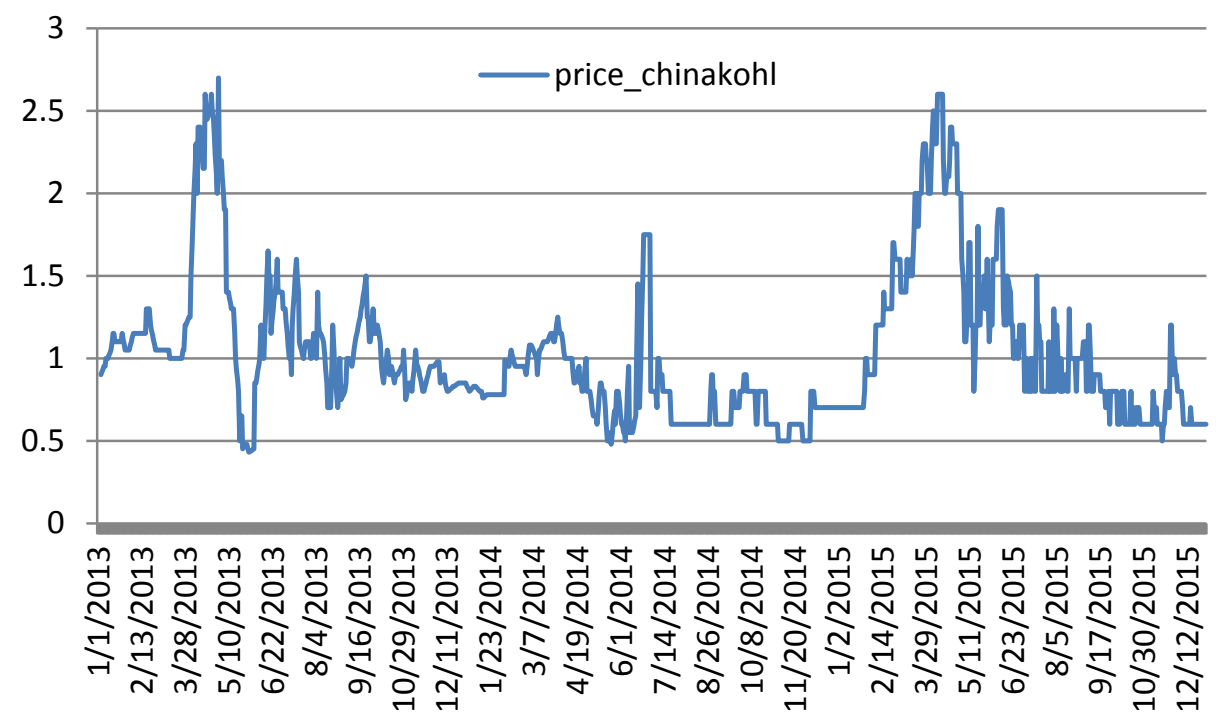

B) Tomato

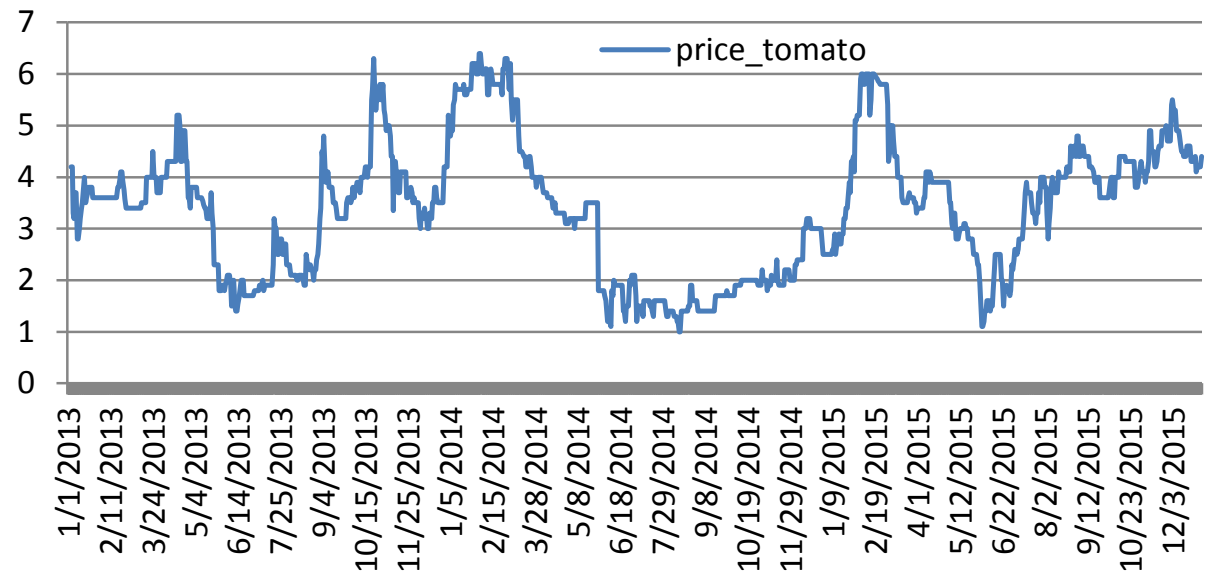

C) Pork

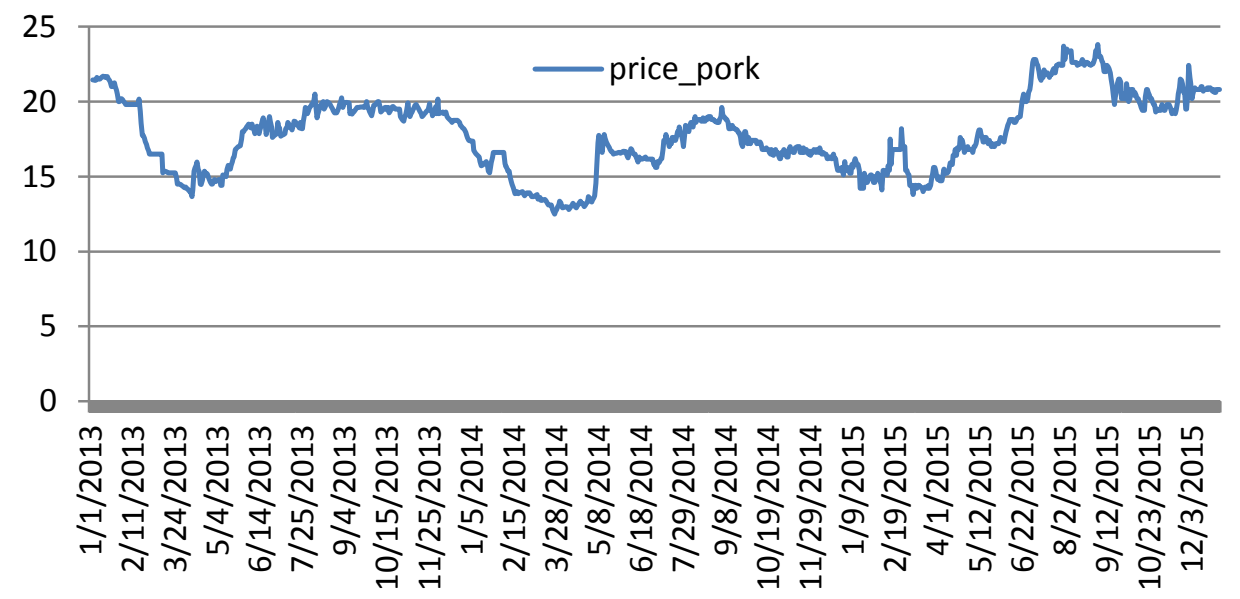

Source: Beijing Xinfadi Agricultural Products Wholesale Market.

Figure5.1 The Trends in Food prices 


\section{(3) Other variables}

Except for pollution, the weather conditions also affect people's outdoor activities. In order to control for these variables, we include temperature (maximum temperature) and precipitation conditions in the regression ${ }^{38}$. Data on minimum daily temperature show similar temporal patterns as the maximum temperature series, and yields similar results to what we find with the maximum temperature, so we do not report these. ${ }^{39}$

Figure 5.1 has demonstrated that food prices show strong seasonality, so do the air pollution indicators. Usually, air pollution reaches high levels in winter seasons due to coal burning for heating and cool weather condition. In order to control for seasonality, we include weekday, month, and year dummies in the econometric models.

It is known that holidays may affect food prices. Hence, a dummy for national holiday is also included.

\footnotetext{
${ }^{38}$ Source: http://www.tianqihoubao.com/lishi/beijing.html.

${ }^{39}$ Source: http://ccm.ytally.com/fileadmin/user_upload/downloads/publications_5th_workshop/Wang_paper.pdf.
} 


\subsubsection{Descriptive Statistics}

Table 5.1 presents the definitions and descriptive statistics of the variables. The average price of Chinese cabbage was 1.02 yuan $/ \mathrm{kg}$, with a standard deviation of 0.44 . Tomatoes had an average price of 3.38 yuan $/ \mathrm{kg}$ and a standard deviation of 1.28 . The pork price was 17.77 yuan $/ \mathrm{kg}$ on average, with a standard deviation of 2.51 . The relatively large deviations show the high volatilities of food prices in Beijing.

Table5.1 Descriptive Analysis of Variables

\begin{tabular}{|c|c|c|c|c|c|c|}
\hline Variable & Obs. & Mean & Std. Dev. & Min & Max & Units/definition \\
\hline \multicolumn{7}{|c|}{ Dependent variable } \\
\hline Price_cabbage $^{\mathrm{a}}$ & 1092 & 1.02 & 0.44 & 0.43 & 2.70 & Chinese cabbage price, yuan $/ \mathrm{kg}$ \\
\hline Price_tomato $^{\mathrm{b}}$ & 1092 & 3.38 & 1.28 & 1.00 & 6.40 & Tomato price, yuan $/ \mathrm{kg}$ \\
\hline Price_pork ${ }^{\mathrm{a}}$ & 1092 & 17.77 & 2.51 & 12.50 & 23.80 & Pork price, yuan $/ \mathrm{kg}$ \\
\hline \multicolumn{7}{|c|}{ Independent variable } \\
\hline $\mathrm{AQI}^{\mathrm{c}}$ & 730 & 125.38 & 76.60 & 23.00 & 485.00 & Daily Air Quality Index \\
\hline $\mathrm{pm} 2.5^{\mathrm{d}}$ & 1095 & 94.00 & 80.43 & 6.08 & 557.31 & Daily PM2.5 Concentrations, $\mu \mathrm{g} / \mathrm{m}^{3}$ \\
\hline $\operatorname{temax}^{\mathrm{e}}$ & 1095 & 18.72 & 11.14 & -6.00 & 39.00 & Daily maximum temperature, ${ }^{\circ} \mathrm{C}$ \\
\hline $\operatorname{rain}^{\mathrm{e}}$ & 1095 & 0.24 & 0.43 & 0 & 1 & Dummy for whether it rains or not \\
\hline holiday & 1095 & 0.08 & 0.26 & 0 & 1 & $\begin{array}{l}\text { Dummy for whether it is a public } \\
\text { holiday or not }\end{array}$ \\
\hline
\end{tabular}

${ }^{a}$ The prices of Chinese cabbage and pork are taken from Chinese Agricultural Information Network ${ }^{40}$. The time frame is from January 4, 2013 to December 31, 2015.

${ }^{\mathrm{b}}$ The price of tomato is taken from the database of Beijing Xinfadi Agricultural Products Wholesale Market ${ }^{41}$.

The time frame is from January 4, 2013 to December 31, 2015.

${ }^{\mathrm{c}}$ The "AQI" is taken from the Ministry of Environmental Protection.

"The "pm2.5" is taken from the U.S. Embassy in Beijing.

e The weather variables, "temax", and "rain" are taken from the network.

During 2014-2015, the average daily AQI was 125.38, with a standard deviation of 76.60. As the national standard for good air quality is an AQI of 100 or less, this reaffirms the severity of air pollution in Beijing.

\footnotetext{
${ }^{40}$ This network is hosted by the Ministry of Agriculture of the P.R. China. Source: http://www.agri.cn/.

${ }^{41}$ Source: http://www.xinfadi.com.cn/marketanalysis/0/list/1.shtml.
} 
Moreover, the average daily PM2.5 concentration was $94.00 \mu \mathrm{g} / \mathrm{m}^{3}$ (standard deviation 80.43) over three years, with highs usually occurring in winter seasons. Given that the national safety standard for PM2.5 is $75 \mu \mathrm{g} / \mathrm{m}^{3}$, this is also evidence for the severe air pollution in Beijing.

\subsubsection{Test for Unit Roots}

If the dependent variables in the ARDL or AR model have unit roots, it would make the model unstable. The augmented Dicky-Fuller test (ADF) is the most prevalent approach in the literature (Dickey and Fuller 1979; Dickey and Fuller 1981; Elliott, Rothenberg and Stock 1996). Table 5.2 reports the unit root test for Chinese cabbage price, tomato price, pork price, AQI and PM2.5 concentration. The results rejected the null hypothesis of existence of unit roots for all variables. Hence, both the ARDL and AR model are legitimate here.

Table5.2 Unit Roots Testa

\begin{tabular}{|c|c|c|c|c|}
\hline & \multicolumn{2}{|c|}{ Augmented Dicky-Fuller test } & $\mathrm{H}_{0}$ : existence of unit roots & \multirow[b]{2}{*}{$10 \%$ Critical Value } \\
\hline & $\mathrm{Z}(\mathrm{t})^{\mathrm{c}}$ & $1 \%$ Critical Value & 5\% Critical Value & \\
\hline Ln(price_cabbage) & $-4.70^{* * *}$ & -2.33 & -1.65 & -1.28 \\
\hline Ln(price_tomato) & $-2.81^{* * *}$ & -2.33 & -1.65 & -1.28 \\
\hline Ln(price_pork) & $-2.08^{* *}$ & -2.33 & -1.65 & -1.28 \\
\hline $\mathrm{AQI} / 100^{\mathrm{b}}$ & $-14.26^{* * * *}$ & -2.33 & -1.65 & -1.28 \\
\hline $\mathrm{pm} 2.5 / 100^{\mathrm{b}}$ & $-17.37^{* * *}$ & -2.33 & -1.65 & -1.28 \\
\hline
\end{tabular}

${ }^{\mathrm{a}}$ These tests aim at level variables and include drift term in regression.

${ }^{\mathrm{b}} \mathrm{AQI}$ and PM2.5 have been rescaled by a factor of $1 / 100$ for better readability.

$\mathrm{c}^{* * * * * *}$, and $^{*}$ denote the significant levels of $1 \%, 5 \%$, and $10 \%$, respectively.

\subsection{Estimation Results and Discussions}

Table 5.3-5.5 present the estimated results of the ARDL and AR models for Chinese cabbage, tomatoes and pork, respectively. The coefficients for time dummies (week, month and year) are not reported due to space limit.

Generally, the AR(1) model performs better in estimating the effects of air pollution on food prices, as all lagged terms for air pollution are not statistically significant. Air pollution 
has immediate negative effects on Chinese cabbage price and tomato price, but has no significant effects on pork price. Moreover, the results between AR(1) and ARDL model are very similar, which mirrors the robustness of our results. The following discussions are based on the results of the AR(1) model.

\section{Chinese cabbage}

Column 2 of Table 5.3 reports the estimation results of the AR(1) model for Chinese cabbages with AQI data. Compared with column 1, the coefficients of all variables are very close, which shows that our results are robust. The price of one-day lag has significant positive effects on present price and the effect is quantitatively large, implying strong price stickiness. Notably, an increase in AQI by 100 units would lead to a 1.19 per cent decrease in Chinese cabbage price. We interpret this as the aggregate effect of air pollution on food demand and supply. Looking back at our theoretical framework, we can infer that the stimulating effect of air pollution on demand is larger than that on supply, so that the price decreases as the severity of air pollution increases. Although the magnitude of the coefficients for air pollution measure does not seem large, the extremely heavy pollution with AQI > 300 could lower vegetable price by 3-5 per cent. This could substantially reduce net income or profit margins of these farmers by 8-13 per cent, as the profit margins of vegetable farmers are around 40 per cent (National Development and Reform Commission 2015, Table 1-21-1). It could also bias CPI statistics and lead to incorrect macroeconomic policies as food expenditure share still remains about 30 per cent in total household expenditure in China $(\mathrm{Yu}$ and Abler 2014; Yu and Abler 2016; Zhou et al. 2015).

As for the weather condition variables (maximum temperature and precipitation dummy) and the holiday variable, their coefficients are all not statistically significant. We attribute this to the seasonal dummy variables.

For comparison, in columns 3 and 4 of Table 5.3, we replace the AQI with the PM2.5 concentration and estimate the $\operatorname{ARDL}(1,1)$ model and the $\operatorname{AR}(1)$ model again, respectively. Consistent with the results of the AQI, the PM2.5 concentration of one period lag does not have a significant effect on Chinese cabbage price, so the AR(1) model is still the best choice. 
Additionally, the outcome of column 4 is very close to that of column 2, reaffirming our abovementioned conclusion. Column 4 shows that an increase in PM2.5 concentration by $100 \mu \mathrm{g} / \mathrm{m}^{3}$ would lead to 0.64 per cent decreases in Chinese cabbage price, and the effect is significant. Consistent with our theory, air pollution could push down both demand and supply, but the plunge of demand is larger than the supply. It eventually pushes down the equilibrium market price.

Table5.3 Empirical Results for Chinese Cabbage Price ${ }^{\text {abc }}$

\begin{tabular}{|c|c|c|c|c|}
\hline & \multicolumn{2}{|c|}{ AQI } & \multicolumn{2}{|c|}{ PM2.5 } \\
\hline & $\operatorname{ARDL}(1,1)$ & $\operatorname{AR}(1)$ & $\operatorname{ARDL}(1,1)$ & $\mathrm{AR}(1)$ \\
\hline \multirow{2}{*}{ L1.( Ln(price_cabbage)) } & $0.8621^{* *}$ & $0.8621^{* *}$ & $0.9001^{* *}$ & $0.9000^{* *}$ \\
\hline & $(0.0247)$ & $(0.0247)$ & $(0.0178)$ & $(0.0178)$ \\
\hline \multirow{2}{*}{$\mathrm{AQI} / 100$ or $\mathrm{pm} 2.5 / 100$} & $-0.0130^{* *}$ & $-0.0119^{* *}$ & $-0.0070^{*}$ & $-0.0064^{*}$ \\
\hline & $(0.0044)$ & $(0.0035)$ & $(0.0030)$ & $(0.0026)$ \\
\hline \multirow{2}{*}{ L1.(AQI/100) or L1.(pm2.5/100) } & 0.0023 & & 0.0012 & \\
\hline & $(0.0055)$ & & $(0.0033)$ & \\
\hline \multirow{2}{*}{ temax } & -0.0007 & -0.0007 & -0.0012 & -0.0012 \\
\hline & $(0.0011)$ & $(0.0011)$ & $(0.0008)$ & $(0.0008)$ \\
\hline \multirow{2}{*}{ rain } & 0.0148 & 0.0150 & 0.0156 & 0.0156 \\
\hline & $(0.0121)$ & $(0.0121)$ & $(0.0093)$ & $(0.0093)$ \\
\hline \multirow{2}{*}{ Holiday } & -0.0195 & -0.0190 & -0.0044 & -0.0046 \\
\hline & $(0.0163)$ & $(0.0160)$ & $(0.0116)$ & $(0.0116)$ \\
\hline Observations & 729 & 730 & 1091 & 1091 \\
\hline \multirow{2}{*}{ F-test for Model Specification } & $F(24,704)$ & $F(23,706)$ & $F(25,1065)$ & $F(24,1066)$ \\
\hline & $=382.71^{* *}$ & $=398.72^{* *}$ & $=747.18^{* *}$ & $=775.52^{* *}$ \\
\hline \multicolumn{5}{|l|}{ Included other explanatory variables } \\
\hline Each day in a week & $\sqrt{ }$ & $\sqrt{ }$ & $\sqrt{ }$ & $\sqrt{ }$ \\
\hline Month & $\sqrt{ }$ & $\sqrt{ }$ & $\sqrt{ }$ & $\sqrt{ }$ \\
\hline Year & $\sqrt{ }$ & $\sqrt{ }$ & $\sqrt{ }$ & $\sqrt{ }$ \\
\hline
\end{tabular}

${ }^{a}$ We only display the regression output of main variables.

${ }^{\mathrm{b}}$ The value in brackets is the Newey-West standard error with lag=6.

$\mathrm{c}^{* * *},{ }^{* *}$, and ${ }^{*}$ denote the significant levels of $1 \%, 5 \%$, and $10 \%$, respectively.

\section{Tomatoes}

Table 5.4 reports the estimation results for tomatoes. As expected, the AR(1) model performs better in estimating the effects of air pollution on tomato price, because the coefficients on $A_{t-1}$ are insignificant in both column 1 and 3. Both coefficients for $A_{t}$ in the AR(1) model (columns 2 and 4) are negative and statistically significant. That is, an increase in AQI by 100 units would lead to a 0.89 per cent decrease in tomato price, while an increase in the PM2.5 concentration by $100 \mu \mathrm{g} / \mathrm{m}^{3}$ would lead to a 0.55 per cent decrease. 
This implies that air pollution has a similar effect on the price of the tomato as on the Chinese cabbage. The explanation is also similar. Air pollution could plunge both demand and supply of tomato, but the magnitude of plunge for demand is larger than supply. Eventually, the market prices go down.

Table5.4 Empirical Results for Tomato Price ${ }^{\text {abc }}$

\begin{tabular}{|c|c|c|c|c|}
\hline & \multicolumn{2}{|c|}{ AQI } & \multicolumn{2}{|c|}{ PM2.5 } \\
\hline & $\operatorname{ARDL}(1,1)$ & $\operatorname{AR}(1)$ & $\operatorname{ARDL}(1,1)$ & $\operatorname{AR}(1)$ \\
\hline \multirow{2}{*}{ L1.( Ln(price_tomato)) } & $0.9667^{* *}$ & $0.9666^{* *}$ & $0.9695^{* *}$ & $0.9695^{* *}$ \\
\hline & $(0.0072)$ & $(0.0072)$ & $(0.0088)$ & $(0.0088)$ \\
\hline \multirow{2}{*}{ AQI/100 or pm2.5/100 } & $-0.0068^{*}$ & $-0.0055^{*}$ & $-0.0093^{*}$ & $-0.0089^{* *}$ \\
\hline & $(0.0030)$ & $(0.0025)$ & $(0.0037)$ & $(0.0028)$ \\
\hline \multirow{2}{*}{ L1.(AQI/100) or L1.(pm2.5/100) } & 0.0027 & & 0.0008 & \\
\hline & $(0.0032)$ & & $(0.0038)$ & \\
\hline \multirow{2}{*}{ temax } & 0.0000 & 0.0000 & 0.0003 & 0.0003 \\
\hline & $(0.0006)$ & $(0.0006)$ & $(0.0008)$ & $(0.0008)$ \\
\hline \multirow{2}{*}{ rain } & 0.0017 & 0.0018 & 0.0004 & 0.0005 \\
\hline & $(0.0052)$ & $(0.0052)$ & $(0.0067)$ & $(0.0067)$ \\
\hline \multirow{2}{*}{ Holiday } & -0.0099 & -0.0102 & -0.0094 & -0.0094 \\
\hline & $(0.0068)$ & $(0.0069)$ & $(0.0067)$ & $(0.0066)$ \\
\hline Observations & 729 & 730 & 1091 & 1091 \\
\hline F-test for Model Specification & $\begin{array}{l}F(24,704) \\
=2387.61^{* *}\end{array}$ & $\begin{array}{l}F(23,706) \\
=2463.00^{* *}\end{array}$ & $\begin{array}{l}F(25,1065) \\
=2156.49^{* *}\end{array}$ & $\begin{array}{l}F(24,1066) \\
=2226.23^{* *}\end{array}$ \\
\hline \multicolumn{5}{|c|}{ Included other explanatory variables } \\
\hline Each day in a week & $\sqrt{ }$ & $\sqrt{ }$ & $\sqrt{ }$ & $\sqrt{ }$ \\
\hline Month & $\sqrt{ }$ & $\sqrt{ }$ & $\sqrt{ }$ & $\sqrt{ }$ \\
\hline Year & $\sqrt{ }$ & $\sqrt{ }$ & $\sqrt{ }$ & $\sqrt{ }$ \\
\hline
\end{tabular}

${ }^{\text {a }}$ We only display the regression output of main variables.

${ }^{\mathrm{b}}$ The value in brackets is the Newey-West standard error with lag=6.

$\mathrm{c}^{* * * * * *}$, and ${ }^{*}$ denote the significant levels of $1 \%, 5 \%$, and $10 \%$, respectively.

\section{Pork}

Table 5.5 reports the effects of air pollution on pork price. Unlike the situation of Chinese cabbage and tomatoes, air pollution seems to have no significant effects on pork price, regardless of the model used. We attribute this difference to the property of meat. First of all, pork can be frozen for future sale, and China's cold storage capacity for meat reached 7 million tons in 2008, with more than 10000 cold storage units across the country ${ }^{42}$. This could imply that air pollution might have negligible effects on pork supply in the short term,

\footnotetext{
${ }^{42}$ Source: http://ccm.ytally.com/fileadmin/user_upload/downloads/publications_5th_workshop/Wang_paper.pdf.
} 
due to a flexible cold storage control system. Second, pork has a relatively longer shelf life, and consumer can chill or freeze pork for future consumption, so the effect of air pollution on daily pork demand is also negligible.

Table5.5 Empirical Results for Pork Price ${ }^{a b c}$

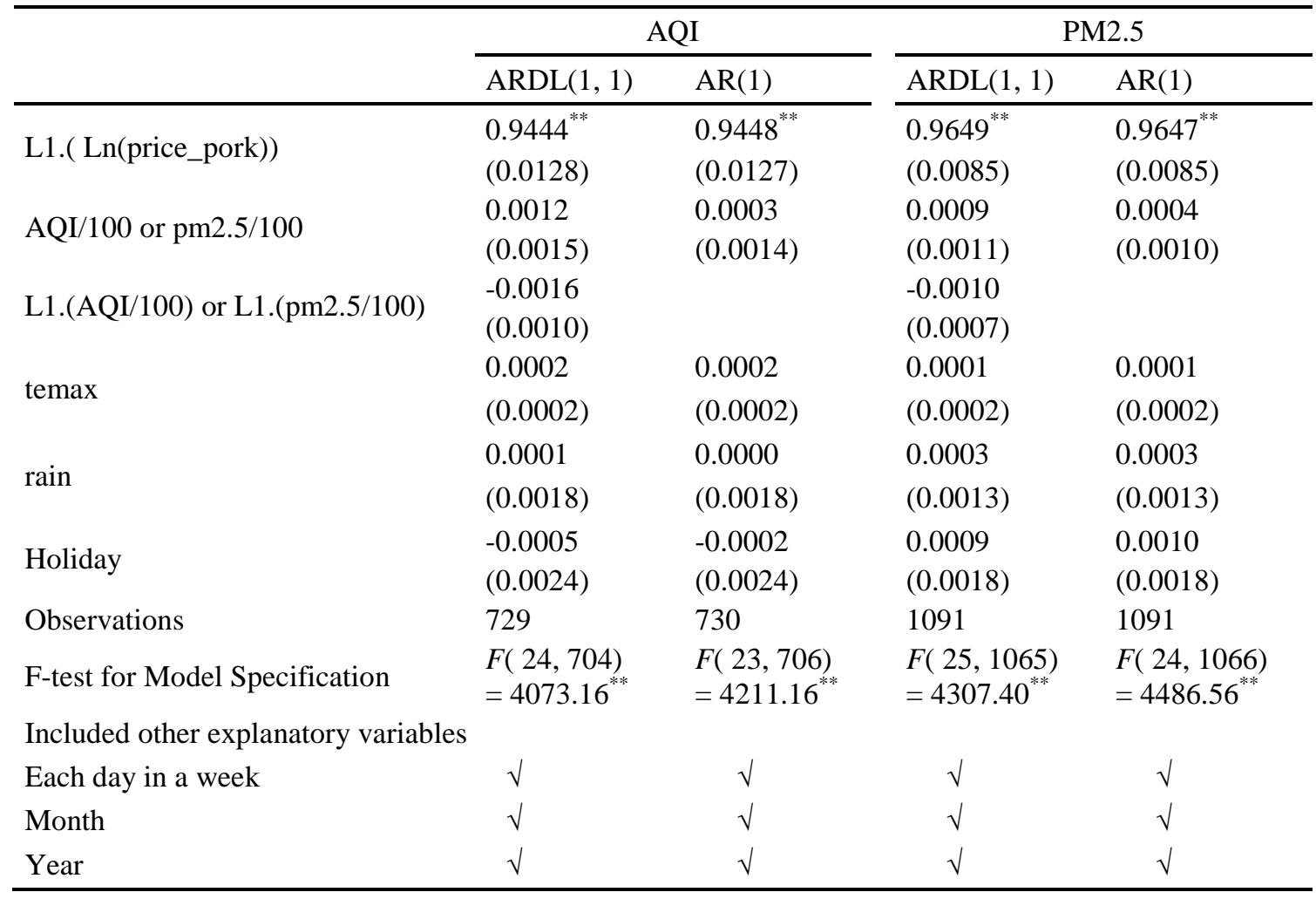

${ }^{\text {a }}$ We only display the regression output of main variables.

${ }^{\mathrm{b}}$ The value in brackets is the Newey-West standard error with lag=6.

$\mathrm{c}^{* * *},{ }^{* *}$, and ${ }^{*}$ denote the significant levels of $1 \%, 5 \%$, and $10 \%$, respectively.

\subsection{Conclusion}

In recent years, air pollution has become one of the top environmental concerns in China. In this study, we first develop a theoretical model based on market equilibrium and then employ econometric tools to evaluate the effects of air pollution on food prices in Beijing, using the wholesale market prices for three major fresh food products consumed in China (Chinese cabbage, tomatoes and pork). We find that air pollution has negative effects on the price of Chinese cabbage and tomatoes, but has no significant effects on pork price in the short term. Specifically, with an increase in AQI by 100 units, the prices for Chinese cabbage and tomatoes decrease by 1.19 and 0.89 per cent, respectively; with an increase in PM2.5 
concentration by $100 \mu \mathrm{g} / \mathrm{m}^{3}$, the prices for Chinese cabbage and tomatoes decreases by 0.64 and 0.55 per cent, respectively.

We interpret these results as the aggregate effect of food demand and supply in response to air pollution, while the stimulating effects on demand and supply are, respectively, determined by natural properties of fresh products, such as shelf life and storability. For instance, fresh vegetables perish relatively quickly and are difficult to preserve, so the supply does not shrink much in the short run. However, when consumers reduce their outdoor activities, the impact on demand could be larger, eventually pushing down their market prices. On the contrary, pork has a longer shelf life and can be frozen for future sale, so the impact of air pollution on the price is insignificant in the short run.

Air pollution can affect social welfares in many dimensions. This study indicates that air pollution decreases prices of fresh vegetables in the short run. Food price volatility is linked to the welfare of both consumers and producers. Even though the magnitude of the coefficients for air pollution measure does not seem substantial, extremely heavy pollution with AQI > 300 still could lower vegetable prices by 2-5 per cent compared to excellent air quality. This could shrink profit margin or net income of vegetable farmers by 5-13 per cent, which is a sizable number, as the profit margin for Chinese vegetable farms is 41 per cent in 2014 (National Development and Reform Commission 2015, Table 1-21-1). It could also alternate CPI statistics and lead to incorrect macroeconomic policies as food expenditure share still remains about 30 per cent in total household expenditure in China ( $\mathrm{Yu}$ and Abler 2016; Yu and Abler 2014; Zhou et al. 2015). Chinese governments are taking different measures to mitigate air pollution and stabilize food prices.

Our main research purpose is to use the market price data to estimate the impact of air pollution. We unfortunately have no household level data to match the time series data, to understand specific behaviors of consumers and suppliers in response to air pollution. It is well known that storage plays important role in food consumption and could mitigate the impacts (Gibson and Kim 2012). We find that the impact of air pollution could differ for different products due to their shelf life length and storability. For instance, there is no significant impact of air pollution on pork price. Our study is to measure the aggregate effect of air pollution, rather than to identify the channels. Air pollution has many channels to affect food prices, which will be our future research. 


\section{Chapter 6 Overall Summary}

Over the past four decades, China has made fruitful achievements in agricultural development, which attracted a great deal of attention within the academy. Meanwhile, Chinese agriculture has also undergone dramatic and continuing structural changes (Chen et al. 2009; Cao and Birchenall 2013), including the spatiotemporal change in crop patterns at the farm stage (Xin et al. 2012) and the structural change in food markets (Qian et al. 2011; Kong 2012). These changes will, no doubt, have impacts on food security, which is essential for political stability and social equity of the country.

In addition, it is in full agreement that economic growth is associated with environmental pollution (Beckerman 1992; de Bruyn, van den Bergh and Opschoor 1998; Selden and Song 1994), and the agricultural development in China is no exception. Nowadays, agriculture has become one prime culprit of air pollution (Erisman et al. 2007; Bauer et al. 2016). In return, air pollution can not only affect plant growth and animal health but also influence both the quantity and quality of agro-inputs in the food supply chain and thereby affect food security indirectly (Sun, Dai, et al. 2017). Therefore, how to ensure food security in a sustainable manner has been becoming a primary concern for both scientists and policymakers.

Inspired by the dramatic structural changes and environmental pollution issues accompanying the rapid agricultural development in China, this study is conducted to estimate the economic returns to fertilizers, to identify the market power for Chinese food industry, and to explore the relationship between air pollution and food security. Specifically, 1) given the fact that China's cropping pattern has been shifting away from cereals and toward vegetables and fruits, we hence shed light on the effects of crop allocation on economic returns to chemical fertilizers in Chinese agriculture; 2) since the 2008 Chinese milk scandal led to an enormous structural change in Chinese dairy industry, we investigate the evolution of market power for Chinese fluid milk industry at the brand level; 3) in order to dig out the potential policy instruments to reduce air pollution while ensuring food security, we review the current literature on the relationship between air pollution and food security from the perspective of the food system; 4) after reviewing previous research, we 
find that there is very limited research addressing the effects of air pollution on food prices, we hence estimate the impact of air pollution on the short run prices of three major fresh food products (Chinese cabbage, tomatoes, and pork) in Beijing, China.

\subsection{General Findings}

In Chapter 2, we first introduce a constrained optimization model and decompose the marginal product of fertilizer into the intensive margin and the extensive margin. According to the law of diminishing marginal returns, for a specific crop, the intensive margin should decline as fertilizer increases. When we take the crop structure change into account, the extensive margin would increase as fertilizer increases. Therefore, if the extensive margin is sufficiently large relative to the intensive margin, it would be possible for the mean marginal value product of fertilizer (MVP) curve to be upward sloping. We hereby propose a hypothesis that the MVP curve, when aggregated across crops, will exhibit a U-shaped pattern as fertilizer use increases. Subsequently, we conduct a simulation analysis and then use farm-level data from Jiangsu Province between 2004 and 2013 to estimate the marginal returns to chemical fertilizers. Fortunately, as we expected, both the simulation analysis and the empirical estimation verify our hypothesis. In particular, we find that the U-shaped curve reaches its lowest point when fertilizer use intensity is around $25 \mathrm{~kg} / \mathrm{mu}$, which is slightly less than the sample mean of $28 \mathrm{~kg} / \mathrm{mu}$.

These results imply that horticultural crops (vegetables and fruits) are gradually becoming the main forces of fertilizer consumption in China. Given the fact that Chinese diets have been shifting away from staples towards vegetables and fruits, the growing demand for vegetables and fruits would definitely boost the expansion of horticultural crops. We hence predict that China's fertilizer consumption will not decrease at least in the short run, which contradicts to the government policy targets of limiting fertilizer use.

In Chapter 3, we propose a simple framework to link the concentration ratio and the Lerner Index and investigate the market power and welfare implications for Chinese fluid milk industry at the brand level after the 2008 Chinese milk formula scandal. Using aggregated supermarket scanner data, we find that the market power was relatively moderate for fluid milk industry in China during 2008-2015. The average markup for top 
five brands (Mengniu, Yili, Bright Dairy, Sanyuan, and Want Want) on Chinese fluid milk was approximately $53 \%$ over the marginal cost, resulting in an annual income transfer of nearly $\$ 2.8$ billion. However, with the increasing aggravation of market competition and government regulation, the power of oligopolies will be weakened in the future. Moreover, the Comparative Static Analysis indicates that low pricing strategy can help firms to gain more market power, which can benefit consumers as well.

In Chapter 4, we find that along the food supply chain, agricultural production, processing, and distribution generate substantial air pollutants, mainly $\mathrm{GHG}, \mathrm{NH}_{3}$, and PM. On average, at the farm stage, overuse of chemical fertilizers and animal husbandry are the largest sources of agricultural emissions. Beyond the farm gate, industrial waste and vehicle exhaust related to food system contribute significantly to air pollution. In return, air pollution not only reduces raw ingredients supply but also obstructs food supply in processing and distribution. Additionally, air pollution may affect consumer behavior in the short run. The impacts of air pollution on consumer demand and food supply would eventually change food price.

Moreover, by evaluating the effects of agricultural policy and energy policy on food security and air pollution, respectively, we conclude that: 1) agricultural intensification can significantly improve agricultural productivity growth but may not conducive to reduce emissions; 2) some agricultural supporting policies that potentially link to production may distort producer decisions, and easily lead to the overuse of farm inputs. At the beginning, it may increase agricultural productivity when agro-inputs are underinvested, whereas it may ultimately reduce productivity and harm the environment when farm inputs are overused; 3) on the contrary, some sustainable farming practices, such as the agri-environmental payment programs in the U.S. and the subsidies for straw recycling in China will enable the farmers to earn a reasonable level of income without damaging the environment; 4) in general, diversion of food crops to biofuels is not available to reduce air pollution, while the application of biomass fuel provides an opportunity for us.

In Chapter 5, we first develop a theoretical model based on market equilibrium and then employ econometric tools to evaluate the effects of air pollution on food prices in Beijing, using the wholesale market prices for three major fresh food products consumed in 
China (Chinese cabbage, tomatoes and pork). We find that air pollution has negative effects on the price of Chinese cabbage and tomatoes, but has no significant effects on pork price in the short term. Specifically, with an increase in AQI by 100 units, the prices for Chinese cabbage and tomatoes decrease by 1.19 and 0.89 per cent, respectively; with an increase in PM2.5 concentration by $100 \mu \mathrm{g} / \mathrm{m} 3$, the prices for Chinese cabbage and tomatoes decreases by 0.64 and 0.55 per cent, respectively.

We interpret these results as the aggregate effect of food demand and supply in response to air pollution, while the stimulating effects on demand and supply are, respectively, determined by natural properties of fresh products, such as shelf life and storability. For instance, fresh vegetables perish relatively quickly and are difficult to preserve, so the supply does not shrink much in the short run. However, when consumers reduce their outdoor activities, the impact on demand could be larger, eventually pushing down their market prices. On the contrary, pork has a longer shelf life and can be frozen for future sale, so the impact of air pollution on the price is insignificant in the short run.

\subsection{Policy Implications and Research Significance}

Food security has long been regarded as one of the highest priorities in national policy agenda, as it is critical to the well-being, especially for populous countries, such as China (Godfray et al. 2010). On the one hand, the population growth and nutritional transition along with accelerated economic growth in China tend to increase the demand for food, particularly for animal-based products (Khan, Hanjra and Mu 2009; Tian and Yu 2015). On the other hand, rapid urbanization has further worsened the shortage of farmland (Chen 2007). Although Chinese government has implemented farmland protection policies, cropland has still continued to decline (Lichtenberg and Ding 2008). In this case, in addition to food imports, the improvement of yields seems to be the only way to address the challenges of food security in China (Xu et al. 2006; Fan et al. 2011).

Traditionally, Chinese government narrowly defined food security as food self-sufficiency (Ghose 2014), implying that Chinese have to feed themselves without relying heavily on foreign countries. To some extent, it exacerbates the pressure on crop yields. To boost agricultural growth, Chinese government has been increasing its financial 
support to the agricultural sector, including various agricultural subsidies and output price supports (Yu and Jensen 2010; Yu and Zhao 2009; Heerink et al. 2006; Huang, Wang and Rozelle 2013). Practically, however, these agricultural policies not only pushed domestic food prices to rise above international prices, but also lead to the overuse of agrochemicals and triggered numerous environmental problems (Huang et al. 2011; Sun et al. 2012).

There is no doubt that global trade in food is essential for every country in the world, especially for China (Headey 2011). China cannot isolate itself from the rest of the world. Moreover, it is evidence that China's food imports have been increasing significantly over the past decades. The official statistics from NBSC indicate that in 2016, China imported more than 3.4 million tons of wheat, 3.6 million tons of rice, and 84 million tons of soybean, reaching its new peak. In other words, if China is rich enough, she can buy enough food from the international market. Hence, we suggest the government should promote economic development and improve the income level of Chinese people rather than doggedly sticking to its food self-sufficiency target. In addition, by virtue of implementation of China's "global land investments" and "One Belt, One Road" strategy to “import” foreign agricultural land, food security will no longer be a problem for China.

Of course, how to increase yield in an environmentally friendly manner is a perennial question in China. Since most of the agrochemicals have been found overused in China (Liu and Huang 2013; Widawsky et al. 1998; Huang et al. 2003; Ma et al. 2014; Zhang, Chen and Vitousek 2013), we hence suggest the government remove its input subsidies and enhance agrochemicals use efficiency (e.g., exploring a cost-efficient fertilization strategies/ spraying pattern). Notably, feminization and aging of the agricultural labor (De Brauw et al. 2008; Bowlus and Sicular 2003; Zhang, De Brauw and Rozelle 2004) have become one of the serious challenges for Chinese agricultural development in recent decades. Therefore, cultivating new-type agricultural management entities, increasing farm size and developing agricultural moderate scale operation, promoting agricultural-production outsourcing service industry, providing specific training and education for farmers, and popularizing advanced techniques to improve technical efficiency (e.g., promoting agricultural machinery usage, breeding and introducing high-yield variety, promoting soil testing and formulated fertilization techniques, and 
developing and popularizing high-efficiency but low-toxicity pesticides) are of primary concern.

According to the definition of food security adopted in 1996 by World Food Summit, food safety is essentially part of food security. Over the past few years, a series of food safety scandals erupted in China due to a lack of supervision and uneven distribution of benefits among players in the food supply chain (Jia and Jukes 2013; Pei et al. 2011), which have reduced the trust of Chinese public in domestic food (Pei et al. 2011; Ortega et al. 2011; Chen 2013; Peng et al. 2015). Meanwhile, agricultural product safety incidents involving pesticide residues or contain traces also forced the government to pay more attention to the food safety issues (Tam and Yang 2005; Liu 2010; Jia and Jukes 2013; Yan 2012). In this case, supporting the development of new-type agricultural management entities, encouraging the vertical integration of food supply chain, and constructing a food traceability system can not only improve product quality and ensure food safety at the source but also increase farmers' market power and thereby boost their income.

Last but not the least, to be honest, most of the achievements made by China's agriculture is coming at the cost of environmental deterioration. Nowadays, Chinese government has been aware of the importance of agricultural sustainability and repeatedly emphasized the necessity of developing green agriculture and promoting the green production mode (Sanders 2006). In specific, we suggest the government to provide financial assistance for promoting organic fertilizers and biological control, so that we can achieve zero growth in the use of chemical fertilizers and pesticides. To restore soil fertility and protect forests, the government should advocate crop rotation and fallow systems and strive to adhere to its "Forest Protection Program" and the "Returning Farmland to Forest/ Grassland Program". Moreover, it is evidence that using agricultural residues as feedstock to produce biofuel does not burden land use, while it can avoid air pollution due to combustion (Sarkar et al. 2012; Searchinger et al. 2008). Therefore we suggest the government should promote no-tillage and straw returning methods to facilitate sustainable agricultural production. 


\subsection{Limitations}

In Chapter 2, we do not address potential inefficiencies in fertilizer use on one specific crop production. A second caveat is that we do not examine environmental externalities from fertilizer use. Additional research is needed on socially optimal levels of fertilizer use in China accounting for environmental externalities, levels which may be much different from those that maximize on-farm economic efficiency. Finally, our results are for chemical fertilizer as a whole; we do not disaggregate fertilizer by active ingredients or by the timing of fertilizer applications.

Moreover, we have to highlight that, in Chapter 3, due to lack of data on wholesale price at the brand level, we regard the retailer and dairy processing enterprises as a whole to analyze. Consequently, the markup we estimated is an upper bound estimate. In addition, we suppose that incumbent firms compete a la Bertrand. Practically, however, it is possible that firms may engage in Stackelberg competition, as retail prices of dairy products are usually set by large firms (Guo et al. 2016). Therefore, additional research is needed on exploring the degree of market power for Chinese dairy industry under different "nature" of competition. Finally, we do not address the heterogeneity in the marginal utility of income for consumers. Further studies can adopt the random coefficients model to tackle this issue.

In Chapter 5, we unfortunately have no household-level data to match the time series data, to understand specific behaviors of consumers and suppliers in response to air pollution in the short-term. We hence cannot identify the channels that air pollution affects food prices. In addition, we propose a hypothesis in Chapter 4 that air pollution may have a minor impact on food demand but may cause a considerable reduction in food supply, so that it may increase food price in the long-term. However, due to lack of data, we cannot verify it in this study. 



\section{Bibliography}

Abdel-Aty, M., A.A. Ekram, H. Huang, and K. Choi. 2011. "A study on crashes related to visibility obstruction due to fog and smoke." Accident Analysis and Prevention 43(5):1730-1737.

Aber, J., W. McDowell, K. Nadelhoffer, A. Magill, G. Berntson, M. Kamakea, S. McNulty, W. Currie, L. Rustad, and I. Fernandez. 1998. "Nitrogen saturation in temperate forest ecosystems." BioScience 48(11):921-934.

Abu-Allaban, M., J.A. Gillies, A.W. Gertler, R. Clayton, and D. Proffitt. 2003. "Tailpipe, resuspended road dust, and brake-wear emission factors from on-road vehicles." In Atmospheric Environment. pp. 5283-5293.

Ackerberg, D., K. Caves, and G. Frazer. 2006. "Structural identification of production functions."

Adhvaryu, A., N. Kala, and A. Nyshadham. 2014. "Management and shocks to worker productivity: evidence from air pollution exposure in an Indian garment factory." Unpublished Working Paper, University of Michigan.

Agnew, M.D., and J.E. Thornes. 1995. "The weather sensitivity of the UK food retail and distribution industry." Meteorological Applications 2(2):137-147.

Agrawal, M., B. Singh, M. Rajput, F. Marshall, and J.N.B. Bell. 2003. "Effect of air pollution on peri-urban agriculture : a case study." Environmental Pollution 126(3):323-329.

Aguirregabiria, V. 2012. Empirical Industrial Organization: Models, Methods, and Applications.

Ajanovic, A. 2011. "Biofuels versus food production: Does biofuels production increase food prices?" Energy 36(4):2070-2076.

Allender, W.J., and T.J. Richards. 2010. "Market Diversion and Market Power: California Eggs." Review of Industrial Organization 36(1):37-58.

Alloway, B.J. 2013. "Sources of heavy metals and metalloids in soils." In Heavy metals in soils. Springer, pp. 11-50.

Anderson, K., and S. Nelgen. 2012. "Trade Barrier Volatility and Agricultural Price Stabilization." World Development 40(1):36-48.

Aneja, V.P., W.H. Schlesinger, and J.W. Erisman. 2009. "Effects of agriculture upon the air quality and climate: Research, policy, and regulations."

Aneja, V.P., W.H. Schlesinger, and J.W. Erisman. 2008. "Farming pollution." Nature Geoscience 1(7):409. 
Aoun, M., A.G. El Samrani, B.S. Lartiges, V. Kazpard, and Z. Saad. 2010. "Releases of phosphate fertilizer industry in the surrounding environment: Investigation on heavy metals and polonium-210 in soil." Journal of Environmental Sciences 22(9):1387-1397.

Appelbaum, E. 1982. "The estimation of the degree of oligopoly power." Journal of Econometrics 19(2-3):287-299.

Arellano, M., and S. Bond. 1991. "Some tests of specification for panel data: Monte Carlo evidence and an application to employment equations." The review of economic studies 58(2):277-297.

Arellano, M., and O. Bover. 1995. "Another look at the instrumental variable estimation of error-components models." Journal of econometrics 68(1):29-51.

Armenta, S., and M. de la Guardia. 2016. "Pesticide Industries Air Quality." Comprehensive Analytical Chemistry 73:655-682.

Arslan, S., A. Aybek, and H.C. Ekerbicer. 2010. "Measurement of personal PM10, PM2. 5 and PM1 exposures in tractor and combine operations and evaluation of health disturbances of operators." Journal of Agricultural Sciences 16:104-115.

Ashenfelter, O., and D. Sullivan. 1987. "Nonparametric tests of market structure: An application to the cigarette industry." The Journal of Industrial Economics:483-498.

Astrakianakis, G., N.S. Seixas, R. Ray, J.E. Camp, D.L. Gao, Z. Feng, W. Li, K.J. Wernli, E.D. Fitzgibbons, and D.B. Thomas. 2007. "Lung cancer risk among female textile workers exposed to endotoxin." Journal of the National Cancer Institute 99(5):357-364.

Australian Government Productivity Commission. 2014. "Relative Costs of Doing Business in Australia: Dairy Product Manufacturing."

Avnery, S., D.L. Mauzerall, J. Liu, and L.W. Horowitz. 2011. "Global crop yield reductions due to surface ozone exposure: 1. Year 2000 crop production losses and economic damage." Atmospheric Environment 45(13):2284-2296.

Azzam, A.M., and E. Pagoulatos. 1990. "Testing oligopolistic and oligopsonistic behaviour: an application to the us meat - packing industry.” Journal of Agricultural Economics 41(3):362-370.

Bai, J., T.I. Wahl, and J.J. McCluskey. 2008. "Fluid milk consumption in urban Qingdao, China." Australian Journal of Agricultural and Resource Economics 52(2):133-147.

Baldi, I., P. Lebailly, B. Mohammed-Brahim, L. Letenneur, J.-F. Dartigues, and P. Brochard. 2003. "Neurodegenerative diseases and exposure to pesticides in the elderly." American journal of epidemiology 157(5):409-414.

Baligar, V.C., and O.L. Bennett. 1986. "Outlook on fertilizer use efficiency in the tropics." Fertilizer Research 10(1):83-96. 
Baligar, V.C., N.K. Fageria, and Z.L. He. 2001. "Nutrient use efficiency in plants." Communications in Soil Science and Plant Analysis 32(7-8):921-950.

Bang, K.M., D.N. Weissman, G.A. Pinheiro, V. Antao, J.M. Wood, and G. Syamlal. 2006. "Twenty three years of hypersensitivity pneumonitis mortality surveillance in the United States." American journal of industrial medicine 49(12):997-1004.

Banse, M., H. van Meijl, A. Tabeau, and G. Woltjer. 2008. "Will EU biofuel policies affect global agricultural markets?" European Review of Agricultural Economics 35(2):117-141.

Bao, Z., W. Wu, H. Liu, H. Chen, and S. Yin. 2014. "Impact of long-term irrigation with sewage on heavy metals in soils, crops, and groundwater - A case study in Beijing." Polish Journal of Environmental Studies 23(2):309-318.

Bauer, S.E., K. Tsigaridis, and R. Miller. 2016. "Significant atmospheric aerosol pollution caused by world food cultivation." Geophysical Research Letters 43(10):5394-5400.

Bayes, A.M., K.A. Parton, and R.R. Piggott. 1985. "Combined price support and fertilizer subsidy policies for food self-sufficiency." Food Policy 10(3):225-236.

Beckerman, W. 1992. "Economic growth and the environment: Whose growth? whose environment?" World Development 20(4):481-496.

Bedos, C., P. Cellier, R. Calvet, E. Barriuso, and B. Gabrielle. 2002. "Mass transfer of pesticides into the atmosphere by volatilization from soils and plants: overview." Agronomie 22(1):21-33.

Bellarby, J., B. Foereid, and A. Hastings. 2008. "Cool farming: Climate impacts of agriculture and mitigation potential."

Bentley, J.W. 1987. "Economic and Ecological Approaches to Land Fragmantation: In Defense of A Much-Maligned Phenomenon." Annual Review of Anthropology 16:31-67.

Van den Berg, F., R. Kubiak, W.G. Benjey, M.S. Majewski, S.R. Yates, G.L. Reeves, J.H. Smelt, and A.M.A. Van der Linden. 1999. "Emission of pesticides into the air." In Fate of Pesticides in the Atmosphere: Implications for Environmental Risk Assessment. Springer, pp. 195-218.

Bhuyan, S., and R.A. Lopez. 1997. "Oligopoly power in the food and tobacco industries." American Journal of Agricultural Economics:1035-1043.

Bidleman, T.F. 1999. "Atmospheric transport and air-surface exchange of pesticides.” Water, Air, and Soil Pollution 115(1-4):115-166.

Blanc, P.D., and K. Toren. 1999. "How much adult asthma can be attributed to occupational factors?" American Journal of Medicine 107(6):580-587.

Blarel, B., P. Hazell, F. Place, and J. Quiggin. 1992. "The economics of farm fragmentation: evidence from Ghana and Rwanda." The World Bank Economic Review 6(2):233-254. 
Bloomfield, J.P., R.J. Williams, D.C. Gooddy, J.N. Cape, and P. Guha. 2006. "Impacts of climate change on the fate and behaviour of pesticides in surface and groundwater-a UK perspective." Science of the Total Environment 369(1-3):163-177.

Blundell, R., and S. Bond. 2000. "GMM estimation with persistent panel data: an application to production functions." Econometric reviews 19(3):321-340.

Blundell, R., and S. Bond. 1998. "Initial conditions and moment restrictions in dynamic panel data models." Journal of econometrics 87(1):115-143.

Bonnet, C., and M. Simioni. 2001. "Assessing consumer response to Protected Designation of Origin labelling: a mixed multinomial logit approach.” European Review of Agricultural Economics 28(4):433-449.

Bouwman, A.F., L.J.M. Boumans, and N.H. Batjes. 2002. "Emissions of N2O and NO from fertilized fields: Summary of available measurement data." Global Biogeochemical Cycles 16(4).

Bowlus, A.J., and T. Sicular. 2003. "Moving toward markets? Labor allocation in rural China.” Journal of Development Economics 71(2):561-583.

Brasington, D.M., and D. Hite. 2005. "Demand for environmental quality : a spatial hedonic analysis." Regional science and urban economics 35(1):57-82.

De Brauw, A., Q. Li, C. Liu, S. Rozelle, and L. Zhang. 2008. "Feminization of agriculture in China? Myths surrounding women's participation in farming." The China Quarterly 194:327-348.

Bremner, J.M., and A.M. Blackmer. 1978. "Nitrous oxide: emission from soils during nitrification of fertilizer nitrogen.” Science 199(4326):295-296.

Bresnahan, B.W., M. Dickie, and S. Gerking. 1997. "Averting Behavior and Urban Air Pollution." 73(3):340-357.

Bresnahan, T.F. 1989. "Chapter 17 Empirical studies of industries with market power." Handbook of Industrial Organization 2:1011-1057.

Bresnahan, T.F. 1982. "The oligopoly solution concept is identified." Economics Letters 10(1-2):87-92.

Brümmer, B., T. Glauben, and W. Lu. 2006. "Policy reform and productivity change in Chinese agriculture: A distance function approach." Journal of Development Economics 81(1):61-79.

Brunekreef, B., and S.T. Holgate. 2002. "Air pollution and health.” The lancet 360(9341):1233-1242.

de Bruyn, S.., J.C.J.. van den Bergh, and J.. Opschoor. 1998. "Economic growth and emissions: reconsidering the empirical basis of environmental Kuznets curves." Ecological Economics 25(2):161-175.

Burholt, V., and C. Dobbs. 2012. "Research on rural ageing: Where have we got to and where are we going in Europe?" Journal of rural studies 28(4):432-446. 
Burney, J.A., S.J. Davis, and D.B. Lobell. 2010. "Greenhouse gas mitigation by agricultural intensification." Proceedings of the national Academy of Sciences 107(26):12052-12057.

Cambra-López, M., A.J.A. Aarnink, Y. Zhao, S. Calvet, and A.G. Torres. 2010. "Airborne particulate matter from livestock production systems: A review of an air pollution problem." Environmental pollution 158(1):1-17.

Cambra-López, M., T. Hermosilla, H.T.L. Lai, A.J.A. Aarnink, and N.W.M. Ogink. 2011. "Particulate matter emitted from poultry and pig houses: source identification and quantification." Transactions of the ASABE 54(2):629-642.

Cao, K.H., and J.A. Birchenall. 2013. "Agricultural productivity, structural change, and economic growth in post-reform China." Journal of Development Economics 104:165-180.

Capps, O., S.-C. Seo, and J.P. Nichols. 1997. "On the estimation of advertising effects for branded products: An application to spaghetti sauces.” Journal of Agricultural and Applied Economics 29(02):291-302.

Carlsson-Kanyama, A. 1998. "Climate change and dietary choices - how can emissions of greenhouse gases from food consumption be reduced?" Food Policy 23(3-4):277-293.

Carpentier, A., and E. Letort. 2011. "Accounting for heterogeneity in multicrop micro-econometric models: implications for variable input demand modeling." American journal of agricultural economics 94(1):209-224.

Carpentier, A., and R.D. Weaver. 1997. "Damage control productivity: why econometrics matters." American journal of agricultural economics 79(1):47-61.

Carvalheiro, M.F., M.J. Gomes, O. Santos, G. Duarte, J. Henriques, B. Mendes, A. Marques, and R. Ávila. 1994. "Symptoms and exposure to endotoxin among brewery employees." American journal of industrial medicine 25(1):113-115.

Catão, L.A.V., and R. Chang. 2015. "World food prices and monetary policy." Journal of Monetary Economics 75:69-88.

Chang, T., J.G. Zivin, T. Gross, and M. Neidell. 2016. "Particulate pollution and the productivity of pear packers." American Economic Journal (Economic Policy) 8:141-169.

Chen, G., X. Wan, G. Yang, and X. Zou. 2015. "Traffic - related air pollution and lung cancer: A meta - analysis." Thoracic cancer 6(3):307-318.

Chen, G.Q., and B. Zhang. 2010. "Greenhouse gas emissions in China 2007: inventory and input-output analysis." Energy Policy 38(10):6180-6193.

Chen, I.-C., J.K. Hill, R. Ohlemüller, D.B. Roy, and C.D. Thomas. 2011. "Rapid range shifts of species associated with high levels of climate warming." Science 333(6045):1024-1026. 
Chen, J. 2007. "Rapid urbanization in China: A real challenge to soil protection and food security." Catena 69(1):1-15.

Chen, J., Y. Huang, and Y. Tang. 2011. "Quantifying economically and ecologically optimum nitrogen rates for rice production in south-eastern China." Agriculture, ecosystems \& environment 142(3):195-204.

Chen, W. 2013. "The effects of different types of trust on consumer perceptions of food safety: An empirical study of consumers in Beijing Municipality, China." China Agricultural Economic Review 5(1):43-65.

Chen, Y., A. Ebenstein, M. Greenstone, and H. Li. 2013. "Evidence on the impact of sustained exposure to air pollution on life expectancy from China's Huai River policy." Proceedings of the National Academy of Sciences 110(32):12936-12941.

Chen, Y., X. Li, Y. Tian, and M. Tan. 2009. "Structural change of agricultural land use intensity and its regional disparity in China." Journal of Geographical Sciences 19(5):545.

Chen, Y., C. Wang, and Z. Wang. 2005. "Residues and source identification of persistent organic pollutants in farmland soils irrigated by effluents from biological treatment plants.” Environment International 31(6):778-783.

Chen, Y., and X. Yu. 2018. "Does the centralized slaughtering policy create market power for pork industry in China?" China Economic Review.

Chen, Z., W.E. Huffman, and S. Rozelle. 2009. "Farm technology and technical efficiency: Evidence from four regions in China." China Economic Review 20(2):153-161.

Chidmi, B., R.A. Lopez, and R.W. Cotterill. 2005. "Retail oligopoly power, dairy compact, and Boston milk prices." Agribusiness 21(4):477-491.

Christoforidis, A., and N. Stamatis. 2009. "Heavy metal contamination in street dust and roadside soil along the major national road in Kavala's region, Greece." Geoderma 151(3):257-263.

Claassen, R., A. Cattaneo, and R. Johansson. 2008. "Cost-effective design of agri-environmental payment programs: U.S. experience in theory and practice." Ecological Economics 65(4):737-752.

Clapp, J. 2009. "Food Price Volatility and Vulnerability in the Global South: considering the global economic context." Third World Quarterly 30(6):1183-1196.

Clarke, R., and S.W. Davies. 1982. "Market structure and price-cost margins." Economica 49(195):277-287.

Clawson, M. 1963. “Aging farmers and agricultural policy.” Journal of Farm Economics 45(1):13-30. 
Cole, C. V, J. Duxbury, J. Freney, O. Heinemeyer, K. Minami, A. Mosier, K. Paustian, N. Rosenberg, N. Sampson, and D. Sauerbeck. 1997. "Global estimates of potential mitigation of greenhouse gas emissions by agriculture." Nutrient cycling in Agroecosystems 49(1):221-228.

Colliver, B.B., and T. Stephenson. 2000. "Production of nitrogen oxide and dinitrogen oxide by autotrophic nitrifiers." Biotechnology advances 18(3):219-232.

Da Conceicao, F.T., and D.M. Bonotto. 2006. "Radionuclides, heavy metals and fluorine incidence at Tapira phosphate rocks, Brazil, and their industrial (by) products.” Environmental Pollution 139(2):232-243.

Conley, T.G., and C.R. Udry. 2010. "Learning about a new technology: Pineapple in Ghana." The American Economic Review 100(1):35-69.

Conrad, R. 1996. "Soil microorganisms as controllers of atmospheric trace gases (H2, CO, CH4, OCS, N2O, and NO)." Microbiological reviews 60(4):609-640.

Cotterill, R.W. 1994. Scanner data: new opportunities for demand and competitive strategy analysis. Citeseer.

Cowling, K., and M. Waterson. 1976. "Price-cost margins and market structure." Economica 43(171):267-274.

Crittenden, P.D., and D.J. Read. 1978. "The effects of air pollution on plant growth with special reference to sulphur dioxide." New Phytologist 80(1):49-62.

Cromwell, G.L. 2002. "Why and how antibiotics are used in swine production." Animal biotechnology 13(1):7-27.

Cross, J. V, P.J. Walklate, R.A. Murray, and G.M. Richardson. 2001. "Spray deposits and losses in different sized apple trees from an axial fan orchard sprayer: 1. Effects of spray liquid flow rate." Crop Protection 20(1):13-30.

Cui, J., H. Lapan, and G. Moschini. 2016. "Productivity, export, and environmental performance: air pollutants in the United States." American Journal of Agricultural Economics 98(2):447-467.

Cui, Z., G. Wang, S. Yue, L. Wu, W. Zhang, F. Zhang, and X. Chen. 2014. "Closing the N-use efficiency gap to achieve food and environmental security." Environmental science \& technology 48(10):5780-5787.

D’Angiola, A., L.E. Dawidowski, D.R. Gómez, and M. Osses. 2010. “On-road traffic emissions in a megacity." Atmospheric Environment 44(4):483-493.

Dai, J.W., and X.Q. Wang. 2014. "Is China's dairy processing industry oligopolistic and/or oligopsonistic?" China Agricultural Economic Review 6(4):644-653. 
Davidson, E.A. 2009. "The contribution of manure and fertilizer nitrogen to atmospheric nitrous oxide since 1860." Nature Geoscience 2(9):659.

Davis, S., and H. Bartlett. 2008. "Healthy ageing in rural Australia: Issues and challenges." Australasian Journal on Ageing 27(2):56-60.

Deininger, K., S. Jin, F. Xia, and J. Huang. 2014. "Moving Off the Farm: Land Institutions to Facilitate Structural Transformation and Agricultural Productivity Growth in China." World Development 59:505-520.

Demers, P.A., K. Teschke, and S.M. Kennedy. 1997. "What to do about softwood? A review of respiratory effects and recommendations regarding exposure limits." American journal of industrial medicine 31(4):385-398.

Dewbre, J., J. Antón, and W. Thompson. 2001. "The transfer efficiency and trade effects of direct payments." American journal of agricultural economics 83(5):1204-1214.

Dickey, D.A., and W.A. Fuller. 1979. "Distribution of the estimators for autoregressive time series with a unit root." Journal of the American Statistical Association 74(366):427-431.

Dickey, D.A., and W.A. Fuller. 1981. "Likelihood Ratio Statistics for Autoregressive Time Series with a Unit Root.” Econometrica 49(4):1057-1072.

Van Dijk, T. 2003. "Scenarios of Central European land fragmentation." Land use policy 20(2):149-158.

Dinham, B. 2003. "Growing vegetables in developing countries for local urban populations and export markets: problems confronting small - scale producers.” Pest Management Science 59(5):575-582.

Donald, P.F., G. Pisano, M.D. Rayment, and D.J. Pain. 2002. “The common agricultural policy, EU enlargement and the conservation of Europe's farmland birds." Agriculture, Ecosystems and Environment 89(3):167-182.

Dong, D., and B. Gould. 2007. "Product quality and the demand for food: the case of urban China." China's Agricultural Trade: Issues and Prospects:249-279.

Dong, F. 2006. "The outlook for Asian dairy markets: The role of demographics, income, and prices." Food Policy 31(3):260-271.

Donham, K.J. 1991. "Association of environmental air contaminants with disease and productivity in swine." American journal of veterinary research 52(10):1723-1730.

Donham, K.J. 2010. "Community and occupational health concerns in pork production: A review." Journal of animal science 88(13):E102-E111.

Donham, K.J. 2000. "The concentration of swine production. Effects on swine health, productivity, human health, and the environment." The Veterinary clinics of North America. Food animal practice 16(3):559-597. 
Donham, K.J., L.J. Scallon, W. Popendorf, M.W. Treuhaft, and R.C. Roberts. 1986. "Characterization of dusts collected from swine confinement buildings." The American Industrial Hygiene Association Journal 47(7):404-410.

Dorward, A., and E. Chirwa. 2011. "The Malawi agricultural input subsidy programme: 2005/06 to 2008/09." International journal of agricultural sustainability 9(1):232-247.

Draganska, M., and D. Klapper. 2007. "Retail environment and manufacturer competitive intensity." Journal of Retailing 83(2):183-198.

Druska, V., and W.C. Horrace. 2004. "Generalized moments estimation for spatial panel data: Indonesian rice farming.” American Journal of Agricultural Economics 86(1):185-198.

Du, S., B. Lu, F. Zhai, and B.M. Popkin. 2002. "A new stage of the nutrition transition in China." Public health nutrition 5(1a):169-174.

Duflo, E., M. Kremer, and J. Robinson. 2008. "How high are rates of return to fertilizer? Evidence from field experiments in Kenya." American Economic Review 98(2):482-488.

Duflo, E., M. Kremer, and J. Robinson. 2011. "Nudging farmers to use fertilizer: Theory and experimental evidence from Kenya." The American Economic Review 101(6):2350-2390.

Dyer, J.A., and R.L. Desjardins. 2006. "Carbon dioxide emissions associated with the manufacturing of tractors and farm machinery in Canada." Biosystems Engineering 93(1):107-118.

Ebenstein, A., J. Zhang, M.S. McMillan, and K. Chen. 2011. "Chemical fertilizer and migration in China." National Bureau of Economic Research.

Elbaz, A., C. Levecque, J. Clavel, J. Vidal, F. Richard, P. Amouyel, A. Alpérovitch, M. Chartier Harlin, and C. Tzourio. 2004. "CYP2D6 polymorphism, pesticide exposure, and Parkinson's disease." Annals of neurology 55(3):430-434.

Elenbaas-Thomas, A.M., L.Y. Zhao, Y. Hyun, X. Wang, B. Anderson, G.L. Riskowski, M. Ellis, and A.J. Heber. 2005. "Effects of room ozonation on air quality and pig performance." Transactions of the ASAE 48(3):1167-1173.

Elliott, G., T.J. Rothenberg, and J.H. Stock. 1996. "Efficient Tests for an Autoregressive Unit Root." Econometrica 64(4):813-836.

Emberson, L., M. Ashmore, and F. Murray. 2003. Air pollution impacts on crops and forests: a global assessment. World Scientific.

Erisman, J.W., A. Bleeker, J. Galloway, and M.S. Sutton. 2007. "Reduced nitrogen in ecology and the environment." Environmental pollution 150(1):140-149.

Erisman, J.W., A. Bleeker, A. Hensen, and A. Vermeulen. 2008. "Agricultural air quality in Europe and the future perspectives." Atmospheric Environment 42(14):3209-3217. 
Evans, G.W., and S. V Jacobs. 1981. "Air pollution and human behavior." Journal of Social Issues 37(1):95-125.

Fan, M., J. Shen, L. Yuan, R. Jiang, X. Chen, W.J. Davies, and F. Zhang. 2011. "Improving crop productivity and resource use efficiency to ensure food security and environmental quality in China." Journal of experimental botany 63(1):13-24.

Fan, S. 1991. "Effects of technological change and institutional reform on production growth in Chinese agriculture.” American Journal of Agricultural Economics 73(2):266-275.

Fan, S., A. Gulati, and S. Thorat. 2008. "Investment, subsidies, and pro - poor growth in rural India." Agricultural Economics 39(2):163-170.

Fan, S., P. Hazell, and S. Thorat. 2000. "Government spending, growth and poverty in rural India." American Journal of Agricultural Economics 82(4):1038-1051.

Fan, S., and P.G. Pardey. 1997. "Research, productivity, and output growth in Chinese agriculture." Journal of Development Economics 53(1):115-137.

Fan, S., E.J. Wailes, and G.L. Cramer. 1995. "Household demand in rural China: a two-stage LES-AIDS model." American Journal of Agricultural Economics 77(1):54-62.

FAO. 2001. "Global estimates of gaseous emissions of NH3 , NO and N2O from agricultural land."

FAO. 2009. "How to Feed the World in 2050."

FAO. 2013. World Livestock 2013: changing disease landscapes. Food and Agriculture Organization of the United Nations (FAO).

Fenger, J. 2009. “Air pollution in the last 50 years - From local to global.” Atmospheric Environment 43(1):13-22.

Fierer, N., and R.B. Jackson. 2006. "The diversity and biogeography of soil bacterial communities." Proceedings of the National Academy of Sciences of the United States of America 103(3):626-631.

Fishwick, D., L.J. Allan, A. Wright, and A.D. Curran. 2001. "Assessment of exposure to organic dust in a hemp processing plant." Annals of Occupational Hygiene 45(7):577-583.

Fleming, P. 2017. "Agricultural Cost Sharing and Water Quality in the Chesapeake Bay: Estimating Indirect Effects of Environmental Payments." American Journal of Agricultural Economics 99(5):1208-1227.

Foley, J.A., R. DeFries, G.P. Asner, C. Barford, G. Bonan, S.R. Carpenter, F.S. Chapin, M.T. Coe, G.C. Daily, and H.K. Gibbs. 2005. "Global consequences of land use." science 309(5734):570-574.

Foltz, J.D. 2004. "Entry, exit, and farm size: assessing an experiment in dairy price policy." American Journal of Agricultural Economics 86(3):594-604. 
Forster, H.W., B. Crook, B.W. Platts, J. Lacey, and M.D. Topping. 1989. "Investigation of organic aerosols generated during sugar beet slicing." The American Industrial Hygiene Association Journal 50(1):44-50.

Fraser, R.W. 1991. "PRICE - SUPPORT EFFECTS ON EC PRODUCERS." Journal of Agricultural Economics 42(1):1-10.

Freire, C., and S. Koifman. 2012. "Pesticide exposure and Parkinson's disease: Epidemiological evidence of association." NeuroToxicology 33(5):947-971.

Friel, S., A.D. Dangour, T. Garnett, K. Lock, Z. Chalabi, I. Roberts, A. Butler, C.D. Butler, J. Waage, A.J. McMichael, and A. Haines. 2009. "Public health benefits of strategies to reduce greenhouse-gas emissions: food and agriculture.” The Lancet 374(9706):2016-2025.

Fuller, F., J. Huang, H. Ma, and S. Rozelle. 2006. "Got milk? The rapid rise of China's dairy sector and its future prospects." Food Policy 31(3 SPEC. ISS.):201-215.

Fuller, F., S. Rozelle, J. Beghin, and D. Hu. 2004. "China's dairy market: survey results for consumer demand and supply characteristics." Center for Agricultural Development, Iowa State University, Staff Paper (04-SR):99.

Fuller, F.H., and J.C. Beghin. 2015. "China's growing market for dairy products." Iowa Ag Review 10(3):5.

Fuller, F.H., and D. Hu. 2005. "Dairy products in southwestern China: anecdotal evidence from Kunming.” Iowa State University, Department of Economics.

Funk, R., H.I. Reuter, C. Hoffmann, W. Engel, and D. Öttl. 2008. "Effect of moisture on fine dust emission from tillage operations on agricultural soils." Earth Surface Processes and Landforms 33(12):1851-1863.

Gale, F., and D. Hu. 2009. "Supply chain issues in China's milk adulteration incident." In IAAE Conference in Beijing, China, August. pp. 16-22.

Gandhi, V.P., and Z. Zhou. 2014. "Food demand and the food security challenge with rapid economic growth in the emerging economies of India and China." Food Research International 63:108-124.

Gardebroek, C., and M.A. Hernandez. 2013. "Do energy prices stimulate food price volatility? Examining volatility transmission between US oil, ethanol and corn markets.” Energy Economics 40:119-129.

Garnett, T. 2011. "Where are the best opportunities for reducing greenhouse gas emissions in the food system (including the food chain)?” Food Policy 36:S23-S32.

Gerrard, C.D., and T. Roe. 1983. "Government intervention in food grain markets: An econometric study of Tanzania." Journal of Development Economics 13(1):109-132. 
Ghanem, D., and J. Zhang. 2014. “'Effortless Perfection:’ Do Chinese cities manipulate air pollution data?" Journal of Environmental Economics and Management 68(2):203-225.

Ghose, B. 2014. "Food security and food self - sufficiency in China: from past to 2050." Food and Energy Security 3(2):86-95.

Gibson, J., and B. Kim. 2012. "Testing the infrequent purchases model using direct measurement of hidden consumption from food stocks.” American Journal of Agricultural Economics 94(1):257-270.

Gil, Y., and C. Sinfort. 2005. "Emission of pesticides to the air during sprayer application: A bibliographic review." Atmospheric Environment 39(28):5183-5193.

Gil, Y., C. Sinfort, Y. Brunet, V. Polveche, and B. Bonicelli. 2007. "Atmospheric loss of pesticides above an artificial vineyard during air-assisted spraying." Atmospheric Environment 41(14):2945-2957.

Godfray, H.C.J., J.R. Beddington, I.R. Crute, L. Haddad, D. Lawrence, J.F. Muir, J. Pretty, S. Robinson, S.M. Thomas, and C. Toulmin. 2010. "Food security: the challenge of feeding 9 billion people." science 327(5967):812-818.

Goebes, M.D., R. Strader, and C. Davidson. 2003. "An ammonia emission inventory for fertilizer application in the United States.” Atmospheric Environment 37(18):2539-2550.

Gohin, A., and H. Guyomard. 2000. "Measuring market power for food retail activities: French evidence." Journal of Agricultural Economics 51(2):181-195.

Goodwin, B.K., and A.K. Mishra. 2005. "Another look at decoupling: additional evidence on the production effects of direct payments." American Journal of Agricultural Economics 87(5):1200-1210.

Goossens, D., J. Gross, and W. Spaan. 2001. "Aeolian dust dynamics in agricultural land areas in lower Saxony, Germany.” Earth Surface Processes and Landforms 26(7):701-720.

Greene, W.H. 2007. Econometric analysis. Upper Saddle River, NJ: Pearson Education India, Prentice Hall.

Greene, W.H. 2002. Econometric Analysis (5th Edition). Prentice Hall.

Griliches, Z. 1963. "The sources of measured productivity growth: United States agriculture, 1940-60.” Journal of Political Economy 71(4):331-346.

Gu, B., Y. Ge, S.X. Chang, W. Luo, and J. Chang. 2013. "Nitrate in groundwater of China: Sources and driving forces." Global environmental change 23(5):1112-1121. 
Gu, B., Y. Ge, Y. Ren, B. Xu, W. Luo, H. Jiang, B. Gu, and J. Chang. 2012. "Atmospheric reactive nitrogen in China: sources, recent trends, and damage costs." Environmental science \& technology 46(17):9420-9427.

Guan, Z., O.L. Alfons, van I. Martin, and W. Ada. 2006. "Integrating agronomic principles into production function specification: a dichotomy of growth inputs and facilitating inputs." American Journal of Agricultural Economics 88(1):203-214.

Guo, Q., H.H. Wang, and Y. Chen. 2016. "Do Chinese dairy firms have market power? An estimation of market power with price heterogeneity." China Agricultural Economic Review 8(2):206-214.

Guyomard, H., M. Baudry, and A. Carpentier. 1996. "Estimating crop supply response in the presence of farm programmes: application to the CAP." European Review of Agricultural Economics 23(4):401-420.

Halbrendt, C., C. Gempesaw, D. Dolk-Etz, and F. Tuan. 1994. "Rural Chinese food consumption: the case of Guangdong." American Journal of Agricultural Economics 76(4):794-799.

Hall, A.R. 2005. Generalized method of moments. Oxford, UK: Oxford University Press.

Hall, R.E. 1988. "The relation between price and marginal cost in US industry." Journal of political Economy 96(5):921-947.

Hamaoui-Laguel, L., F. Meleux, M. Beekmann, B. Bessagnet, S. Génermont, P. Cellier, and L. Létinois. 2014. "Improving ammonia emissions in air quality modelling for France." Atmospheric environment 92:584-595.

Hansen, E.S. 1993. "A follow - up study on the mortality of truck drivers." American journal of industrial medicine 23(5):811-821.

Harrison, D., and D.L. Rubinfeld. 1978. "Hedonic housing prices and the demand for clean air." Journal of environmental economics and management 5(1):81-102.

Hasiner, E., and X. Yu. 2016. "Meat consumption and democratic governance: A cross-national analysis." China Economic Review.

Hatirli, S.A., B. Ozkan, E. Jones, and A.R. Aktas. 2006. "Application of measuring market power and costefficiency in the milk sub-sector in Turkey compared to other European countries." Trends in food science \& technology 17(7):367-372.

Hausman, J.A. 1978. "Specification tests in econometrics." Econometrica: Journal of the Econometric Society:1251-1271.

Headey, D. 2011. "Rethinking the global food crisis: The role of trade shocks." Food Policy 36(2):136-146. 
Heagle, A.S., D.E. Body, and W.W. Heck. 1973. "An open-top field chamber to assess the impact of air pollution on plants." Journal of Environmental Quality 2(3):365-368.

Heber, A.J., M. Stroik, J.M. Faubion, and L.H. Willard. 1988. "Size distribution and identification of aerial dust particles in swine finishing buildings." Transactions of the ASAE 31(3):882-887.

Heck, W.W., O.C. Taylor, and D.T. Tingey. 1988. Assessment of crop loss from air pollutants. London and New York: Elsevier Applied Science.

Heckelei, T., and H. Wolff. 2003. "Estimation of constrained optimisation models for agricultural supply analysis based on generalised maximum entropy." European review of agricultural economics 30(1):27-50.

Heerink, N., M. Kuiper, and X. Shi. 2006. “China's new rural income support policy: Impacts on grain production and rural income inequality." China \& World Economy 14(6):58-69.

Heffer, P., and M. Prud'homme. 2010. "Fertilizer outlook 2010-2014." In 78th IFA annual conference, Paris.

Hertel, T.W. 1989. "Negotiating reductions in agricultural support: Implications of technology and factor mobility." American Journal of Agricultural Economics 71(3):559-573.

Hildebrandt, L., and D. Klapper. 2001. "The analysis of price competition between corporate brands." International Journal of Research in Marketing 18(1):139-159.

Hill, J., E. Nelson, D. Tilman, S. Polasky, and D. Tiffany. 2006. "Environmental, economic, and energetic costs and benefits of biodiesel and ethanol biofuels." Proceedings of the National Academy of sciences 103(30):11206-11210.

Hill, J., S. Polasky, E. Nelson, D. Tilman, H. Huo, L. Ludwig, J. Neumann, H. Zheng, and D. Bonta. 2009. "Climate change and health costs of air emissions from biofuels and gasoline." Proceedings of the National Academy of Sciences 106(6):2077-2082.

Hockmann, H., and É. Vöneki. 2007. "Assessing market functioning: The case of the Hungarian milk chain." In 104th EAAE-IAAE Seminar Agricultural Economics and Transition of European Association of Agricultural Economists, Budapest, Hungary, September.

Hoek, G., B. Brunekreef, S. Goldbohm, P. Fischer, and P.A. van den Brandt. 2002. "Association between mortality and indicators of traffic-related air pollution in the Netherlands : a cohort study." The lancet 360(9341):1203-1209.

Holgate, S.T., H.S. Koren, J.M. Samet, and R.L. Maynard. 1999. Air pollution and health. Academic Press.

Homidan, A. Al. 1998. "Effect of environmental factors on ammonia and dust production and broiler performance." British Poultry Science 39(S1):9-10. 
Honour, S.L., J.N.B. Bell, T.W. Ashenden, J.N. Cape, and S.A. Power. 2009. "Responses of herbaceous plants to urban air pollution: Effects on growth, phenology and leaf surface characteristics." Environmental Pollution 157(4):1279-1286.

Hoppin, J.A., D.M. Umbach, S.J. London, M.C.R. Alavanja, and D.P. Sandler. 2002. "Chemical predictors of wheeze among farmer pesticide applicators in the Agricultural Health Study." American Journal of Respiratory and Critical care medicine 165(5):683-689.

Hoppin, J.A., D.M. Umbach, S.J. London, P.K. Henneberger, G.J. Kullman, J. Coble, M.C.R. Alavanja, L.E.B. Freeman, and D.P. Sandler. 2009. "Pesticide use and adult-onset asthma among male farmers in the Agricultural Health Study.” European Respiratory Journal 34(6):1296-1303.

Hou, H., S. Peng, J. Xu, S. Yang, and Z. Mao. 2012. "Seasonal variations of CH4 and N2O emissions in response to water management of paddy fields located in Southeast China." Chemosphere 89(7):884-892.

Hovhannisyan, V., and B.W. Gould. 2012. "A structural model of the analysis of retail market power: The case of fluid milk." American journal of agricultural economics 94(1):67-79.

Hristov, A.N. 2011. "Contribution of ammonia emitted from livestock to atmospheric fine particulate matter (PM 2.5) in the United States.” Journal of dairy science 94(6):3130-3136.

Hu, D. 2009. "China: dairy product quality as the new industry driver." Animal Production and Health Commission for Asia and The Pacific, FAO Regional Office for Asia and The Pacific, Bangkok:22-43.

Hu, D., F.H. Fuller, and T. Reardon. 2004. "The impact of the rapid development of supermarkets on the dairy industry in China." Chinese Rural Economy 235(7):12-18.

Huang, J., R. Hu, C. Pray, F. Qiao, and S. Rozelle. 2003. "Biotechnology as an alternative to chemical pesticides: a case study of Bt cotton in China." Agricultural Economics 29(1):55-67.

Huang, J., R. Hu, S. Rozelle, F. Qiao, and C.E. Pray. 2002. "Transgenic varieties and productivity of smallholder cotton farmers in China." Australian Journal of Agricultural and Resource Economics 46(3):367-387.

Huang, J., Z. Huang, X. Jia, R. Hu, and C. Xiang. 2015. "Long-term reduction of nitrogen fertilizer use through knowledge training in rice production in China." Agricultural Systems 135:105-111.

Huang, J., and S. Rozelle. 1995. "Environmental stress and grain yields in China." American Journal of Agricultural Economics 77(4):853-864.

Huang, J., X. Wang, and S. Rozelle. 2013. "The subsidization of farming households in China's agriculture." Food Policy 41:124-132. 
Huang, J., X. Wang, H. Zhi, Z. Huang, and S. Rozelle. 2011. "Subsidies and distortions in China's agriculture: evidence from producer - level data." Australian Journal of Agricultural and Resource Economics 55(1):53-71.

Huang, Q., S. Rozelle, B. Lohmar, J. Huang, and J. Wang. 2006. "Irrigation, agricultural performance and poverty reduction in China." Food Policy 31(1):30-52.

Huang, X., Y. Song, M. Li, J. Li, Q. Huo, X. Cai, T. Zhu, M. Hu, and H. Zhang. 2012. "A high resolution ammonia emission inventory in China." Global Biogeochemical Cycles 26(1).

Huxham, M., L. Emerton, J. Kairo, F. Munyi, H. Abdirizak, T. Muriuki, F. Nunan, and R.A. Briers. 2015. "Applying Climate Compatible Development and economic valuation to coastal management: A case study of Kenya's mangrove forests." Journal of Environmental Management 157:168-181.

Hyslop, N.P. 2009. "Impaired visibility: the air pollution people see." Atmospheric Environment 43(1):182-195.

IPCC. 2007. "Climate Change 2007: The Physical Science Basis: Summary for Policymakers. Contribution of Working Group I to the Fourth Assessment Report of the Intergovernmental Panel on Climate Change." NYREV, INC.

Isermann, K. 1994. "Agriculture's share in the emission of trace gases affecting the climate and some cause-oriented proposals for sufficiently reducing this share." Environmental Pollution 83(1-2):95-111.

Janzen, H.H. 2004. "Carbon cycling in earth systems-a soil science perspective." Agriculture, Ecosystems \& Environment 104(3):399-417.

Jayne, T.S., and S. Rashid. 2013. "Input subsidy programs in sub - Saharan Africa: a synthesis of recent evidence." Agricultural economics 44(6):547-562.

Jensen, H.H. 2002. "Empirical analysis using scanner data: Econometric issues and policy implications." American Journal of Agricultural Economics 84(3):824-825.

Jia, C., and D. Jukes. 2013. "The national food safety control system of China - A systematic review." Food Control 32(1):236-245.

Jia, X., J. Huang, H. Luan, S. Rozelle, and J. Swinnen. 2012. “China’s Milk Scandal, government policy and production decisions of dairy farmers: The case of Greater Beijing." Food Policy 37(4):390-400.

Jia, X., J. Huang, C. Xiang, and D. Powlson. 2015. "Reducing Excessive Nitrogen Use in Chinese Wheat Production Through Knowledge Training: What Are the Implications for the Public Extension System?" Agroecology and Sustainable Food Systems 39(2):189-208. 
Jiao, W., W. Chen, A.C. Chang, and A.L. Page. 2012. "Environmental risks of trace elements associated with long-term phosphate fertilizers applications: A review." Environmental Pollution 168:44-53.

Ju, X.-T., G.-X. Xing, X.-P. Chen, S.-L. Zhang, L.-J. Zhang, X.-J. Liu, Z.-L. Cui, B. Yin, P. Christie, and Z.-L. Zhu. 2009. "Reducing environmental risk by improving $\mathrm{N}$ management in intensive Chinese agricultural systems." Proceedings of the National Academy of Sciences 106(9):3041-3046.

Ju, X.T., C.L. Kou, F.S. Zhang, and P. Christie. 2006. "Nitrogen balance and groundwater nitrate contamination: Comparison among three intensive cropping systems on the North China Plain." Environmental Pollution 143(1):117-125.

Just, R.E., D. Zilberman, and E. Hochman. 1983. "Estimation of multicrop production functions." American Journal of Agricultural Economics 65(4):770-780.

Kahrl, F., Y. Li, Y. Su, T. Tennigkeit, A. Wilkes, and J. Xu. 2010. "Greenhouse gas emissions from nitrogen fertilizer use in China." Environmental Science \& Policy 13(8):688-694.

Kalirajan, K.P., M.B. Obwona, and S. Zhao. 1996. "A decomposition of total factor productivity growth: the case of Chinese agricultural growth before and after reforms." American Journal of Agricultural Economics 78(2):331-338.

Kamenica, E., S. Mullainathan, and R. Thaler. 2011. "Helping consumers know themselves." The American Economic Review 101(3):417-422.

Kampa, M., and E. Castanas. 2008. "Human health effects of air pollution." Environmental Pollution 151(2):362-367.

Kang, H., B. Zhu, J. Su, H. Wang, Q. Zhang, and F. Wang. 2013. "Analysis of a long-lasting haze episode in Nanjing, China." Atmospheric Research 120-121:78-87.

Karjalainen, A., R. Martikainen, T. Klaukka, K. Saarinen, and J. Uitti. 2003. "Risk of asthma among finnish patients with occupational rhinitis." Chest 123(1):283-288.

Kelly, F.J., G.W. Fuller, H.A. Walton, and J.C. Fussell. 2012. "Monitoring air pollution: Use of early warning systems for public health." Respirology 17(1):7-19.

Khan, S., M.A. Hanjra, and J. Mu. 2009. "Water management and crop production for food security in China: A review." Agricultural Water Management 96(3):349-360.

Khor, L.Y., and M. Zeller. 2014. "Inaccurate fertilizer content and its effect on the estimation of production functions." China Economic Review 30:123-132.

Kim, K.-H., S.A. Jahan, and E. Kabir. 2013. "A review on human health perspective of air pollution with respectto allergies and asthma." Environmental International 59:41-52. 
Kimbell - Dunn, M.R., R.D. Fishwick, L. Bradshaw, R. Erkinjuntti - Pekkanen, and N. Pearce. 2001. "Work - related respiratory symptoms in New Zealand farmers." American journal of industrial medicine 39(3):292-300.

Kimbrell, A. 2002. The fatal harvest reader: the tragedy of industrial agriculture. Island Press.

Kloke, A., D.R. Sauerbeck, and H. Vetter. 1984. "The contamination of plants and soils with heavy metals and the transport of metals in terrestrial food chains." In Changing metal cycles and human health. Springer, pp. 113-141.

Kochian, L. V, O.A. Hoekenga, and M.A. Piñeros. 2004. "How do crop plants tolerate acid soils? Mechanisms of aluminum tolerance and phosphorous efficiency." Annu. Rev. Plant Biol. 55:459-493.

Kogevinas, M., J.M. Antó, J. Sunyer, A. Tobias, H. Kromhout, and P. Burney. 1999. "Occupational asthma in Europe and other industrialised areas: A population-based study." Lancet 353(9166):1750-1754.

Kompas, T., and T.N. Che. 2006. "Technology choice and efficiency on Australian dairy farms." Australian Journal of Agricultural and Resource Economics 50(1):65-83.

Kong, D. 2012. "Does corporate social responsibility matter in the food industry? Evidence from a nature experiment in China." Food Policy 37(3):323-334.

Kongshaug, G. 1998. "Energy consumption and greenhouse gas emissions in fertilizer production.” In IFA technical conference, Marrakech, Morocco. p. 18.

Kummer, U., J. Pacyna, E. Pacyna, and R. Friedrich. 2009. "Assessment of heavy metal releases from the use phase of road transport in??Europe." Atmospheric Environment 43(3):640-647.

Künzli, N., R. Kaiser, S. Medina, M. Studnicka, O. Chanel, P. Filliger, M. Herry, F.H. Jr, V. Puybonnieux-Texier, P. Quénel, J. Schneider, R. Seethaler, J.-C. Vergnaud, and H. Sommer. 2000. "Public-health impact of outdoor and traffic-related air pollution: a European assessment." The Lancet 356(9232):795-801.

Lan, H., and X. Wang. 2018. "Estimating Market Power in the Chinese Pork-Packing Industry: A Structural Approach."

Lee, E., C.A. Burnett, N. Lalich, L.L. Cameron, and J.P. Sestito. 2002. "Proportionate mortality of crop and livestock farmers in the United States, 1984-1993." American journal of industrial medicine 42(5):410-420.

Legret, M., and C. Pagotto. 2006. "Heavy metal deposition and soil pollution along two major rural highways." Environmental Technology 27(3):247-254. 
Lence, S.H., and D.J. Miller. 1998. "Recovering output-specific inputs from aggregate input data: A generalized cross-entropy approach.” American Journal of Agricultural Economics 80(4):852-867.

Lenters, V., I. Basinas, L. Beane-Freeman, P. Boffetta, H. Checkoway, D. Coggon, L. Portengen, M. Sim, I.M. Wouters, and D. Heederik. 2010. "Endotoxin exposure and lung cancer risk: a systematic review and meta-analysis of the published literature on agriculture and cotton textile workers." Cancer Causes \& Control 21(4):523-555.

Levinsohn, J., and A. Petrin. 2003. "Estimating production functions using inputs to control for unobservables." The Review of Economic Studies 70(2):317-341.

Li, C., J. Qiu, S. Frolking, X. Xiao, W. Salas, B. Moore, S. Boles, Y. Huang, and R. Sass. 2002. "Reduced methane emissions from large-scale changes in water management of China's rice paddies during 1980-2000." Geophysical Research Letters 29(20).

Li, F.R., L.Y. Zhao, H. Zhang, T.H. Zhang, and Y. Shirato. 2004. "Wind erosion and airborne dust deposition in farmland during spring in the Horqin Sandy Land of eastern Inner Mongolia, China." Soil and Tillage Research 75(2):121-130.

Li, M., and T. Sicular. 2013. "Aging of the labor force and technical efficiency in crop production." China Agricultural Economic Review 5(3):342-359.

Li, X., C.S. Poon, and P.S. Liu. 2001. "Heavy metal contamination of urban soils and street dusts in Hong Kong.” Applied Geochemistry 16(11-12):1361-1368.

Lichtenberg, E., and C. Ding. 2008. “Assessing farmland protection policy in China.” Land Use Policy 25(1):59-68.

Liebers, V., T. Brüning, and M. Raulf-Heimsoth. 2006. "Occupational endotoxin - exposure and possible health effects on humans." American journal of industrial medicine 49(6):474-491.

Lijesen, M.G. 2007. “The real-time price elasticity of electricity.” Energy Economics 29(2):249-258.

Lin, B.-H., T.A. Smith, and C.L. Huang. 2008. "Organic premiums of US fresh produce.” Renewable Agriculture and Food Systems 23(03):208-216.

Lin, J.Y. 1992. "Rural Reforms and Agricultural Growth in China." The American Economic Review 82(1):34-51.

Linaker, C., and J. Smedley. 2002. "Respiratory illness in agricultural workers." Occupational Medicine 52(8):451-459.

Lindbeck, A. 1997. "Incentives and social norms in household behavior." The American Economic Review 87(2):370-377.

Liu, E.M., and J. Huang. 2013. "Risk preferences and pesticide use by cotton farmers in China." Journal of Development Economics 103:202-215. 
Liu, K.E., and W.S. Chern. 2003. "Food demand in urban China: an application of a multi-stage censored demand system."

Liu, P. 2010. “Tracing and periodizing China's food safety regulation: A study on China's food safety regime change." Regulation \& Governance 4(2):244-260.

Liu, S., R. Wang, and G. Shi. 2018. "Historical Transformation of China's Agriculture: Productivity Changes and Other Key Features." China \& World Economy 26(1):42-65.

Liu, W.H., J.Z. Zhao, Z.Y. Ouyang, L. Söderlund, and G.H. Liu. 2005. "Impacts of sewage irrigation on heavy metal distribution and contamination in Beijing, China." Environment International 31(6):805-812.

Liu, X., Y. Zhang, W. Han, A. Tang, J. Shen, Z. Cui, P. Vitousek, J.W. Erisman, K. Goulding, and P. Christie. 2013. "Enhanced nitrogen deposition over China." Nature 494(7438):459-462.

Lobell, D.B., and S.M. Gourdji. 2012. "The influence of climate change on global crop productivity." Plant Physiology 160(4):1686-1697.

Lopez, R.E. 1984. "Measuring oligopoly power and production responses of the Canadian food processing industry." Journal of Agricultural Economics 35(2):219-230.

Loska, K., D. Wiechulła, and I. Korus. 2004. "Metal contamination of farming soils affected by industry.” Environment International 30(2):159-165.

Lovelock, K. 2012. "The injured and diseased farmer: Occupational health, embodiment and technologies of harm and care." Sociology of health \& illness 34(4):576-590.

Lowe, P., H. Buller, and N. Ward. 2002. "Setting the next agenda? British and French approaches to the second pillar of the Common Agricultural Policy." Journal of Rural Studies 18(1):1-17.

Lu, X., L. Wang, L.Y. Li, K. Lei, L. Huang, and D. Kang. 2010. "Multivariate statistical analysis of heavy metals in street dust of Baoji, NW China." Journal of hazardous materials 173(1):744-749.

Ma, L., S. Feng, P. Reidsma, F. Qu, and N. Heerink. 2014. "Identifying entry points to improve fertilizer use efficiency in Taihu Basin, China." Land Use Policy 37:52-59.

Ma, L., F. Wang, W. Zhang, W. Ma, G. Velthof, W. Qin, O. Oenema, and F. Zhang. 2013. "Environmental assessment of management options for nutrient flows in the food chain in China." Environmental science \& technology 47(13):7260-7268.

Van Maele-Fabry, G., P. Hoet, F. Vilain, and D. Lison. 2012. "Occupational exposure to pesticides and Parkinson's disease: A systematic review and meta-analysis of cohort studies." Environment International 46:30-43.

Majewski, M.S., W.T. Foreman, D.A. Goolsby, and N. Nakagaki. 1998. "Airborne pesticide residues along the Mississippi River." Environmental science \& technology 32(23):3689-3698. 
Mandryk, J., K.U. Alwis, and A.D. Hocking. 2000. "Effects of personal exposures on pulmonary function and work-related symptoms among sawmill workers." Annals of occupational hygiene 44(4):281-289.

Mao, W., and W.W. Koo. 1997. "Productivity growth, technological progress, and efficiency change in Chinese agriculture after rural economic reforms: a DEA approach." China Economic Review $8(2): 157-174$.

Marenya, P.P., and C.B. Barrett. 2009. "State-conditional fertilizer yield response on western Kenyan farms." American Journal of Agricultural Economics 91(4):991-1006.

Matson, P.A., W.J. Parton, A.G. Power, and M.J. Swift. 1997. "Agricultural intensification and ecosystem properties." Science 277(5325):504-509.

Matsumoto, T., and Y. Takashi. 2011. "Optimal fertilizer use on maize production in East Africa." In Emerging Development of Agriculture in East Africa. pp. 117-132.

May, S., D.J. Romberger, and J.A. Poole. 2012. "Respiratory health effects of large animal farming environments.” Journal of Toxicology and Environmental Health, Part B 15(8):524-541.

McCormick, J. 1989. Acid Earth: the global threat of acid pollution. London, UK: Earthscan.

McMillan, J., J. Whalley, and L. Zhu. 1989. “The impact of China's economic reforms on agricultural productivity growth.” Journal of Political Economy 97(4):781-807.

Mehmood, T., M.M. Chaudhry, M. Tufail, and N. Irfan. 2009. "Heavy metal pollution from phosphate rock used for the production of fertilizer in Pakistan." Microchemical Journal 91(1):94-99.

Melillo, J.M., J.M. Reilly, D.W. Kicklighter, A.C. Gurgel, T.W. Cronin, S. Paltsev, B.S. Felzer, X. Wang, A.P. Sokolov, and C.A. Schlosser. 2009. "Indirect emissions from biofuels: how important?" science 326(5958):1397-1399.

De Mello, M., and A. Brandao. 1999. "Measuring the market power of the Portuguese milk industry." International Journal of the Economics of Business 6(2):209-222.

Mendell, M.J. 1993. "Non - Specific Symptoms In Office Workers: A Review And Summary Of The Epidemiologic Literature.” Indoor Air 3(4):227-236.

Mergenthaler, M., K. Weinberger, and M. Qaim. 2009. "The food system transformation in developing countries: A disaggregate demand analysis for fruits and vegetables in Vietnam." Food Policy 34(5):426-436.

Meyer, S., and X. Yu. 2013. "The impacts of production uncertainties on world food prices." China Agricultural Economic Review 5(4):459-472. 
Mo, D., J. Huang, X. Jia, H. Luan, S. Rozelle, and J. Swinnen. 2012. "Checking into China's cow hotels: Have policies following the milk scandal changed the structure of the dairy sector?" Journal of dairy science 95(5):2282-2298.

Mosier, A.R., J.M. Duxbury, J.R. Freney, O. Heinemeyer, K. Minami, and D.E. Johnson. 1998. "Mitigating agricultural emissions of methane." Climatic Change 40(1):39-80.

Mostafalou, S., and M. Abdollahi. 2013. "Pesticides and human chronic diseases: Evidences, mechanisms, and perspectives." Toxicology and Applied Pharmacology 268(2):157-177.

Mueller, S.A., J.E. Anderson, and T.J. Wallington. 2011. "Impact of biofuel production and other supply and demand factors on food price increases in 2008." Biomass and Bioenergy 35(5):1623-1632.

Mundlak, Y. 2001. “Agricultural Production.” In Handbook of Agricultural Economics. pp. 3-85.

Mundlak, Y. 1961. "Empirical production function free of management bias." Journal of Farm Economics 43(1):44-56.

Mundlak, Y., R. Butzer, and D.F. Larson. 2012. "Heterogeneous technology and panel data: The case of the agricultural production function.” Journal of Development Economics 99(1):139-149.

Murray, K.B., F. Di Muro, A. Finn, and P.P. Leszczyc. 2010. "The effect of weather on consumer spending." Journal of Retailing and Consumer Services 17(6):512-520.

Nagajyoti, P.C., K.D. Lee, and T.V.M. Sreekanth. 2010. "Heavy metals, occurrence and toxicity for plants: a review." Environmental Chemistry Letters 8(3):199-216.

Ndegwa, P.M., A.N. Hristov, J. Arogo, and R.E. Sheffield. 2008. “A review of ammonia emission mitigation techniques for concentrated animal feeding operations." Biosystems Engineering 100(4):453-469.

Neidell, M. 2009. "Information, Avoidance behavior, and health the effect of ozone on asthma hospitalizations." Journal of Human resources 44(2):450-478.

Neidell, M. 2005. "Public Information and Avoidance Behavior: Do People Respond to Smog Alerts?"

Nevo, A. 2001. "Measuring Market Power in the Ready-to-Eat Cereal Industry." Econometrica 69(2):307-342.

Newey, W.K., and K.D. West. 1987. "A simple, positive semi-definite, heteroskedasticity and autocorrelationconsistent covariance matrix." Econometrica 55:703-708.

Nguyen, S.G., R.B. Guevarra, J. Kim, C.T. Ho, M. V Trinh, and T. Unno. 2015. "Impacts of Initial Fertilizers and Irrigation Systems on Paddy Methanogens and Methane Emission." Water, Air, \& Soil Pollution 226(9):309.

Ni, J.-Q., L. Chai, L. Chen, B.W. Bogan, K. Wang, E.L. Cortus, A.J. Heber, T.-T. Lim, and C.A. Diehl. 2012. "Characteristics of ammonia, hydrogen sul fi de , carbon dioxide, and particulate matter 
concentrations in high-rise and manure-belt layer hen houses." Atmospheric Environment $57: 165-174$.

Nilsson, C.-A., R. Lindahl, and Å.K.E. Norström. 1987. “Occupational exposure to chain saw exhausts in logging operations." The American Industrial Hygiene Association Journal 48(2):99-105.

Nishimura, S., T. Sawamoto, H. Akiyama, S. Sudo, and K. Yagi. 2004. "Methane and nitrous oxide emissions from a paddy field with Japanese conventional water management and fertilizer application." Global Biogeochemical Cycles 18(2).

Nordstrom, K.F., and S. Hotta. 2004. "Wind erosion from cropland in the USA: a review of problems, solutions and prospects." Geoderma 121(3):157-167.

Norrbin, S.C. 1993. "The relation between price and marginal cost in US industry: a contradiction." Journal of political Economy 101(6):1149-1164.

Nosengo, N. 2003. "Fertilized to death.” Nature 425(6961):894-895.

Offermann, F., H. Nieberg, and K. Zander. 2009. "Dependency of organic farms on direct payments in selected EU member states: Today and tomorrow." Food Policy 34(3):273-279.

Oki, M., and P.A.L. Anawe. 2015. "A Review of Corrosion in Agricultural Industries." Physical Science International Journal 5(4):216-222.

Oki, T., and S. Kanae. 2006. "Global hydrological cycles and world water resources." science 313(5790):1068-1072.

Olesen, J.E., and M. Bindi. 2002. "Consequences of climate change for European agricultural productivity, land use and policy." European Journal of Agronomy 16(4):239-262.

Olesen, J.E., M. Trnka, K.C. Kersebaum, A.O. Skjelvåg, B. Seguin, P. Peltonen-Sainio, F. Rossi, J. Kozyra, and F. Micale. 2011. "Impacts and adaptation of European crop production systems to climate change." European Journal of Agronomy 34(2):96-112.

Olley, G.S., and A. Pakes. 1996. "The dynamics of productivity in the telecommunications equipment industry." Econometrica 64:1263-1298.

Ongley, E.D., X. Zhang, and T. status of agricultural and rural non-point source P. assessment in C. Yu. 2010. "Current status of agricultural and rural non-point source Pollution assessment in China." Environmental Pollution 158(5):1159-1168.

Ortega, D.L., H.H. Wang, N.J. Olynk, L. Wu, and J. Bai. 2011. “Chinese consumers' demand for food safety attributes: A push for government and industry regulations." American Journal of Agricultural Economics 94(2):489-495.

Pagotto, C., N. Remy, M. Legret, and P. Le Cloirec. 2001. "Heavy metal pollution of road dust and roadside soil near a major rural highway." Environmental Technology 22(3):307-319. 
Pandey, N., and C.P. Sharma. 2002. "Effect of heavy metals Co2+, Ni2+ and $\mathrm{Cd} 2+$ on growth and metabolism of cabbage." Plant Science 163(4):753-758.

Paris, Q., and R.E. Howitt. 1998. "An analysis of ill-posed production problems using maximum entropy." American journal of agricultural economics 80(1):124-138.

Patton, M., P. Kostov, S. McErlean, and J. Moss. 2008. "Assessing the influence of direct payments on the rental value of agricultural land." Food Policy 33(5):397-405.

Paulson, N.D., and B.A. Babcock. 2010. "Readdressing the fertilizer problem.” Journal of Agricultural and Resource Economics:368-384.

Pei, X., A. Tandon, A. Alldrick, L. Giorgi, W. Huang, and R. Yang. 2011. "The China melamine milk scandal and its implications for food safety regulation." Food Policy 36(3):412-420.

Penagos, H. 2002. "Contact dermatitis caused by pesticides among banana plantation workers in Panama." International journal of occupational and environmental health 8(1):14-18.

Peng, S., R.J. Buresh, J. Huang, X. Zhong, Y. Zou, J. Yang, G. Wang, Y. Liu, R. Hu, and Q. Tang. 2011. "Improving nitrogen fertilization in rice by site-specific $\mathrm{N}$ management." In Sustainable Agriculture Volume 2. Springer, pp. 943-952.

Peng, Y., J. Li, H. Xia, S. Qi, and J. Li. 2015. “The effects of food safety issues released by we media on consumers' awareness and purchasing behavior: A case study in China.” Food Policy 51:44-52.

Peralta, J.R., J.L. Gardea-Torresdey, K.J. Tiemann, E. Gomez, S. Arteaga, E. Rascon, and J.G. Parsons. 2001. "Uptake and effects of five heavy metals on seed germination and plant growth in alfalfa (Medicago sativa L.).” Bulletin of Environmental Contamination and toxicology 66(6):727-734.

Pingali, P. 2015. "Agricultural policy and nutrition outcomes-getting beyond the preoccupation with staple grains." Food Security 7(3):583-591.

Pingali, P. 2007. "Westernization of Asian diets and the transformation of food systems: Implications for research and policy." Food Policy 32(3):281-298.

Pingali, P.L. 1997. "From subsistence to commercial production systems: The transformation of Asian agriculture." American Journal of Agricultural Economics 79(2):628-634.

Van Pul, W.A.J., T.F. Bidleman, E. Brorström-Lundén, P.J.H. Builtjes, S. Dutchak, J.H. Duyzer, S.-E. Gryning, K.C. Jones, H.F.G. Van Dijk, and J.H.A. Van Jaarsveld. 1999. "Atmospheric transport and deposition of pesticides: An assessment of current knowledge." In Fate of Pesticides in the Atmosphere: Implications for Environmental Risk Assessment. Springer, pp. 245-256.

Putsis, W.P. 1997. "An empirical study of the effect of brand proliferation on private label-national brand pricing behavior." Review of industrial Organization 12(3):355-371. 
Qian, G., X. Guo, J. Guo, and J. Wu. 2011. “China’s dairy crisis: impacts, causes and policy implications for a sustainable dairy industry." International Journal of Sustainable Development \& World Ecology 18(5):434-441.

Qiao, F., B. Lohmar, J. Huang, S. Rozelle, and L. Zhang. 2003. "Producer benefits from input market and trade liberalization: the case of fertilizer in China." American Journal of Agricultural Economics 85(5):1223-1227.

Qu, C., B. Li, H. Wu, and J.P. Giesy. 2012. "Controlling air pollution from straw burning in China calls for efficient recycling."

Radon, K., C. Weber, M. Iversen, B. Danuser, S. Pedersen, and D. Nowak. 2001. "Exposure assessment and lung function in pig and poultry farmers." Occupational and Environmental Medicine 58(6):405-410.

Rai, A., K. Kulshreshtha, P.K. Srivastava, and C.S. Mohanty. 2010. "Leaf surface structure alterations due to particulate pollution in some common plants." The Environmentalist 30(1):18-23.

Rajsic, P., and A. Weersink. 2008. "Do farmers waste fertilizer? A comparison of ex post optimal nitrogen rates and ex ante recommendations by model, site and year." Agricultural Systems 97(1-2):56-67.

Rajsic, P., A. Weersink, and M. Gandorfer. 2009. "Risk and nitrogen application levels." Canadian Journal of Agricultural Economics/Revue canadienne d'agroeconomie 57(2):223-239.

Ramanathan, V., P.J. Crutzen, J.T. Kiehl, and D. Rosenfeld. 2001. "Aerosols, climate, and the hydrological cycle." science 294(5549):2119-2124.

Ramaswami, B., and P. Balakrishnan. 2002. "Food prices and the efficiency of public intervention: the case of the public distribution system in India." Food Policy 27(5):419-436.

Rank, J., J. Folke, and P.H. Jespersen. 2001. "Differences in cyclists and car drivers exposure to air pollution from traffic in the city of Copenhagen." Science of the Total Environment 279(1):131-136.

Raper, K.C., H.A. Love, and C.R. Shumway. 2007. "Distinguishing the source of market power." American Journal of Agricultural Economics 89(1):78-90.

Rathmann, R., A. Szklo, and R. Schaeffer. 2010. "Land use competition for production of food and liquid biofuels: An analysis of the arguments in the current debate." Renewable Energy 35(1):14-22.

Reardon, T., C.B. Barrett, J.A. Berdegué, and J.F.M. Swinnen. 2009. “Agrifood Industry Transformation and Small Farmers in Developing Countries.” World Development 37(11):1717-1727. 
Reiman, M., and J. Uitti. 2000. "Exposure to microbes, endotoxins and total dust in cigarette and cigar manufacturing: an evaluation of health hazards." Annals of Occupational Hygiene 44(6):467-473.

Richards, T.J., R.N. Acharya, and I. Molina. 2011. "Retail and wholesale market power in organic apples." Agribusiness 27(1):62-81.

Richards, T.J., M.I. Gómez, and J. Lee. 2014. "Pass-through and consumer search: An empirical analysis.” American Journal of Agricultural Economics 96(4):1049-1069.

Ricker-Gilbert, J. 2014. "Wage and employment effects of Malawi's fertilizer subsidy program." Agricultural Economics 45(3):337-353.

Ricker-Gilbert, J., N.M. Mason, F.A. Darko, and S.T. Tembo. 2013. "What are the effects of input subsidy programs on maize prices? Evidence from Malawi and Zambia.” Agricultural Economics 44(6):671-686.

Ridker, R.G., and J.A. Henning. 1967. "The Determinants of Residential Property Values with Special Reference to Air Pollution." The Review of Economics and Statistics 49(2):246-257.

Roeger, W. 1995. "Can imperfect competition explain the difference between primal and dual productivity measures? Estimates for US manufacturing." Journal of political Economy 103(2):316-330.

Roheim, C.A., F. Asche, and J.I. Santos. 2011. "The elusive price premium for ecolabelled products: evidence from seafood in the UK market." Journal of Agricultural Economics 62(3):655-668.

Rozelle, S., G. Veeck, and J. Huang. 1997. "The impact of environmental degradation on grain production in China, 1975-1990." Economic Geography 73(1):44-66.

Sanders, R. 2006. "A market road to sustainable agriculture? Ecological agriculture, green food and organic agriculture in China." Development and Change 37(1):201-226.

Sarkar, N., S.K. Ghosh, S. Bannerjee, and K. Aikat. 2012. "Bioethanol production from agricultural wastes: An overview." Renewable Energy 37(1):19-27.

Schmid, E., F. Sinabell, and M.F. Hofreither. 2007. "Phasing out of environmentally harmful subsidies: Consequences of the 2003 CAP reform." Ecological Economics 60(3):596-604.

Searchinger, T., R. Heimlich, R.A. Houghton, F. Dong, A. Elobeid, J. Fabiosa, S. Tokgoz, D. Hayes, and T.-H. Yu. 2008. "Use of US croplands for biofuels increases greenhouse gases through emissions from land-use change." Science 319(5867):1238-1240.

Seaton, A., D. Godden, W. MacNee, and K. Donaldson. 1995. "Particulate air pollution and acute health effects." The lancet 345(8943):176-178.

Seedorf, J. 2004. "An emission inventory of livestock-related bioaerosols for Lower Saxony, Germany." Atmospheric Environment 38(38):6565-6581. 
Selden, T.M., and D. Song. 1994. "Environmental Quality and Development: Is There a Kuznets Curve for Air Pollution Emissions?" Journal of Environmental Economics and Management 27(2):147-162.

Sevi, A., S. Massa, G. Annicchiarico, S. Dell'Aquila, and A. Muscio. 1999. "Effect of stocking density on ewes' milk yield, udder health and microenvironment." Journal of Dairy Research 66(4):489-499.

Shen, G., Y. Lu, M. Wang, and Y. Sun. 2005. "Status and fuzzy comprehensive assessment of combined heavy metal and organo-chlorine pesticide pollution in the Taihu Lake region of China." Journal of Environmental Management 76(4):355-362.

Sheppard, S.C., S. Bittman, and T.W. Bruulsema. 2010. "Monthly ammonia emissions from fertilizers in 12 Canadian Ecoregions." Canadian journal of soil science 90(1):113-127.

Sheriff, G. 2005. "Efficient waste? Why farmers over-apply nutrients and the implications for policy design." Applied Economic Perspectives and Policy 27(4):542-557.

Singh, P.K., P.B. Deshbhratar, and D.S. Ramteke. 2012. "Effects of sewage wastewater irrigation on soil properties, crop yield and environment.” Agricultural Water Management 103:100-104.

Smith, K.A., T. Ball, F. Conen, K.E. Dobbie, J. Massheder, and A. Rey. 2003. "Exchange of greenhouse gases between soil and atmosphere: interactions of soil physical factors and biological processes.” European Journal of Soil Science 54(4):779-791.

Smith, P., D. Martino, Z. Cai, D. Gwary, H. Janzen, P. Kumar, B. McCarl, S. Ogle, F. O'Mara, and C. Rice. 2008. "Greenhouse gas mitigation in agriculture." Philosophical Transactions of the Royal Society of London B: Biological Sciences 363(1492):789-813.

Smith, T.A., C.L. Huang, and B.-H. Lin. 2009. "Estimating organic premiums in the US fluid milk market." Renewable agriculture and food systems 24(03):197-204.

Smith, V.K., and T.A. Deyak. 1975. "Measuring the impact of air pollution on property values." Journal of Regional Science 15(3):277-288.

Smith, V.K., and J.C. Huang. 1995. "Can Markets Value Air Quality? A Meta-Analysis of Hedonic Property Value Models.” Journal of political economy 103(1):209-227.

Solomon, S., G.-K. Plattner, R. Knutti, and P. Friedlingstein. 2009. "Irreversible climate change due to carbon dioxide emissions." Proceedings of the national academy of sciences 106(6):1704-1709.

Sommer, S.G., and N.J. Hutchings. 2001. "Ammonia emission from field applied manure and its reduction." European journal of agronomy 15(1):1-15. 
Sommer, S.G., J.E. Olesen, and B.T. Christensen. 1991. "Effects of temperature, wind speed and air humidity on ammonia volatilization from surface applied cattle slurry." The Journal of Agricultural Science 117(1):91-100.

Sonoda, T., and A. Mishra. 2015. "Production function estimation using cross sectional data: A partial identification approach.” In Selected paper for 2015 AAEA and WAEA Annual Meeting, July. pp. 26-28.

Spiewak, R. 2003. "Occupational dermatoses among Polish private farmers, 1991-1999.” American journal of industrial medicine 43(6):647-655.

Spiewak, R. 2001. "Pesticides as a cause of occupational skin diseases in farmers." Annals of agricultural and environmental medicine 8(1):1-5.

Sridhara, C.N., C.T. Kamala, and S.R.D. Samuel. 2008. "Assessing risk of heavy metals from consuming food grown on sewage irrigated soils and food chain transfer." Ecotoxicology and Environmental Safety 69(3):513-524.

Steenkamp, J.-B.E.M., and K. Gielens. 2003. "Consumer and market drivers of the trial probability of new consumer packaged goods." Journal of Consumer Research 30(3):368-384.

Stehfest, E., and L. Bouwman. 2006. "N 2 O and NO emission from agricultural fields and soils under natural vegetation: summarizing available measurement data and modeling of global annual emissions." Nutrient Cycling in Agroecosystems 74(3):207-228.

Stevenson, J.R., N. Villoria, D. Byerlee, T. Kelley, and M. Maredia. 2013. "Green Revolution research saved an estimated 18 to 27 million hectares from being brought into agricultural production." Proceedings of the National Academy of Sciences 110(21):8363-8368.

Stewart, W.M., D.W. Dibb, A.E. Johnston, and T.J. Smyth. 2005. "The contribution of commercial fertilizer nutrients to food production." Agronomy Journal 97(1):1-6.

Sudhir, K. 2001. "Structural analysis of manufacturer pricing in the presence of a strategic retailer." Marketing Science 20(3):244-264.

Sun, B., L. Zhang, L. Yang, F. Zhang, D. Norse, and Z. Zhu. 2012. "Agricultural non-point source pollution in China: causes and mitigation measures." Ambio 41(4):370-379.

Sun, C., M.E. Kahn, and S. Zheng. 2017. "Self-protection investment exacerbates air pollution exposure inequality in urban China." Ecological Economics 131:468-474.

Sun, F., Y. Dai, and X. Yu. 2017. "Air pollution, food production and food security: A review from the perspective of food system.” Journal of Integrative Agriculture 16(12):2945-2962.

Sun, F., D. Koemle, and X. Yu. 2017. "Air pollution and food prices: evidence from China." Australian Journal of Agricultural and Resource Economics 61(2):195-210. 
Suri, T. 2011. "Selection and comparative advantage in technology adoption." Econometrica 79(1):159-209.

Takai, H., S. Pedersen, J.O. Johnsen, J.H.M. Metz, P.W. Koerkamp Groot, G., G.H. Uenk, V.R. Phillips, M.R. Holden, R.W. Sneath, J.L. Short, R.P. White, J. Hartung, J. Seedorf, M. Schroeder, K.H. Linkert, and C.M. Wathes. 1998. "Concentrations and Emissions of Airborne Endotoxins and Microorganisms in Livestock Buildings in Northern Europe.” Journal of Agricultural Engineering Research 70(1):97-109.

Takeshima, H., and E. Nkonya. 2014. "Government fertilizer subsidy and commercial sector fertilizer demand: Evidence from the Federal Market Stabilization Program (FMSP) in Nigeria." Food Policy 47:1-12.

Tam, W., and D. Yang. 2005. "Food safety and the development of regulatory institutions in China." Asian Perspective:5-36.

Tan, S., N. Heerink, and F. Qu. 2006. "Land fragmentation and its driving forces in China." Land use policy 23(3):272-285.

Thaler, R.H. 2008. "Mental accounting and consumer choice.” Marketing Science 27(1):15-25.

Thaler, R.H., and C.R. Sunstein. 2008. Nudge: Improving decisions about health, wealth, and happiness. USA: Penguin Books.

Thanh Nguyen, T., V. Hoang, and B. Seo. 2012. "Cost and environmental efficiency of rice farms in South Korea." Agricultural Economics 43(4):369-378.

Thijssen, G. 1992. “A comparison of production technology using primal and dual approaches: The case of Dutch dairy farms." European Review of Agricultural Economics 19(1):49-65.

Thirtle, C., L. Lin, and J. Piesse. 2003. "The Impact of Research-Led Agricultural Productivity Growth on Poverty Reduction in Africa, Asia and Latin America." World Development 31(12):1959-1975.

Tian, X., F. Sun, and Y. Zhou. 2015. "Technical efficiency and its determinants in China's hog production." Journal of Integrative Agriculture 14(6):1057-1068.

Tian, X., and X. Yu. 2015. "Using semiparametric models to study nutrition improvement and dietary change with different indices: The case of China." Food Policy 53:67-81.

Tilman, D., C. Balzer, J. Hill, and B.L. Befort. 2011. "Global food demand and the sustainable intensification of agriculture." Proceedings of the National Academy of Sciences 108(50):20260-20264.

Timilsina, G.R., J.C. Beghin, D. van der Mensbrugghe, and S. Mevel. 2012. "The impacts of biofuels targets on land - use change and food supply: A global CGE assessment." Agricultural Economics 43(3):315-332. 
Tracey, D., and R.P. Walsh. 2008. "Do people vote with their feet? An empirical test of Tiebout's mechanism." The American Economic Review 98(3):843-863.

Tubiello, F.N., M. Salvatore, R.D. Cóndor Golec, A. Ferrara, S. Rossi, R. Biancalani, S. Federici, H. Jacobs, and A. Flammini. 2014. "Agriculture, forestry and other land use emissions by sources and removals by sinks." Rome, Italy.

Tumusiime, E., B.W. Brorsen, J. Mosali, J. Johnson, J. Locke, and J.T. Biermacher. 2011. "Determining optimal levels of nitrogen fertilizer using random parameter models." Journal of Agricultural and Applied Economics 43(4):541-552.

Tuomisto, H.L., I.D. Hodge, P. Riordan, and D.W. Macdonald. 2012. "Does organic farming reduce environmental impacts? - A meta-analysis of European research.” Journal of Environmental Management 112:309-320.

Unnevehr, L.J., and F.C. Gouzou. 1998. "Retail premiums for honey characteristics." Agribusiness 14(1):49-54.

Voutsa, D., A. Grimanis, and C. Samara. 1996. "Trace elements in vegetables grown in an industrial area in relation to soil and air particulate matter." Environmental Pollution 94(3):325-335.

Wan, G.H., and E. Cheng. 2001. "Effects of land fragmentation and returns to scale in the Chinese farming sector." Applied Economics 33(2):183-194.

Wang, X., and D.L. Mauzerall. 2004. "Characterizing distributions of surface ozone and its impact on grain production in China, Japan and South Korea: 1990 and 2020." Atmospheric Environment 38(26):4383-4402.

Wang, Y., X. Li, L. Xin, M. Tan, and M. Jiang. 2018. "Spatiotemporal changes in Chinese land circulation between 2003 and 2013." Journal of Geographical Sciences 28(6):707-724.

Wang, Y.F., K.L. Huang, C.T. Li, H.H. Mi, J.H. Luo, and P.J. Tsai. 2003. "Emissions of fuel metals content from a diesel vehicle engine.” Atmospheric Environment 37(33):4637-4643.

Wang, Z., Y. Mao, and F. Gale. 2008. "Chinese consumer demand for food safety attributes in milk products." Food Policy 33(1):27-36.

Wathes, C.M., V.R. Phillips, M.R. Holden, R.W. Sneath, J.L. Short, R.P.P. White, J. Hartung, J. Seedorf, M. Schröder, K.H. Linkert, S. Pedersen, H. Takai, J.O. Johnsen, P.W.G. Groot Koerkamp, G.H. Uenk, J.H.M. Metz, T. Hinz, V. Caspary, and S. Linke. 1998. "Emissions of Aerial Pollutants in Livestock Buildings in Northern Europe: Overview of a Multinational Project." Journal of Agricultural Engineering Research 70(1):3-9. 
Webb, J., H. Menzi, B.F. Pain, T.H. Misselbrook, U. Dämmgen, H. Hendriks, and H. Döhler. 2005. "Managing ammonia emissions from livestock production in Europe." In Environmental Pollution. pp. 399-406.

Weber, C.L., and H.S. Matthews. 2008. "Food-miles and the relative climate impacts of food choices in the United States."

Wei, B., and L. Yang. 2010. "A review of heavy metal contaminations in urban soils, urban road dusts and agricultural soils from China." Microchemical Journal 94(2):99-107.

Wen, X.J., L. Balluz, and A. Mokdad. 2009. "Association between media alerts of air quality index and change of outdoor activity among adult asthma in six states, BRFSS, 2005." Journal of community health 34(1):40-46.

Werkenthin, M., B. Kluge, and G. Wessolek. 2014. "Metals in European roadside soils and soil solution - A review.” Environmental Pollution 189:98-110.

White, H. 1980. "A heteroskedasticity-consistent covariance matrix estimator and a direct test for heteroskedasticity." Econometrica: Journal of the Econometric Society:817-838.

WHO (World Health Organization). 2009. Global health risks: mortality and burden of disease attributable to selected major risks. World Health Organization,Geneva.

Widawsky, D., S. Rozelle, S. Jin, and J. Huang. 1998. "Pesticide productivity, host-plant resistance and productivity in China." Agricultural Economics 19(1-2):203-217.

van Wijnen, J.H., A.P. Verhoeff, H.W.A. Jans, and M. van Bruggen. 1995. "The exposure of cyclists, car drivers and pedestrians to traffic-related air pollutants." International archives of occupational and environmental health 67(3):187-193.

Wilson, T.O., F.M. McNeal, S. Spatari, D. G. Abler, and P.R. Adler. 2011. "Densified biomass can cost-effectively mitigate greenhouse gas emissions and address energy security in thermal applications.” Environmental science \& technology 46(2):1270-1277.

Windmeijer, F. 2005. "A finite sample correction for the variance of linear efficient two-step GMM estimators." Journal of econometrics 126(1):25-51.

Wong, M.H., S.C. Wu, W.J. Deng, X.Z. Yu, Q. Luo, A.O.W. Leung, C.S.C. Wong, W.J. Luksemburg, and A.S. Wong. 2007. "Export of toxic chemicals - A review of the case of uncontrolled electronic-waste recycling." Environmental Pollution 149(2):131-140.

Wood, S.W., and A. Cowie. 2004. "A review of greenhouse gas emission factors for fertiliser production."

Woodhouse, P. 2010. "Beyond industrial agriculture? Some questions about farm size, productivity and sustainability." Journal of agrarian change 10(3):437-453. 
Woolridge, J.M. 2008. Introductory Econometrics 4th (Fourth) Edition. South-Western College Pub.

$\mathrm{Wu}, \mathrm{Y}$. 2011. "Chemical fertilizer use efficiency and its determinants in China's farming sector: Implications for environmental protection." China Agricultural Economic Review 3(2):117-130.

Wu, Y., E. Li, and S.N. Samuel. 1995. "Food consumption in urban China: an empirical analysis." Applied Economics 27(6):509-515.

Wu, Z., M. Liu, and J. Davis. 2005. "Land consolidation and productivity in Chinese household crop production." China Economic Review 16(1):28-49.

Wyon, D.P. 2004. "The effects of indoor air quality on performance and productivity." Indoor air 14(s7):92-101.

Xie, H., and H. Lu. 2017. "Impact of land fragmentation and non-agricultural labor supply on circulation of agricultural land management rights." Land Use Policy 68:355-364.

Xin, L., X. Li, and M. Tan. 2012. "Temporal and regional variations of China's fertilizer consumption by crops during 1998-2008." Journal of Geographical Sciences 22(4):643-652.

Xiu, C., and K.K. Klein. 2010. "Melamine in milk products in China: Examining the factors that led to deliberate use of the contaminant." Food Policy 35(5):463-470.

Xu, C., C. Han, and D.C. Taylor. 1992. "Sustainable agricultural development in China." World Development 20(8):1127-1144.

Xu, Z., J. Xu, X. Deng, J. Huang, E. Uchida, and S. Rozelle. 2006. "Grain for Green versus Grain: Conflict between Food Security and Conservation Set-Aside in China." World Development 34(1):130-148.

Yamada, H., K. Misawa, D. Suzuki, K. Tanaka, J. Matsumoto, M. Fujii, and K. Tanaka. 2011. "Detailed analysis of diesel vehicle exhaust emissions: Nitrogen oxides, hydrocarbons and particulate size distributions." Proceedings of the Combustion Institute 33(2):2895-2902.

Yan, Y. 2012. "Food safety and social risk in contemporary China." The Journal of Asian Studies 71(3):705-729.

Yan, Z., P. Liu, Y. Li, L. Ma, A. Alva, Z. Dou, Q. Chen, and F. Zhang. 2013. "Phosphorus in China's intensive vegetable production systems: Overfertilization, soil enrichment, and environmental implications." Journal of environmental quality 42(4):982-989.

Yang, S., S. Peng, J. Xu, Y. Luo, and D. Li. 2012. "Methane and nitrous oxide emissions from paddy field as affected by water-saving irrigation." Physics and Chemistry of the Earth, Parts $A / B / C$ 53-54:30-37.

Yang, X., and S. Fang. 2015. "Practices, perceptions, and implications of fertilizer use in East-Central China." Ambio 44(7):647-652. 
Yi, F., D. Sun, and Y. Zhou. 2015. "Grain subsidy, liquidity constraints and food security-Impact of the grain subsidy program on the grain-sown areas in China." Food Policy 50:114-124.

Yonezawa, K., and T.J. Richards. 2016. "Competitive package size decisions.” Journal of Retailing 92(4):445-469.

Young, C.E., and P.C. Westcott. 2000. "How decoupled is US agricultural support for major crops?" American Journal of Agricultural Economics 82(3):762-767.

Yu, K., L. Qiu, J. Wang, L. Sun, and Z. Wang. 2017. "Winter wheat straw return monitoring by UAVs observations at different resolutions." International Journal of Remote Sensing 38(8-10):2260-2272.

Yu, W., and H.G. Jensen. 2010. "China's agricultural policy transition: impacts of recent reforms and future scenarios.” Journal of Agricultural Economics 61(2):343-368.

$\mathrm{Yu}, \mathrm{X}$. 2015. "Meat consumption in China and its impact on international food security: Status quo, trends, and policies." Journal of Integrative Agriculture 6(14):989-994.

Yu, X. 2014a. "Monetary easing policy and long-run food prices: Evidence from China." Economic Modelling 40:175-183.

Yu, X. 2012. "Productivity, efficiency and structural problems in Chinese dairy farms." China Agricultural Economic Review 4(2):168-175.

Yu, X. 2014b. "Raising food prices and welfare change: a simple calibration." Applied Economics Letters 21(9):643-645.

Yu, X., and D. Abler. 2010. "Incorporating zero and missing responses into CVM with open-ended bidding: willingness to pay for blue skies in Beijing." Environment and Development Economics 15(5):535-556.

Yu, X., and D. Abler. 2016. "Matching food with mouths: A statistical explanation to the abnormal decline of per capita food consumption in rural China." Food Policy 63:36-43.

Yu, X., and D. Abler. 2009. "The demand for food quality in rural China." American Journal of Agricultural Economics 91(1):57-69.

Yu, X., and D. Abler. 2014. "Where have all the pigs gone? Inconsistencies in pork statistics in China." China Economic Review 30:469-484.

$\mathrm{Yu}, \mathrm{X}$., and G. Zhao. 2009. "Chinese agricultural development in 30 years: A literature review." Frontiers of Economics in China 4(4):633-648.

Zhang, B., and C.A. Carter. 1997. "Reforms, the weather, and productivity growth in China's grain sector." American Journal of Agricultural Economics 79(4):1266-1277. 
Zhang, C., J. Bai, B.T. Lohmar, and J. Huang. 2010. "How do consumers determine the safety of milk in Beijing, China?" China Economic Review 21:S45-S54.

Zhang, F., X. Chen, and P. Vitousek. 2013. "Chinese agriculture: An experiment for the world." Nature 497(7447):33.

Zhang, J., and Q. Mu. 2017. "Air Pollution and Defensive Expenditures: Evidence from Particulate-Filtering Facemasks.” Journal of Environmental Economics and Management.

Zhang, K., and S. Batterman. 2013. "Air pollution and health risks due to vehicle traffic." Science of the Total Environment 450-451:307-316.

Zhang, L., A. De Brauw, and S. Rozelle. 2004. "China's rural labor market development and its gender implications." China Economic Review 15(2):230-247.

Zhang, S., P. Gao, Y. Tong, D. Norse, Y. Lu, and D. Powlson. 2015. "Overcoming nitrogen fertilizer over-use through technical and advisory approaches: A case study from Shaanxi Province, northwest China." Agriculture, Ecosystems \& Environment 209:89-99.

Zhang, X., and S. Fan. 2001. "Estimating crop-specific production technologies in Chinese agriculture: a generalized maximum entropy approach." American Journal of Agricultural Economics 83(2):378-388.

Zhang, X., J. Yang, and S. Wang. 2011. "China has reached the Lewis turning point.” China Economic Review 22(4):542-554.

Zheng, Q., and H.H. Wang. 2017. "Market Power in the Chinese Wine Industry." Agribusiness 33(1):30-42.

Zheng, S., and M.E. Kahn. 2013. "Understanding China's urban pollution dynamics." Journal of Economic Literature 51(3):731-772.

Zheng, Y., F. Liu, and H.-P. Hsieh. 2013. "U-Air: When urban air quality inference meets big data." In Proceedings of the 19th ACM SIGKDD international conference on Knowledge discovery and data mining. ACM, pp. 1436-1444.

Zhong, H. 2011. "The impact of population aging on income inequality in developing countries: Evidence from rural China." China Economic Review 22(1):98-107.

Zhou, D., X. Yu, and T. Herzfeld. 2015. "Dynamic food demand in urban China." China Agricultural Economic Review 7(1):27-44.

Zhou, Y., and E. Wang. 2011. 'Urban consumers' attitudes towards the safety of milk powder after the melamine scandal in 2008 and the factors influencing the attitudes." China Agricultural Economic Review 3(1):101-111. 
Zhou, Z.-Y., W. Tian, and J.-L. Zhou. 2001. The emerging dairy economy in China: production, consumption and trade prospects. Asian Agribusiness Research Centre, University of Sydney.

Zhu, Z.L., and D.L. Chen. 2002. "Nitrogen fertilizer use in China-Contributions to food production, impacts on the environment and best management strategies." Nutrient Cycling in Agroecosystems 63(2-3):117-127.

Zilberman, D., S.R. Templeton, and M. Khanna. 1999. "Agriculture and the environment: an economic perspective with implications for nutrition." Food Policy 24(2-3):211-229.

Zivin, J.G., and M. Neidell. 2009. "Days of haze: Environmental information disclosure and intertemporal avoidance behavior." Journal of Environmental Economics and Management 58(2):119-128.

Zivin, J.S.G., and M.J. Neidell. 2012. "The Impact of Pollution on Worker Productivity.” The American Economic Review 102:3652-3673.

Zock, J., Paul, A. Hollander, D. Heederik, and J. Douwes. 1998. "Acute lung function changes and low endotoxin exposures in the potato processing industry." American journal of industrial medicine 33(4):384-391.

Zock, J.P., D. Heederik, and K. Hans. 1995. "Exposure to dust, endotoxin and micro-organisms in the potato processing industry." Annals of Occupational Hygiene 39(6):841-854.

Zou, J., Y. Lu, and Y. Huang. 2010. "Estimates of synthetic fertilizer N-induced direct nitrous oxide emission from Chinese croplands during 1980-2000.” Environmental Pollution 158(2):631-635.

Zuo, Y., L. Ma, H. Cai, T. Wu, and X. Xin. 2015. “China's on-going debates over large-scale farming: what are the pros and cons?" China Agricultural Economic Review 7(3):338-343. 
Essays on Economic Returns to Fertilizer, Market Structure of Milk Industry, and Air Pollution and Food Security in China 


\section{Curriculum Vitae}

\section{PERSONAL DETAILS}

$\begin{array}{ll}\text { Name: } & \text { Feifei Sun } \\ \text { Address: } & \text { Goßlerstraße 33A, 118, 37075 Göttingen } \\ \text { Email: } & \text { fsun@ gwdg.de } \\ \text { Tel: } & \text { +49-(0)551-3921668 }\end{array}$

\section{EDUCATION}

$\begin{array}{ll}2007-2011 & \text { Nanjing Agricultural University, Nanjing, China } \\ & \text { Bachelor of Economics and Management of Agriculture and } \\ & \text { Forestry } \\ & \text { Nanjing Agricultural University, Nanjing, China } \\ & \text { Master of Economics and Management of Agriculture } \\ & \text { (Combined Bachelor's/Master's Degree Program) } \\ & \text { Georg-August-Universität Göttingen, Göttingen,Germany } \\ & \text { Ph.D. at the department of Agricultural Economics and Rural } \\ & \text { Development, University of Göttingen (Prof. Dr. Xiaohua Yu) }\end{array}$

\section{PUBLICATIONS}

\section{[Published papers]}

- Sun. F., Y. Dai and X. Yu (2017). Air Pollution, Food Production and Food Security: A Review from the Perspective of Food System. Journal of Integrative Agriculture. Vol. 16(12): 2945-2962.

- Sun. F., D. Koemle and X. Yu (2017) Air pollution and food prices: evidence from China. Australian Journal of Agricultural and Resource Economics. Vol. 61(2): 195-210.

- Tian. X., F. Sun and Y. Zhou (2015). Technical efficiency and its determinants in China's hog production. Journal of Integrative Agriculture, 14(6), 1057-1068.

\section{CONFERENCE PRESENTATIONS}

09/2016

Duisburg,

Germany
The $27^{\text {th }} \mathrm{CEA}(\mathrm{UK})$ and $8^{\text {th }} \mathrm{CEA}$ (Europe) annual conference "China's New Way of Integration with the World: the New Silk Road and the Opportunities for the World Economy" 